\title{
Geotechnical properties of hydrocarbon-contaminated soils: a comprehensive review
}

DOI:

10.1007/s10064-018-1343-1

\section{Document Version}

Accepted author manuscript

Link to publication record in Manchester Research Explorer

\section{Citation for published version (APA):}

Rajabi, H., \& Sharifipour, M. (2018). Geotechnical properties of hydrocarbon-contaminated soils: a comprehensive review. Bulletin of Engineering Geology and the Environment. https://doi.org/10.1007/s10064-018-1343-1

\section{Published in:}

Bulletin of Engineering Geology and the Environment

\section{Citing this paper}

Please note that where the full-text provided on Manchester Research Explorer is the Author Accepted Manuscript or Proof version this may differ from the final Published version. If citing, it is advised that you check and use the publisher's definitive version.

\section{General rights}

Copyright and moral rights for the publications made accessible in the Research Explorer are retained by the authors and/or other copyright owners and it is a condition of accessing publications that users recognise and abide by the legal requirements associated with these rights.

\section{Takedown policy}

If you believe that this document breaches copyright please refer to the University of Manchester's Takedown Procedures [http://man.ac.uk/04Y6Bo] or contact uml.scholarlycommunications@manchester.ac.uk providing relevant details, so we can investigate your claim.

\section{OPEN ACCESS}




\section{Bulletin of Engineering Geology and the Environment Geotechnical Properties of Hydrocarbon-Contaminated Soils: A Comprehensive Review \\ --Manuscript Draft--}

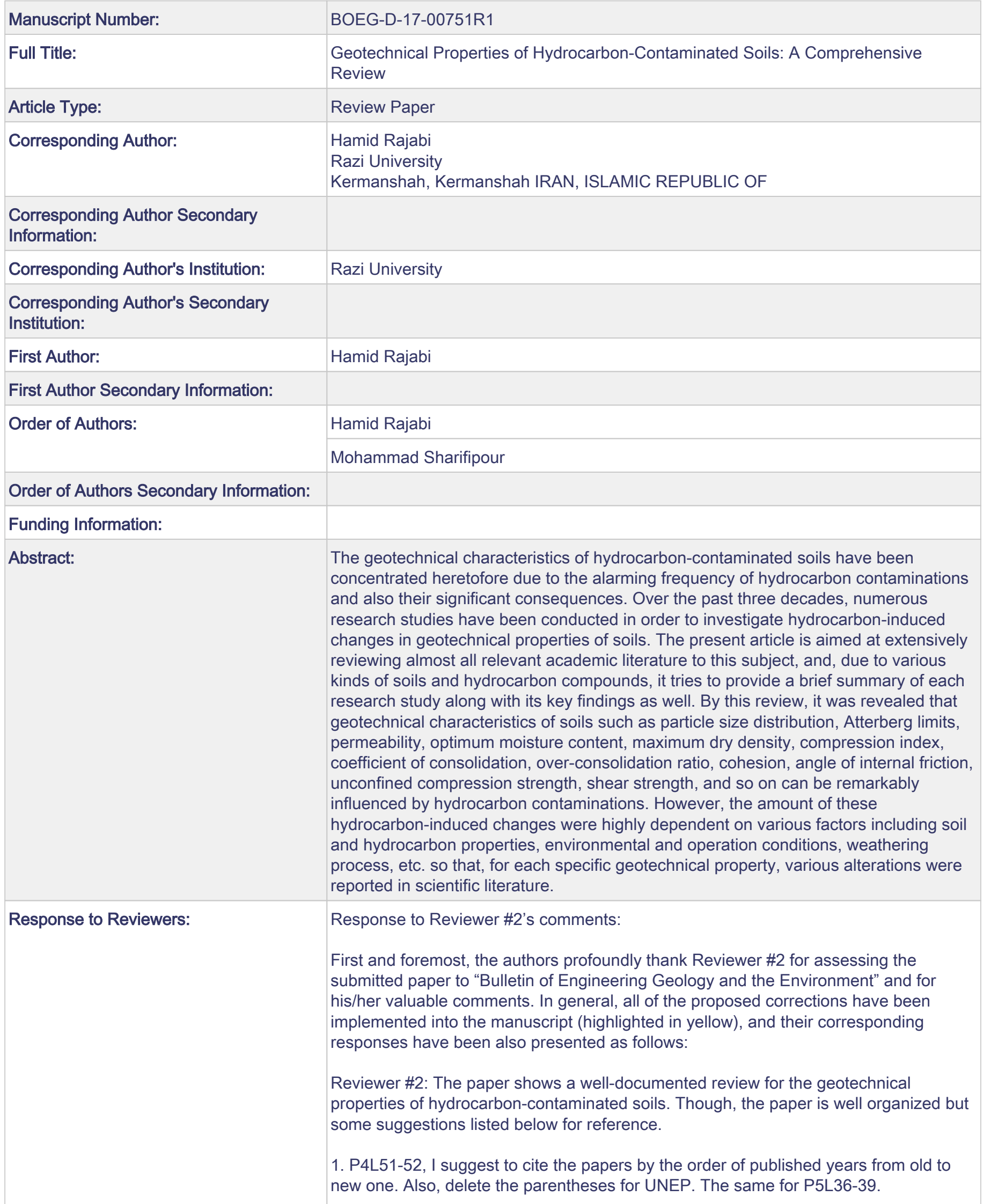


Response: With regard to this reviewer's comment ("years from old to new"), it should be stated that the authors used EndNote X8 software for organizing the references along with the specific EndNote style available in the journal's website (www.springer.com/earth+sciences+and+geography/engineering+geology/journal/1006 4 ?detailsPage) which determines/implements all the references automatically. However, the reference of UNEP was corrected throughout the manuscript.

2. P5L31-32, why a symbol (a) here?

Response: "Benzo (a) pyrene" was replaced by "benzo[a]pyrene". Benzo[a]pyrene is a polycyclic aromatic hydrocarbon with the formula of $\mathrm{C} 2 \mathrm{OH} 12$ which is one of the benzopyrenes, formed by a benzene ring fused to pyrene.

3. P6L29-30, delete the term "by the authors" and "Precisely speaking" in L34.

Response: These phrases were omitted.

4. P7L46-47, delete the sentence "Based on the information presented by Chang et al. (2014)" and add the referee (Chang et al. 2014) at the end of the sentence.

Response: Thanks to this reviewer's comment, the mentioned phrase was deleted, and the relevant reference was embedded at the end of the paragraph.

5. P8L7-15, try to simply this long sentence here.

Response: The long sentence was properly outlined.

6. P11L2-3, do not use the term "something along those lines."

Response: The phrase was deleted.

7. P24, please number the equations and add () for the unit (\%).

Response: The number and parentheses were added.

8. P26L34-36, delete "see also," and replace (Jia et al. 2010) by (2010).

Response: The mentioned corrections were implemented

9. P27L53-54, delete "see also," and the outer ().

Response: The phrase and parentheses were deleted.

10. P49L2-3, delete (UNEP).

Response: It was deleted.

11. Delete all the referee's parentheses () for Table 2 and Table 5-6, Table 8-9.

Response: As it was previously mentioned, EndNote X8 software with the specific EndNote style for BOEG (which includes parentheses) was used in this article to organize the references. This procedure was also utilized for writing references in all the tables since the authors believed that a similarity between the references in the context and the tables can be more understandable/trackable for readers. However, if Reviewer \#2 still insists on it, the authors will do it accordingly.

12. P65, Table 5, I do not understand the meaning for the column Amount 5,10,15.

Response: The main aim of this table was to summarize types and amounts of hydrocarbon contamination used in the relevant literature to provide a brighter view in readers' mind so that they can find in the table that what type/amount of the contaminants were utilized by the researchers so far. Approximately in all research, hydrocarbon contaminants were reported in terms of wt.\% of clean soils. For example, 
Tuncan and Pamukcu (1992) used different amounts of Philadelphia Crude oil which equal to 5,10 , and 15 wt.\% of basic soil (Marine sediments).

13. All the figures should be revised. For example, the legend should be double column (wider) and put inside the figure to spare the space. Also, adjust the position of symbol (a), (b) etc. on the corner but inside of the figure.

Response: According to the reviewer's comment, all the figures were corrected to convey a better and more obvious meanings, especially for the legends and symbols. However, it was somehow difficult for Fig. 10(b).

14. In Figure 11, revise the referee used in legend e.g. 2017(b) not 2017-b.

Response: The format was corrected.

15. Finally, from figures $7-9$, the data shows scattered without a visible trend. The effect of hydrocarbon-contaminated soil on geotechnical properties seems complicated. Can the authors give us some guideline how to evaluate.

Response: With reference to Atterberg limits (Fig. 7), it should be stated that the authors studied precisely all the relevant data reported in the literature, and were not able to find a comprehensive trend describing the effects of hydrocarbons on these limits. To elucidate this fact, the authors have approximately accumulated all the data provided in the literature regarding both $\mathrm{LL}$ and $\mathrm{PI}$ of hydrocarbon-contaminated soils in this figure. As it can be obviously seen in Fig. 7(a), LL of hydrocarbon-contaminated soils were placed within a specific range of percentages; however, all of the determined PI were somehow scattered (Fig. $7($ b)) and there was not an expressive trend to present. However, in each particular research, it could be possible for the authors to draw a specific tendency for the limits. Based on DDL theory, most hydrocarbon compounds, as non-polar fluid, are immiscible in water and acting as two separated phases, and won't be able to create bonds with clay particles. Moreover, the thickness of DDL may be affected by various characteristics of pore fluid. The thickness decreases with increase in valency, and also it is significantly influenced by viscosity. When hydrocarbon compounds are added to fine-grained soils, their viscosity may be also affected, thereby altering the thickness of DDL. In general, these factors may result in not expanding diffuse double-layers around clay particles in the presence of hydrocarbon compounds, and soil plasticity has to take place in different amounts of water, compared with clean soil, thereby making an alteration in PL. However, regarding LL in hydrocarbon-contaminated soils, hydrocarbon molecules forming thin viscous layers surrounding clay particles make $L L$ to change.

As for hydraulic conductivity (Fig. 8), the deposition of hydrocarbon compounds into soil pores, as influential elements governing hydraulic conductivity of soils, considerably decreases soil permeability. Of course, it should be stated that this reduction is highly depended on the properties of soil and hydrocarbon, but, in all cases, a negative impact of contamination on hydraulic conductivity of soil can be detected.

With regard to Fig. 9, based on a careful review on the effects of hydrocarbon contamination on consolidation phenomenon in soils, it can be inferred that hydrocarbon-induced changes in consolidation characteristics ( $\mathrm{Cc}$ and $\mathrm{Cv}$ ) of soils were highly dependent on types of both soil and hydrocarbon. On one hand, some of these studies stated that compression index (Cc) of soil increased with adding oil content, and on the other hand, a few researchers claimed the opposite behaviour, especially for clayey soils. According to the surface energy method, the surface energy at the hydrocarbon-water interface creates a higher surface tension on the considered interface, and results in decreasing water drainage from soil structure. This procedure can reduce the compressibility of clayey hydrocarbon-contaminated soils. All in all, notwithstanding the proposed trend in the figure, as it was also pointed in the manuscript, it should be stated that there is no clear-cut trend demonstrating the straightforward effects of hydrocarbon contamination on consolidation characteristics of soils, and it is highly dependent on both soil and hydrocarbon properties, and should be separately assessed for each particular case. 
Response to Reviewer \#3's comments:

Above all, the authors would like to deeply thank Reviewer \#3 for assessing our submitted article to Bulletin of Engineering Geology and the Environment and for his/her valuable comments. In general, all of the required corrections have been implemented into manuscript, and their corresponding responses have been also presented as follows:

Reviewer \#3: This manuscript has reviewed almost all relevant academic literature about hydrocarbon-contaminated soils, and provided a brief summary of research studies based on various kinds of soils and hydrocarbon compounds. The topic is very important and of great significance, and the methodology is sound. Prior to acceptance for publication, the authors should address the following comments:

1. charts and diagrams are not enough detailed in the front of the passage. Although many descriptions are in the article. But they are not visualized.

Response: With reference to this comment of Reviewer \#3, it should be initially stated that the procedure used by the authors in this review article was to do a deep and brief review on all relevant literature to the scope of geotechnical properties of hydrocarboncontaminated soils. To this aim, firstly, the authors struggled to study all articles and to concisely articulate their research aims and limitations, materials and methods, key results and discussion which the results of these attempts shaped the section of 3.1 (Review of literature). As the respected Reviewer \#3 completely knows, it is not possible/reasonable/acceptable to visualize all the results of all the studies in this article, so the authors decided to accumulate/justify/conclude a wide range of scattered results in several figures and tables in section of 3.2 (Review summary), and provide a brief discussion over the results (and possible trends). Generally, for each geotechnical property of hydrocarbon-contaminated soils (i.e. materials and methods, soil microstructure and particle size distribution, Atterberg Limits, hydraulic conductivity, compaction behaviour, consolidation characteristics, angle of internal friction and cohesion, unconfined compression strength, maximum shear modulus ( $\mathrm{G}$ or $\mathrm{G} 0$ ), and weathering) reported in the studied literature, section of 3.2 provides a particular subsection including figures and tables showing detailed data. Moreover, the authors believe that, as a review article, the present work had to observe an acceptable balance in the provision of very detailed data in the context and in the figures/tables since it is not possible to provide very detailed information for several articles of 19912017 in an article which must have a reasonable number of words, tables, figures and pages. With regard to this comment, it is also beneficial to observe that although the authors have tried to summarize different aspects of each research and to summarize their key outcomes, this review basically have an aim to clarify the previous endeavors and to uncover future capacity of research in the field of geotechnical characteristics of hydrocarbon-contaminated soils. However, it is still needed to refer to each original work and to be benefitted from their research studies profoundly, based on specific and urgent research needs of readers.

2. Reviews are important in this article.but the author should pay attention to telling us that the relationship between the previous results and present results. The author's innovation is what we focus.

Response: Totally speaking, the authors have the same opinion with Reviewer \#3 about the academic/research values of comparing results of similar research on common topics chronologically, and we all know that the key prerequisite of this valuable work is to maintain a few basic common items in all research. By the same token, in the first draft of this review, the authors made an attempt to prepare comparisons among specific geotechnical properties of hydrocarbon-contaminated soils over years, but this strategy could not result in an acceptable/engineering report due to this undeniable fact that, in each work, researchers had their specific choices of soil and hydrocarbon type, there was not a particular common soil/contamination to track, and also their experimental circumstances were also different. Therefore, the authors decided to follow a novel method of reviewing the literature including a provision of an outlined summary of each work in chronological order, and then a summary of probable effects of hydrocarbon contamination on each geotechnical properties showing reasonable trends of hydrocarbon influences on these basic/engineering aspects of soil. Notwithstanding the aforementioned explanation, in 
all tables of 5-11 and all figures of 7-11, it was tried to present comparisons among all the reported outcomes for some geotechnical properties of hydrocarbon-contaminated soils; however, due to obvious differences between soil/hydrocarbon types, the observed scattered data are somehow reasonable.

3. The author should highlight that the limitation and weakness of the previous studies and the novelty of the current study.

Response: It should be noted that the main aim of the authors was to write an article reviewing/accumulating all the relevant literature to the scheme of hydrocarboncontaminated soils. However, in comparison with the other review articles regarding broader topics in geotechnical engineering, the used methodology in this review possesses some novel aspects, it does not merely propose novel methods to assess geotechnical properties of hydrocarbon-contaminated soils which could be compared with the previous studies. However, according to the first part of this beneficial Reviewer \#3's comment, it is logical to highlight the limitations/weaknesses of the previous studies and provide a better perspective for the future research. As for the limitations/weaknesses projecting the future possibilities of novel topics of research and not to prolong the manuscript more, wherever it is logical/necessary in subsections of 3.2, the authors added some explanations so as to observe Reviewer \#3's ideas, and provide general limitations of the available research which ultimately propose novel topics of research for those interested.

4. Page8, Line24 : What's your reason to raise such a hypothesis? Some details should be told us clearly.

Response: Thanks to this valuable Reviewer \#3's comment, these irrelevant sentences were deleted from the manuscript.

5. Page 40, Line12 :What's the detailed benefits that considering the impacts of weathering and aging process?

Response: In this regard, it should be initially stated that the effects of weathering on properties of hydrocarbon-contaminated soils have been concentrated so far by some researchers like Al-Sanad and Ismael (1997) and Nazir (2011) due to this fact that hydrocarbon compounds can be greatly influenced by weathering process as it was reported by the aforementioned studies. More importantly, the hydrocarboncontaminated soils are usually exposed to serious environmental conditions, and knowing influences of these factors on geotechnical properties of these soils is beneficial. In this connection, Reviewer \#3 can take a look at the authors' recently published article in 2018 in "Soil Dynamics and Earthquake Engineering" entitled "Influence of weathering process on small-strain shear modulus (Gmax) of hydrocarbon-contaminated sand" (via https://doi.org/10.1016/j.soildyn.2018.01.006) which clearly assessed the effects of weathering on one of the important geotechnical properties of hydrocarbon-contaminated sand. Moreover, the mentioned article along with its brief summary was added to the end of the section of 3.2.10 (highlighted in Yellow). 


\section{Response to Reviewer \#2's comments:}

First and foremost, the authors profoundly thank Reviewer \#2 for assessing the submitted paper to "Bulletin of Engineering Geology and the Environment" and for his/her valuable comments.

In general, all of the proposed corrections have been implemented into the manuscript (highlighted in yellow), and their corresponding responses have been also presented as follows:

Reviewer \#2: The paper shows a well-documented review for the geotechnical properties of hydrocarbon-contaminated soils. Though, the paper is well organized but some suggestions listed below for reference.

1. P4L51-52, I suggest to cite the papers by the order of published years from old to new one. Also, delete the parentheses for UNEP. The same for P5L36-39.

Response: With regard to this reviewer's comment ("years from old to new"), it should be stated that the authors used EndNote X8 software for organizing the references along with the specific EndNote style ${ }^{1}$ available in the journal's website which determines/implements all the references automatically. However, the reference of UNEP was corrected throughout the manuscript.

2. P5L31-32, why a symbol (a) here?

Response: "Benzo (a) pyrene" was replaced by "benzo[a]pyrene". Benzo[a]pyrene is a polycyclic aromatic hydrocarbon with the formula of $\mathrm{C}_{20} \mathrm{H}_{12}$ which is one of the benzopyrenes, formed by a benzene ring fused to pyrene.

\footnotetext{
${ }^{1}$ Available on www.springer.com/earth+sciences+and+geography/engineering+geology/journal/10064?detailsPage
} 
3. P6L29-30, delete the term "by the authors" and "Precisely speaking" in L34.

Response: These phrases were omitted.

4. P7L46-47, delete the sentence "Based on the information presented by Chang et al. (2014)" and add the referee (Chang et al. 2014) at the end of the sentence.

Response: Thanks to this reviewer's comment, the mentioned phrase was deleted, and the relevant reference was embedded at the end of the paragraph.

5. P8L7-15, try to simply this long sentence here.

Response: The long sentence was properly outlined.

6. P11L2-3, do not use the term "something along those lines."

Response: The phrase was deleted.

7. P24, please number the equations and add () for the unit (\%).

Response: The number and parentheses were added.

8. P26L34-36, delete "see also," and replace (Jia et al. 2010) by (2010).

Response: The mentioned corrections were implemented

9. P27L53-54, delete "see also," and the outer ().

Response: The phrase and parentheses were deleted. 
10. P49L2-3, delete (UNEP).

Response: It was deleted.

11. Delete all the referee's parentheses () for Table 2 and Table 5-6, Table 8-9.

Response: As it was previously mentioned, EndNote X8 software with the specific EndNote style for BOEG (which includes parentheses) was used in this article to organize the references. This procedure was also utilized for writing references in all the tables since the authors believed that a similarity between the references in the context and the tables can be more understandable/trackable for readers. However, if Reviewer \#2 still insists on it, the authors will do it accordingly.

12. P65, Table 5, I do not understand the meaning for the column Amount 5,10,15.

Response: The main aim of this table was to summarize types and amounts of hydrocarbon contaminations used in the relevant literature to provide a brighter view in readers' mind so that they can find in the table that what type/amount of the contaminants were utilized by the researchers so far. Approximately in all research, hydrocarbon contaminants were reported in terms of wt.\% of clean soils. For example, Tuncan and Pamukcu (1992) used different amounts of Philadelphia Crude oil which equal to 5, 10, and 15 wt.\% of basic soil (Marine sediments). 
13. All the figures should be revised. For example, the legend should be double column (wider) and put inside the figure to spare the space. Also, adjust the position of symbol (a), (b) etc. on the corner but inside of the figure.

Response: According to the reviewer's comment, all the figures were corrected to convey a better and more obvious meanings, especially for the legends and symbols. However, it was somehow difficult for Fig. 10(b).

14. In Figure 11, revise the referee used in legend e.g. 2017(b) not 2017-b.

Response: The format was corrected.

15. Finally, from figures $7-9$, the data shows scattered without a visible trend. The effect of hydrocarbon-contaminated soil on geotechnical properties seems complicated. Can the authors give us some guideline how to evaluate.

Response: With reference to Atterberg limits (Fig. 7), it should be stated that the authors studied precisely all the relevant data reported in the literature, and were not able to find a comprehensive trend describing the effects of hydrocarbons on these limits. To elucidate this fact, the authors have approximately accumulated all the data provided in the literature regarding both LL and PI of hydrocarboncontaminated soils in this figure. As it can be obviously seen in Fig. 7(a), LL of hydrocarbon-contaminated soils were placed within a specific range of percentages; however, all of the determined PI were somehow scattered (Fig. 7(b)) and there was not an expressive trend to present. However, in each particular research, it could be possible for the authors to draw a specific 
tendency for the limits. Based on DDL theory, most hydrocarbon compounds, as non-polar fluid, are immiscible in water and acting as two separated phases, and won't be able to create bonds with clay particles. Moreover, the thickness of DDL may be affected by various characteristics of pore fluid. The thickness decreases with increase in valency, and also it is significantly influenced by viscosity. When hydrocarbon compounds are added to fine-grained soils, their viscosity may be also affected, thereby altering the thickness of DDL. In general, these factors may result in not expanding diffuse double-layers around clay particles in the presence of hydrocarbon compounds, and soil plasticity has to take place in different amounts of water, compared with clean soil, thereby making an alteration in PL. However, regarding LL in hydrocarbon-contaminated soils, hydrocarbon molecules forming thin viscous layers surrounding clay particles make LL to change.

As for hydraulic conductivity (Fig. 8), the deposition of hydrocarbon compounds into soil pores, as influential elements governing hydraulic conductivity of soils, considerably decreases soil permeability. Of course, it should be stated that this reduction is highly depended on the properties of soil and hydrocarbon, but, in all cases, a negative impact of contamination on hydraulic conductivity of soil can be detected.

With regard to Fig. 9, based on a careful review on the effects of hydrocarbon contaminations on consolidation phenomenon in soils, it can be inferred that hydrocarbon-induced changes in consolidation characteristics $\left(\mathrm{C}_{\mathrm{c}}\right.$ and $\left.\mathrm{C}_{\mathrm{v}}\right)$ of soils were highly dependent on types of both soil and hydrocarbon. On one hand, some 
of these studies stated that compression index $\left(\mathrm{C}_{\mathrm{c}}\right)$ of soil increased with adding oil content, and on the other hand, a few researchers claimed the opposite behaviour, especially for clayey soils. According to the surface energy method, the surface energy at the hydrocarbon-water interface creates a higher surface tension on the considered interface, and results in decreasing water drainage from soil structure. This procedure can reduce the compressibility of clayey hydrocarbon-contaminated soils. All in all, notwithstanding the proposed trend in the figure, as it was also pointed in the manuscript, it should be stated that there is no clear-cut trend demonstrating the straightforward effects of hydrocarbon contamination on consolidation characteristics of soils, and it is highly dependent on both soil and hydrocarbon properties, and should be separately assessed for each particular case.

\section{Response to Reviewer \#3's comments:}

Above all, the authors would like to deeply thank Reviewer \#3 for assessing our submitted article to Bulletin of Engineering Geology and the Environment and for his/her valuable comments. In general, all of the required corrections have been implemented into manuscript, and their corresponding responses have been also presented as follows:

Reviewer \#3: This manuscript has reviewed almost all relevant academic literature about hydrocarbon-contaminated soils, and provided a brief summary of research studies based on various kinds of soils and hydrocarbon compounds. The topic is very important and of great 
significance, and the methodology is sound. Prior to acceptance for publication, the authors should address the following comments:

1. charts and diagrams are not enough detailed in the front of the passage. Although many descriptions are in the article. But they are not visualized.

Response: With reference to this comment of Reviewer \#3, it should be initially stated that the procedure used by the authors in this review article was to do a deep and brief review on all relevant literature to the scope of geotechnical properties of hydrocarbon-contaminated soils. To this aim, firstly, the authors struggled to study all articles and to concisely articulate their research aims and limitations, materials and methods, key results and discussion which the results of these attempts shaped the section of 3.1 (Review of literature). As the respected Reviewer \#3 completely knows, it is not possible/reasonable/acceptable to visualize all the results of all the studies in this article, so the authors decided to accumulate/justify/conclude a wide range of scattered results in several figures and tables in section of 3.2 (Review summary), and provide a brief discussion over the results (and possible trends). Generally, for each geotechnical property of hydrocarbon-contaminated soils (i.e. materials and methods, soil microstructure and particle size distribution, Atterberg Limits, hydraulic conductivity, compaction behaviour, consolidation characteristics, angle of internal friction and cohesion, unconfined compression strength, maximum shear modulus $\left(\mathrm{G}_{\max }\right.$ or $\left.\mathrm{G}_{0}\right)$, and weathering) reported in the studied literature, section of 3.2 provides a particular subsection including figures and tables showing 
detailed data. Moreover, the authors believe that, as a review article, the present work had to observe an acceptable balance in the provision of very detailed data in the context and in the figures/tables since it is not possible to provide very detailed information for several articles of 1991-2017 in an article which must have a reasonable number of words, tables, figures and pages. With regard to this comment, it is also beneficial to observe that although the authors have tried to summarize different aspects of each research and to summarize their key outcomes, this review basically have an aim to clarify the previous endeavors and to uncover future capacity of research in the field of geotechnical characteristics of hydrocarbon-contaminated soils. However, it is still needed to refer to each original work and to be benefitted from their research studies profoundly, based on specific and urgent research needs of readers.

2. Reviews are important in this article.but the author should pay attention to telling us that the relationship between the previous results and present results. The author's innovation is what we focus.

Response: Totally speaking, the authors have the same opinion with Reviewer \#3 about the academic/research values of comparing results of similar research on common topics chronologically, and we all know that the key prerequisite of this valuable work is to maintain a few basic common items in all research. By the same token, in the first draft of this review, the authors made an attempt to prepare comparisons among specific geotechnical properties of hydrocarboncontaminated soils over years, but this strategy could not result in an 
acceptable/engineering report due to this undeniable fact that, in each work, researchers had their specific choices of soil and hydrocarbon type, there was not a particular common soil/contamination to track, and also their experimental circumstances were also different. Therefore, the authors decided to follow a novel method of reviewing the literature including a provision of an outlined summary of each work in chronological order, and then a summary of probable effects of hydrocarbon contamination on each geotechnical properties showing reasonable trends of hydrocarbon influences on these basic/engineering aspects of soil. Notwithstanding the aforementioned explanation, in all tables of 5-11 and all figures of 7-11, it was tried to present comparisons among all the reported outcomes for some geotechnical properties of hydrocarbon-contaminated soils; however, due to obvious differences between soil/hydrocarbon types, the observed scattered data are somehow reasonable.

3. The author should highlight that the limitation and weakness of the previous studies and the novelty of the current study.

Response: It should be noted that the main aim of the authors was to write an article reviewing/accumulating all the relevant literature to the scheme of hydrocarboncontaminated soils. However, in comparison with the other review articles regarding broader topics in geotechnical engineering, the used methodology in this review possesses some novel aspects, it does not merely propose novel methods to assess geotechnical properties of hydrocarbon-contaminated soils which could be compared with the previous studies. However, according to the 
first part of this beneficial Reviewer \#3's comment, it is logical to highlight the limitations/weaknesses of the previous studies and provide a better perspective for the future research. As for the limitations/weaknesses projecting the future possibilities of novel topics of research and not to prolong the manuscript more, wherever it is logical/necessary in subsections of 3.2, the authors added some explanations so as to observe Reviewer \#3's ideas, and provide general limitations of the available research which ultimately propose novel topics of research for those interested.

4. Page8, Line24: What's your reason to raise such a hypothesis? Some details should be told us clearly.

Response: Thanks to this valuable Reviewer \#3's comment, these irrelevant sentences were deleted from the manuscript.

5. Page 40, Line 12 :What's the detailed benefits that considering the impacts of weathering and aging process?

Response: In this regard, it should be initially stated that the effects of weathering on properties of hydrocarbon-contaminated soils have been concentrated so far by some researchers like Al-Sanad and Ismael (1997) and Nazir (2011) due to this fact that hydrocarbon compounds can be greatly influenced by weathering process as it was reported by the aforementioned studies. More importantly, the hydrocarbon-contaminated soils are usually exposed to serious environmental conditions, and knowing influences of these factors on geotechnical properties of 
these soils is beneficial. In this connection, Reviewer \#3 can take a look at the authors' recently published article in 2018 in "Soil Dynamics and Earthquake Engineering" entitled "Influence of weathering process on small-strain shear modulus $\left(\mathrm{G}_{\max }\right) \quad$ of hydrocarbon-contaminated sand" (via https://doi.org/10.1016/j.soildyn.2018.01.006) which clearly assessed the effects of weathering on one of the important geotechnical properties of hydrocarboncontaminated sand. Moreover, the mentioned article along with its brief summary was added to the end of the section of 3.2.10 (highlighted in Yellow). 


\title{
Geotechnical Properties of Hydrocarbon-
}

\section{Contaminated Soils: A Comprehensive Review}

\author{
Hamid Rajabi, Mohammad Sharifipour*
}

\author{
Department of Civil Engineering,
}

Faculty of Engineering, Razi University, Kermanshah 67149, Iran

\section{* Corresponding author:}

Department of Civil Engineering, Faculty of Engineering,

Razi University, Kermanshah 67149, Iran

Tel.: +98 8334274535

- Mohammad Sharifipour (E-mail: sharifipour@razi.ac.ir) 


\section{Highlights}

Academic literature discussing geotechnical properties of hydrocarbon-contaminated soils were summarised/reviewed.

Determination methods of hydrocarbon type and content in soils were concisely pointed.

Microstructures of hydrocarbon-contaminated soils were evaluated.

Geotechnical properties of hydrocarbon-contaminated soil were singly analysed. 


\begin{abstract}
The geotechnical characteristics of hydrocarbon-contaminated soils have been concentrated heretofore due to the alarming frequency of hydrocarbon contaminations and also their significant consequences. Over the past three decades, numerous research studies have been conducted in order to investigate hydrocarbon-induced changes in geotechnical properties of soils. The present article is aimed at extensively reviewing almost all relevant academic literature to this subject, and, due to various kinds of soils and hydrocarbon compounds, it tries to provide a brief summary of each research study along with its key findings as well. By this review, it was revealed that geotechnical characteristics of soils such as particle size distribution, Atterberg limits, permeability, optimum moisture content, maximum dry density, compression index, coefficient of consolidation, over-consolidation ratio, cohesion, angle of internal friction, unconfined compression strength, shear strength, and so on can be remarkably influenced by hydrocarbon contaminations. However, the amount of these hydrocarbon-induced changes were highly dependent on various factors including soil and hydrocarbon properties, environmental and operation conditions, weathering process, etc. so that, for each specific geotechnical property, various alterations were reported in scientific literature.
\end{abstract}

Keywords: Hydrocarbon; Contamination; Geotechnical properties; Soil; Crude oil 


\section{Introduction}

Contamination is described as natural and/or artificial presence of adverse substances into our ecosystem with permanent or transient unfavorable effects (Harrison 2006; Howard et al. 1991), and can be classified into major types including air pollution, water pollution, plastic pollution, noise pollution, light pollution, visual pollution, thermal pollution, littering, radioactive contamination, and soil contamination (Harrison 2001; Harrison 2006). Meanwhile, soil contamination, an aspect of land degradation, is one of the most influential issues in the nature, and may happen in different ways in which diverse materials can act as contaminant including hydrocarbons, heavy metals, herbicides, pesticides, etc. (Arman 1969; Calabrese et al. 2005; Fang and Daniels 1997; Kabata-Pendias 2010). Moreover, soil contamination is noticeable with reference to this fact that soil always plays crucial and basic roles in our lives, and its efficacy has been gradually intensified by ever-increasing pace of life in which industrialization is an undeniable necessity (Yong 2000). The seriousness of quantitative and/or qualitative effects on soil originated by the mentioned types of contaminants have been greatly important so that Food and Agriculture Organization of the United Nation (FAO) announced the year of 2015 as the International Year of Soils (IYS 2015) (Nachtergaele 2015). Intensive farming, deforestation activities, contaminated surface water, agro industry, leaching and landfills, oil drilling and mining, waste disposal, and underground storage tank (UST) as well as all of nonstandard and careless activities on and/or beneath ground surface in industrial and urban areas have been proclaimed in the relevant literature as the main elements which undermine physical, chemical, and engineering properties of soils (Calabrese et al. 2005; Nachtergaele 2015; UNEP 2014; Yong 2000). Beside unavoidable changes in soil caused by environmental factors, man-made activities releasing contaminants into our surroundings can be oftentimes associated with agricultural and/or industrial activities in rural and urban areas. As an example, inappropriate disposal of 
different kinds of domestic, industrial, and nuclear wastes are among these adverse human actions (Mirsal 2004).

In a general view, the seriousness of soil contamination is highly dependent on properties of soil contaminants which can be grouped into two main kinds including micro- and macropollutants. Macro-pollutants are on many occasions observed in soil structure in large amounts; however, micro-pollutants frequently occur in small quantities. Acid-rain-induced deposits and fertilizers can be grouped as macro-pollutants, and micro-pollutants may include organic and inorganic materials like heavy metals, pesticides, non-pesticides, hydrocarbons, and so on (Huat et al. 2014; Mirsal 2004). In the other words, soil contaminants can be generally defined as natural or artificial chemicals which may be originated from environmental changes or human interference, and have the capabilities to significantly influence soil properties in various ways (Pascucci 2011). In this regard, the most involved chemicals are petroleum hydrocarbons, polynuclear aromatic hydrocarbons (such as naphthalene and benzo[a]pyrene), solvents, pesticides, lead, and other heavy metals (van der Perk 2006). The frequency of occurrence of these contaminations in soil are associated with the degree of industrialization and also intensity of pollution incidences (Calabrese et al. 2005; Nachtergaele 2015; Pascucci 2011; UNEP 2014; van der Perk 2006; Yong 2000). Among the mentioned types of soil contaminants, hydrocarbon-based contaminants are significant due to several main reasons including increasing demands on petroleum products in developed and developing countries, beneficial oil market for both private and public sectors as well as oil spillage during practical activities (oil exploration, extraction, refining, storage, and transpiration) (Davis et al. 1972; Hoddinott and O'Shay 1994; Stegmann et al. 2001). As an unforgettable fact, it is worth mentioning that hydrocarbon contamination can take place without human intervention. Tar pits and seeps are the suitable examples of the naturally happened hydrocarbon contamination. An area may be a petroleum seep where 
natural hydrocarbon compounds escape from the ground to the surface or the atmosphere, and seep generally occurs above natural petroleum accumulation reservoirs. However, a tar pit, a particular type of seeps and also named as asphalt pit, is an area where underground bitumen naturally permeates onto the earth surface and forms a lake of asphalt (Bunger et al. 1979; Carrigy 1967). In order to provide factual information about the occurrences of hydrocarbon contaminations and their importance, the largest hydrocarbon contaminations in history, since 1901, have been tabulated and presented in Table 1 (Aigner et al. 2010; Etkin 1999; Whitson 1999).

Moreover, as an example highlighting frequency of occurrences of hydrocarbon contaminations, the volume of different type of hydrocarbon contaminations occurred in the west coast of United States of America during the last 14 years (2002-2015) which were precisely measured by Pacific States/British Columbia Oil Spill Task Force has been provided in Fig. 1 (Pacific States/British Columbia Oil Spill Task Force 2016). Based on the data, it was clearly obvious that the total volume of hydrocarbons releasing into the area has been on the rise during the period of the survey. The total volume of hydrocarbon compounds released into the environment increased from almost 380000 US gallons in 2002 to near 630000 US gallons in 2015. Furthermore, the types of hydrocarbon compounds determined by Pacific States/British Columbia Oil Spill Task Force were also presented in Fig. 1. It can be inferred that crude oil and diesel/marine gas oil were the significant types of hydrocarbonbased spills in this period of time in the west coast. According to the data which were provided as a partial record of the global situation, it can be concluded that hydrocarbon contamination has been a serious issue, and specific attentions have been concentrated to prevent, control, and remediate its consequences.

Due to profits of oil market and its practical usage to respond human's industrial and domestic demands, since 30s, petroleum exploration has been on the rise. In this regard, 
petroleum geologists and geophysicists have aimed to search over any probable site to find suitable points for extraction of crude oil and natural gas (Ahmadi et al. 2016; Rosenberger 2015; Secretariat 2010; Secretariat 2012). From the early stages of exploration to the final steps of consumption, contamination is an unavoidable phenomenon, and hydrocarbon contaminants can leak into environment. To add to that, hydrocarbon contaminants may move downward into the groundwater zone under gravity, and besides contaminating soil on their pathway, they can be horizontally carried by water, thereby reaching soil elsewhere again with the aid of capillary action (Bossert and Bartha 1984; Duffy et al. 1980; van der Perk 2006; Yong 2000).

Generally, considering all possible sources of hydrocarbon contaminations in soils, hydrocarbon-induced influences on the nature can be classified as direct and indirect ones. Oil spills and tar balls are the important examples of the direct types, but global warming as well as ocean acidification can be named as the indirect ones. Releasing carbon dioxide into the air as a by-product of burning petroleum products causes global warming and ocean acidification. However, presence of hydrocarbon compounds into the nature via oil spills and tar balls can directly influence soil properties (Hoddinott and O'Shay 1994; Stegmann et al. 2001). Chang et al. (2014) reviewed short- and long-term consequences of oil spillage, as a hydrocarbon contaminant, into our ecosystem from ecological and societal viewpoints, and proposed an extensive framework to specify oil impacts on our ecosystem (Chang et al. 2014). It can be concluded that location, time, and rate of oil spills can affect the amount, extent, depth, toxicity, and duration of contamination. Furthermore, this process may be influenced by any alteration in weather and temperature of the contaminated area, and also may be intensified or alleviated if local tides and currents take place (Chang et al. 2014). The environmental influences of hydrocarbon contamination on our ecosystem have been suitably distinguished so far, and several protocols have been established by authorities in 
order to mitigate their short- and long-term consequences (Durand and Liss 2002; Loehr et al. 2000). Moreover, soil is a vital element in construction industry, and the effects of hydrocarbon contaminations on engineering properties of soil should be considered (Das 2015). Without a doubt, performance of soil as foundations has been a major research topic so far in order to evaluate and to improve its efficiency under different conditions. This matter has had significant level of importance with respect to this fact that improvements in construction projects in both residential and/or industrial zones has been an incremental necessity (Bon and Minami 1986). Due to the previously mentioned requisites of construction advancement in oil and gas industries, the improvement strategies in these areas on many occasions encounter the challenge of dealing with hydrocarbon-contaminated soils. This problem has been intensified considering the benefits of oil market as well as domestic and/or industrial needs for petroleum products (Ahmadi et al. 2016; Rosenberger 2015; Secretariat 2010; Secretariat 2012). With the aim of accurately tackling this situation, numerous research studies have been carried out so far in order to investigate the effects of hydrocarbon contamination on physical, chemical, and geotechnical characteristics of soils. In these endeavors, various soil types and different hydrocarbon contaminants have been considered by the use of several analytical methods and experimental apparatus. To the best of our knowledge, there has not been any comprehensive review article focusing on geotechnical properties of hydrocarbon-contaminated soils up to now. The present article aims at extensively reviewing almost all relevant research papers to geotechnical behavior of hydrocarbon-contaminated soils. In the first place, the present review provides basic information about different hydrocarbons which can be found in soil as contaminants. As an important prerequisite for the characterization of hydrocarbon-contaminated soils, a brief review on analytical methods of determination of hydrocarbon compounds in soils has been also presented. Moreover, after the relevant published research articles were precisely studied 
by the authors, a suitable summary of each research work has been briefly stated in this article, thereby enabling interested readers to concisely evaluate research circumstances and results with an acceptable level of preciseness. Afterwards, based on the authors' findings in this review, the remarkable effects of hydrocarbon contaminations on each one of important geotechnical properties of soils have been separately summarized. Additionally, wherever it is required and beneficial, comparable articles are provided as further references.

\section{Hydrocarbon-contaminated soils}

According to the importance and necessity of fundamental information about hydrocarbon compounds and their presence in soil structures in assessing geotechnical behavior of hydrocarbon-contaminated soils, this section aims at comprehensively reviewing the published scientific literature which discuss some aspects of hydrocarbon-contaminated soils including hydrocarbon compounds, microstructures of hydrocarbon-contaminated soils, and available methods for determination of hydrocarbons in contaminated soils.

\subsection{Hydrocarbons}

Hydrocarbons are organic compounds which are entirely made of carbon and hydrogen atoms. In the first place, it should be stated that although hydrocarbons have simple chemical structures by definition, there are a wide variety of hydrocarbon compounds with different properties which can be generally categorized into two major groups including aliphatic and aromatic hydrocarbons (Olah and Molnar 2003). Aliphatic compounds (non-aromatics) are most often flammable, and could be used as fuel such as methane and liquefied natural gas (LNG). In addition, aliphatic hydrocarbons as cyclic compounds may be saturated or unsaturated with single- or multi-bond structures, respectively, and are totally divided into three different types including alkanes, alkenes, and cycloalkanes. Alkanes (paraffin) are hydrocarbon structures which purely consist of carbon and hydrogen atoms in tree-like 
configurations with single carbon-carbon bonds $\left(\mathrm{C}_{2 n} \mathrm{H}_{2 n+2}\right)$ like Methane, Ethane, Propane, Butane, etc. However, unsaturated hydrocarbons having at least one carbon-carbon double bond are recognized as alkenes or olefins $\left(\mathrm{C}_{2 n} \mathrm{H}_{2 n}\right)$ such as ethylene, ethane, ethanol, and so on. Furthermore, monocyclic saturated hydrocarbons with chemical structures having only single side carbon rings are known as cycloalkanes (e.g. cyclopropane, cyclopentane, cyclohexane, etc.) (Gale 2013). On the other hand, aromatic hydrocarbons (arenes) are chemical compounds with the strongest type of covalent chemical bonds (sigma bonds) among carbon atoms shaping a circle. Having a high ratio of carbon-hydrogen in structure, showing considerable capacity to be subjected to electrophilic substitution reactions, and enduring significant amount of nucleophilic aromatic substitutions are the most general characteristics of aromatic hydrocarbons. Monoaromatic (MAHs) and polycyclic aromatic hydrocarbons (PAHs) are the main categories of aromatic hydrocarbons which consist of only one benzene ring and two or more benzene rings, respectively. Benzene, toluene, ethylbenzene, and xylenes (BTEX) are the most seen monoaromatic compounds in petroleum hydrocarbons, and the simple samples of polycyclic-aromatic hydrocarbons are tetracene, anthracene, and phenanthrene (Bjørseth 1983). A flowchart which briefly describes different kinds of hydrocarbons along with their subsets and well-known examples has been provided by the authors in Fig. 2.

In hydrocarbon-contaminated areas, various types of hydrocarbon products with particular commercial/technical names can be found so that each one may contain some of the above mentioned kinds of hydrocarbon compounds. In general, the most observed types of hydrocarbon-based products in soils have been crude oil, bitumen, gasoline, motor oil, engine oil, diesels, etc. (Harrison 2001) which can be found in Table 2 as well. Meanwhile, it should be noted that crude oil and natural gas mainly consist of aliphatic compounds in compared with gasoline which is mainly made of aromatic hydrocarbons. Moreover, bitumen is formed 
by four major compounds including naphthene aromatics, polar aromatics, asphaltenes, and some saturated hydrocarbons. Motor oil (or engine oil) is mainly derived from crude oil along with other particular non-petroleum-based compounds as additives for the purpose of providing adequate viscosity for being used as lubricant in internal combustion engines. Furthermore, diesels can be found in three different forms in soils such as petroleum diesel, synthetic diesel, and biodiesel. Petroleum diesel as the most common form of diesel fuel is derived from crude oil by use of fractional distillation at atmospheric pressure. However, synthetic diesel is prepared by use of various raw carbonaceous materials such as biomass (biomass-to-liquid (BTL)), biogas and natural gas (gas-to-liquid (GTL)), and coal (coal-toliquid (CTL)). To add to that, biodiesel or fatty-acid methyl ester (FAME) is produced by herbal oils or animal fats (biolipids) under transesterification process with methanol (Archer and Wall 2012).

\subsection{Microstructural characterization of hydrocarbon-contaminated soils}

According to the literature (Berger et al. 2002; Izdebska-Muchaa et al. 2011; Khamehchiyan et al. 2007), hydrocarbon compounds have the ability to make serious changes in particle interactions, grain size characteristics, and fabric of fine-grained soils. In this regard, it should be stated that hydrocarbon-induced alterations can be obviously observed in morphologies and geometrical specifications of fine-grained soils, thereby making several changes in their engineering behaviors. As a matter of fact, macroscale behavior of both soil types can be associated with microscale conditions of their structures which are controlled by particle conditions and their interactions. Therefore, it can be greatly beneficial to consider hydrocarbon-induced changes in microstructure of both fine- and coarse-grained soils with the intent of clearly understanding and analyzing geotechnical behavior of hydrocarboncontaminated soils. 
In the case of fine-grained soils, hydrocarbon-induced changes in microscale characteristics of soil can be associated with various factors such as double layer theory, physicochemical effects, soil fabric and microstructure conditions (Izdebska-Mucha and Trzciński 2008; Izdebska-Muchaa et al. 2011; Quigley and Fernandez 1991). Firstly, it should be noted here that hydrocarbon compounds can affect porosity of fine-grained soils so that the number and total area of micropores greatly decrease, but conditions of macropores remain approximately unchanged. However, the degree of changes is greatly depended on hydrocarbon and soil properties, and has been different from case to case. Precisely, several parameters defining morphometric characteristics of pores may be used to describe hydrocarbon-induced changes in porosity of fine-grained soils including area, perimeter, and diameter of pores. However, due to a variety of hydrocarbon compounds which may be present in fine-grained soils, such quantitative morphometric studies should be conducted for each case, and then analyze accordingly. Moreover, some of geometric parameters of soil pores may be altered by hydrocarbon contaminants such as shape, anisotropy, and degree of orientation. These geometric and morphometric characteristics should be accurately studied to analyze the hydrocarbon-induced changes in microstructure of fine-grained soils (Izdebska-Muchaa et al. 2011). As previously explained, due to influential effects of soil and hydrocarbon properties on physicochemical and structural properties of hydrocarbon-contaminated soils, it should be proposed that the evaluation of soil microstructure must be separately conducted for each particular case. In general, based on the relevant literature (Acar and Olivieri 1989; Fernandez and Quigley 1991; Izdebska-Mucha and Trzciński 2008; Izdebska-Muchaa et al. 2011; Khamehchiyan et al. 2007; Quigley and Fernandez 1991), it can be stated that hydrocarbon compounds coating surfaces of clay particles in fine-grained soils can alter hydrophilic nature of clean clay grains to hydrophobic manner. In addition, hydrocarbons can create considerable amount of adhesion in inter-particle states of fine-grained soils, and also 
they can reduce electromagnetic repulsive forces between particles. More importantly, dispersed state of particles in clean fine-grained soils can be altered into a flocculated structure due to presence of hydrocarbon compounds in soil skeleton. According to (Izdebska-Mucha and Trzciński 2008), hydrocarbons can bring about drastic changes in the fabric of fine-grained soils so that much more isometric pores with bigger size are clearly observable in contaminated soils in comparison with clean one. However, it may be generally stated based on filtration studies conducted by Quigley and Fernandez (1991) and Anandarajah (2003) on the permeability of contaminated soils by organic fluid that hydrocarbon contaminants can reduce the amount of porosity of fine-grained soils so that its pore number and total pore perimeter are considerably lower than clean soil (Anandarajah 2003; Quigley and Fernandez 1991). All in all, it is worth mentioning that the induced alterations in specifications of clay surface caused by non-polar hydrocarbon compounds with lower dielectric constant may be responsible for disintegrating microaggregates of soil which forms weakened microstructures for fine-grained soils.

In Fig. 3, SEM images of a natural hydrocarbon-contaminated fine-grained soil collected from a contaminated area in a fuel transportation center covered by many underground fuel tanks in northeastern of Poland have been presented (Izdebska-Mucha and Trzciński 2008). All the specimens of both clean and diesel oil contaminated clayey soil were collected from a 2 meter depth beneath the ground surface. Based on a precise inspection on the provided SEM images (Fig. 3), obvious changes made by hydrocarbon compounds (diesel oil) in microstructure of the natural clayey soil can be found. A flocculated fabric along with more Edge-to-Face (EF) contacts among particles as well as the disintegrated aggregates can be seen in diesel oil contaminated sample (Fig. 3 (b and d)) in compared with clean one (Fig. 3 (a and c)). Moreover, it can be inferred from the images that hydrocarbon compounds could change aggregated matrix of clean clayey soil into a loose structure so that a strongly packed 
aggregates and microaggregates in clean sample has altered into a disintegrated loosely structure. More importantly, in the contaminated structure, Edge-to-Face (EF) contacts are predominant when compared with clean samples in which the majority of contacts is Face-toFace (FF) and Edge-to-Edge (EE).

In the case of coarse-grained soils, microstructural characterization of hydrocarbon-induced changes may be more straightforward in comparison with fine-grained soils due to this fact that physical interactions among particles are dominant in this kind of soil. In general, adding a particular amount of a hydrocarbon into a coarse-grained soil can create hydrocarboncoated particles and fill micro- and macropores of soil. The thickness of the coated layer of hydrocarbon around each particle can affect its surface roughness (friction) and also create hydrocarbon-induced cohesion among particles. It seems that, in lower contents of hydrocarbon, the coated layer can bring about influential amount of cohesion into interparticle conditions while its amount is not as much as the required amount to eliminate friction among particles. However, by adding further hydrocarbons, it can be possible to completely cover roughness of particles, and consequently omit frictional behavior of soil. Moreover, it seem that more and more increasing content of hydrocarbon into coarse-grained soils can effectively decompose interaction relationships among particles, and finally the majority of soil grains will lose their contacts with neighboring grains. More importantly, it should be noticed here that this classification of hydrocarbon-induced changes in behavior of coarse-grained soil is deeply dependent on structural properties of soil and also hydrocarbon characteristics.

\subsection{Determination of hydrocarbons in contaminated soils}

Above all, an accurate determination of amount and type of hydrocarbon compounds in contaminated soils is a fundamental factor to assess rate of damage and to clarify procedures 
which should be employed to remediate contaminated areas (Brown et al. 1975; McGill and Rowell 1980; Mirsal 2004). Moreover, a precise determination of hydrocarbon compounds in contaminated soil is hugely depended on using a careful soil sampling procedure and also an efficient analytical method (Loehr and Higgins 1965). Due to importance of primary analyses of hydrocarbon-contaminated soils in assessing the induced changes in soil properties and also in proposing an efficient protocol to eliminate damages, in this section, a brief summary of the available methods for determining hydrocarbon compounds in contaminated soils have been presented herein.

Variety of methods for determining amount/type of existing hydrocarbons in soil structure have been frequently employed in the literature (Okparanma and Mouazen 2013a). These means have not been comprehensively authenticated as a result of this fact that a great variety of hydrocarbon materials with various chemical compositions and properties have the possibility of contaminating soils, and each one requires particular methods to be used. More importantly, it should be stated here that, on one hand, it is essential to determine total amount of hydrocarbon compounds in a specific hydrocarbon-contaminated soils, and on the other hand, it may be required to precisely ascertain the amount of particular hydrocarbon compound in the considered area. All in all, this section is aimed at briefly reviewing the available methods of characterizing content of hydrocarbon compounds in hydrocarboncontaminated soils.

In total, two technical terms usually used to describe hydrocarbon-based compounds in soil are petroleum hydrocarbons (PHC) and total petroleum hydrocarbons (TPH) (Archer and Wall 2012). PHC points to an absolute and precise amount of the whole hydrocarbon compounds available in soil which is difficult to be accurately measured. However, the measurable amount of hydrocarbons in contaminated soil is usually defined as total petroleum hydrocarbons (TPH). Several methods have been utilized by researchers so far in 
order to accurately determine TPH in hydrocarbon-contaminated soil. However, these methods are not precise enough by reason of "weathering" and "analytical/extraction limitations" (Okparanma and Mouazen 2013a). Firstly, hydrocarbon compounds in soil may be gradually altered as a result of various phenomena such as sorption into soil structure, chemical reaction by existing substances in soil, volatilization into air, microbial degradation, and also dissolution in water (Sadler and Connell 2003). Consequently, these weathering procedures can alter hydrocarbon compounds of soil in terms of both chemical compositions and physical volume. Hence, characterization of hydrocarbons existing in soil may be a problematic and challenging task owing to the probable weathering-induced alterations. Secondly, all proposed methods have their own particular limitations in analytical and extraction procedures so that each one detects some particular parts of existing hydrocarbons in contaminated soil. On this subject, it may be beneficial to state that various subsets have been defined in the literature for hydrocarbon compounds found in soils such as polycyclic aromatic hydrocarbon (PAH) (Fabbri et al. 2013; Hosseini et al. 2012; Shang et al. 2014), Volatile Petroleum Hydrocarbons (VPH) (Chang et al. 2010; Elazhari-Ali et al. 2013; Yang et al. 1995), Extractable Petroleum Hydrocarbons (EPH) (Seeley et al. 2007; Summons et al. 1988), Gasoline Range Organic (GRO) (Suatoni et al. 1975), Diesel Range Organic (DRO) (Fanchi and Christiansen 2016), etc.

Heretofore, various methods have been proposed in literature in order to characterize TPH in hydrocarbon-contaminated soils. Based on their functionalities and performances, these methods can be classified into in situ (filed) and laboratory methods. In the first place, fieldbased methods can be generally categorized into common and special methods (Table 3) (Whittaker et al. 1995). Common (non-specific) methods are those means by which the contaminated sites can be fairly assessed, and all types of TPH, saturated and aromatic hydrocarbons in sediments, can be determined. More importantly, common methods have the 
required capabilities to analyze hydrocarbon compounds existing in soil and also their weathering-induced changes. The most applicable non-specific methods are Gas Chromatography with Flame Ionization (GC-FID) (Snape et al. 2005), Gas Chromatography with Photo-ionization Detection (GC-PID) (Nölscher et al. 2012), Gravimetric Determination (Villalobos et al. 2008), Infrared Spectrophotometry (IR) (Aske et al. 2001), Turbidimetry Ultraviolet and Fluorescence Spectroscopy (Lakowicz 1999), Thin-layer Chromatography (TLC) (Sherma 2006), High Performance Liquid Chromatography (HPLC) (Engelhardt 2012), Size-exclusion Chromatography (Mori and Barth 2013), Supercritical Fluid Chromatography (SFC) (Taylor 2008), Total Organic Carbon (Schumacher 2002), Isotope Ratio Mass Spectrometry (Muccio and Jackson 2009), and Fiber Optic IR Sensor (Harrington 2003). Moreover, some advanced and modified methods (special methods) with a considerable preciseness in both selectivity and sensitivity have been hitherto proposed to determine hydrocarbon compounds in soil. The most prominent examples of these specific methods are Nuclear Magnetic Resonance (NMR) (Andrew 2009), Isotope Dilution Mass Spectrometry (IDMS) (Heumann 1992), Gas Chromatography Mass Spectrometry (GC-MS), Electrospray Ionization Mass Spectrometry (ESI-MS) (Molnárné Guricza and Schrader 2015), and High Performance Liquid Chromatography Mass Spectrometry (HPLC-MS) (Galceran and Moyano 1994). However, there are some laboratory-based techniques to assess TPH in soils including General Gravimetry (Villalobos et al. 2008), Infrared (IR) Spectroscopy (Oomens et al. 2003), Gas Chromatography Flame Ionization Detection (GCFID), and Gas Chromatography Mass Spectrometry (GC-MS) (Kopka 2006). In addition, it is worth noting that GC-MS and GC-FID can be used in both filed and laboratory.

In a general sense, the available lab-oriented and in situ methods determining TPH in soil (Table 3) can be compared and contrasted in terms of important criteria including preciseness, safety, time, cost, and so on. For a long time, some particular methods have been 
frequently utilized to investigate TPH and PAH in hydrocarbon-contaminated soils including lab-based gas chromatography (GC-FID and GC-MS), General Gravimetry, Immunoassay (IMA) (Wei et al. 2009), and spectroscopic methods (infrared (IR), Raman, and fluorescence). However, these methods have been always accompanied with a few disadvantages such as sampling resolution, lack of preciseness, and high costs. Hence, with the aim of achieving rapid, user-friendly, more accurate and economical methods with fewer occupational hazards, several new techniques have been recently developed by researchers to provide much reliable information about hydrocarbon-contaminated soil. In this connection, field Portable Gas Chromatography Mass Spectrometry (GC-MS) (Haas et al. 2002) as well as visible and Near-Infrared (vis-NIR) spectroscopy (Okparanma and Mouazen 2013b) can be mentioned.

As the subsets of electromagnetic spectroscopy, fluorescence spectroscopic methods (ultraviolet-induced fluorescence, Rapid Optical Screening Tool, and laser induced fluorescence) are in situ methods detecting PAHs and some other aromatic rings in hydrocarbon-contaminated soil (Aldstadt et al. 2002). Ultraviolet-induced fluorescence (UVIF) can be used with cone penetrometer test (CPT) to provide in situ continuous analyses of contaminated soil, and can detect TPH, petroleum fuels, oils, and PAHs.

\section{Geotechncial properties of hydrocarbon-contaminated soils}

In this section, firstly, the authors make an effort to briefly review some research articles with significant and key results about various aspects of geotechnical properties of hydrocarboncontaminated soils. To this aim, it is tried to concisely pinpoint to the main elements of their research with the intent of forming a general picture of their frameworks, limitations, and outcomes. More importantly, the findings published in these relevant literature regarding geotechnical characteristics of hydrocarbon-contaminated soils have been accurately 
summarized and then presented in several subsections. It should be also added that the authors have made their best to provide an acceptable level of comparisons with other relevant literature, wherever if required and beneficial, so as to shape a clear view in the readers' minds.

\subsection{Review of literature}

From 1986 to 1994, several research studies were conducted to examine various geotechnical properties of hydrocarbon-contaminated soils (Budhu et al. 1991; Cook et al. 1992; Evgin and Das 1992; Foreman and Daniel 1986; Meegoda 1992; Meegoda and Rajapakse 1993; Meegoda and Ratnaweera 1994; Puri et al. 1994; Tuncan and Pamukcu 1992; Uppot and Stephenson 1989). In their studies, particular characteristics of geotechnical behavior of hydrocarbon-contaminated soils were concentrated such as hydraulic conductivity (Budhu et al. 1991; Cook et al. 1992; Meegoda and Rajapakse 1993; Puri et al. 1994; Tuncan and Pamukcu 1992), consolidation (Meegoda and Rajapakse 1993; Tuncan and Pamukcu 1992), and shear strength (Cook et al. 1992; Evgin and Das 1992).

However, the first comprehensive research in this field, based on the authors' view, was performed by Al-Sanad et al. in 1995. They carried out several experimental geotechnical tests on soil samples collected from an area in Kuwait which had been contaminated by a series of explosions and destruction of oil wells and storage tanks as well as occurrences of vast oil lakes at the end of the Gulf War (AI-Awadhi et al. 1992; Al-Sanad et al. 1995). To simulate the conditions of contamination, the researchers mixed Jahra sand, a typical surface desert sand in Kuwait, with four kinds of crude oil (Benzene, AI-Ritga heavy crude oil, Rawdatain light crude oil, and AI-Zoor gas oil) with the amount of 2, 4 and 6 wt.\% of the dry sand resembling the actual in-situ circumstances of oil contamination in the area reported by Kuwait Oil Company in 1991 (Al-Mutairi 1995; Kuwait-Oil-Company 1991a; Kuwait- 
Oil-Company 1991b). The researchers conducted a series of permeability tests with a constant head on the clean and $6 \%$ oil-contaminated sands with a relative density of $60 \%$. The results disclosed a reduction of about $20 \%$ (from $1.72 \times 10^{-5} \mathrm{~m} / \mathrm{sec}$ to $1.38 \times 10^{-5} \mathrm{~m} / \mathrm{sec}$ ) in the coefficient of permeability due to adding crude oil up to $6 \%$ for this reason that waterinsoluble hydrocarbon compounds can occupy the majority of soil pore volume as a fundamental element controlling sand hydraulic conductivity (Budhu et al. 1991). Furthermore, the authors utilized a series of modified proctor compaction tests in order to evaluate compaction properties of heavy crude oil contaminated Jahra sand. The maximum dry density (MDD) and optimum moisture content (OMC) of clean Jahra sand was about $1900 \mathrm{~kg} / \mathrm{m}^{3}$ and $12 \%$, respectively. Adding further crude oil, up to $4 \mathrm{wt} . \%$, significantly improved both MDD and OMC as a result of lubrication effect of oil. MDD and OMC of 4 wt. $\%$ oil-contaminated sand were about $1940 \mathrm{~kg} / \mathrm{m}^{3}$ and $6.9 \%$, respectively, and a decrease of approximately $42.5 \%$ in OMC was observed after the presence of 4 wt.\% of crude oil in the sand. In addition, increasing oil content, from 4 wt. $\%$ to 6 wt. $\%$, negatively affects the compaction curve and its shape transformed to a strange style. In general, it can be said that there was a critical value of oil content (4 wt.\%) in terms of compaction properties. Moreover, based on the results of their isotropically consolidated undrained triaxial tests on the clean and 6 wt.\% crude oil-contaminated Jahra sand with a relative density of $60 \%, 6$ wt.\% crude oil-contaminated sand at all confining pressures presented smoother behavior than the clean ones with no obvious peaks. Additionally, the elastic modulus (E modulus) of 6 wt. $\%$ crude oil-contaminated sand were about half of that of clean sand. Based on a detailed investigation into the results of triaxial tests, a typical medium and also dense behavior can be attributed to the clean and contaminated sand, respectively. According to the presented results of a series of consolidation tests in the form of e-log p curves on clean and 6 wt.\% crude oilcontaminated Jahra sand (with a relative density of 60\%), an increase in sand compressibility 
with the presence of crude oil (6 wt.\% of both light and heavy crude oil) could be obviously observed as a result of lubricant effects of hydrocarbons on the inter-particle sliding and slipping of the sand. Precisely speaking, Al-Sanad et al. reported that the compression index was 0.03 in the clean sand, and this value increased to 0.06 and 0.07 after 6 wt.\% of light and heavy crude oil were added into the sand, respectively. In addition, direct shear apparatus was utilized by Al-Sanad et al. (1995) in order to examine influences of relative density, type, and amount of the different hydrocarbon contaminants on shear strength of the Jahra sand. In this regard, they considered three different relative densities $(30 \%, 60 \%$, and $90 \%)$ and three different oil contents $(2,4$, and 6 wt.\%). However, the authors believed that the amount of oil contamination did not have significant effects on the angle of internal friction, they reported that the maximum reduction in angle of internal friction was about $5-7^{\circ}$. It should be added here that, at each particular relative density, increasing amount of crude oil in sand diminished the angle of internal friction. This reduction was approximately similar in relative density of $30 \%$ and $60 \%$, but it was slightly less in relative density of $90 \%$.

Following their previous research (Al-Sanad et al. 1995), Al-Sanad and Ismael in 1997 conducted a series of laboratory strength and compressibility tests to evaluate aging effects on important geotechnical properties of crude oil-contaminated Jahra sand (Al-Sanad and Ismael 1997). They prepared several 6 wt.\% oil-contaminated soil samples, and left them under severe environmental conditions, including wind and high temperature, for about 6 months. Based on the results of isotropically consolidated undrained triaxial test, it can be concluded that initial and tangent E modulus of the fresh contaminated soil are approximately half the modulus of clean ones. The moduli of 6-month-aged contaminated sand were clearly lower than those of the fresh ones; however, they still remained under moduli of the clean sand. This phenomenon indicates a stiffer behavior of aged oil-contaminated sand in comparison with the fresh ones. With reference to e-log $\mathrm{p}$ curves of consolidation tests on 
aged oil-contaminated Jahra sand, the compressibility of oil-contaminated sand decreased with time so that compression index $\left(\mathrm{C}_{\mathrm{c}}\right)$ decreased in the first 3 months, and then remained almost unchanged in the second 3 months. Al-Sanad and Ismael also reported from in their direct shear tests that angle of internal friction of contaminated sand enjoyed an almost $15 \%$ increase after 6 months. However, the rate of aging-induced changes in angle of internal friction was significant during the first month (Al-Sanad and Ismael 1997).

Srivastava and Pandey in 1998 presented results of their geotechnical tests on two Indian oilcontaminated soil including alluvial soil and sand (Srivastava and Pandey 1998). In this regard, soil specimens were provided by mixing oil contaminates with soil in various percentages $(0,3,6,9$ and $12 \mathrm{wt} . \%)$. According to PSD analysis, particle size of both soil types increased as a result of oil coated particles. Moreover, the authors reported that both Liquid Limit (LL) and Plasticity Index (PI) of alluvial soil increased by adding oil, but Plastic Limit (PL) and Shrinkage Limit (SL) diminished. The results of compaction tests revealed that both MDD and OMC decreased as oil content increased; however, in the case sandy soil, the reduction in OMC was noticeable. Additionally, with reference to the results of UU triaxial tests on both alluvial soil and sand, oil contaminant decreased both cohesion and angle of internal friction of alluvial soil showing the loss of shear strength; however, cohesion and angle of internal friction of sandy soil firstly enjoyed an increase and then both of them decreased. According to Srivastava and Pandey, compression index $\left(\mathrm{C}_{\mathrm{c}}\right)$ of all contaminated soil samples rose as oil content increased.

In 2007, Khamehchiyan et al. studied the effects of crude oil contamination on geotechnical properties of clayey and sandy soil collected from a beach area of Bushehr city in Iran (Khamehchiyan et al. 2007). These soil were categorized as SM (silty sand), SP (poorlygraded sand), and CL (lean clay) according to the USCS. The used crude oil was paraffinic in composition and mixed with soil in the amount of $0,4,8,12$, and $16 \mathrm{wt} . \%$. With reference to 
the published results, both MDD and OMC of sandy soil decreased due to crude oil contamination; however, some previous researchers (Al-Sanad et al. 1995; Meegoda et al. 1998) had the opposite findings for sands in which there was a critical oil content that, before and after this point, MDD increased and then decreased. Of course, the decrease in MDD of poorly-graded sand was very moderate owing to considerable large pore spaces into soil structure (Khamehchiyan et al. 2007). Moreover, the shape of compaction curves of SP sand obviously altered from a double-peak type to a bell shape as oil content increased (see also (Lee and Suedkamp 1972)). Precisely speaking, it can be mentioned that hydrophobic hydrocarbon molecules limit the contact between water and soil grains, and therefore, any increment in oil concentration reduces the capillary tension force (Franklin et al. 1973), thereby changing the shape of compaction curves. Khamehchiyan et al. also claimed that it is not logical to use usual methods (ASTM-D-4959 (ASTM 1999)) for determining Atterberg Limits in the case of fine-grained oil-contaminated soils since oil can evaporate in a wide range of temperature, even under room conditions (Sleep and McClure 2001), and this phenomenon can alter the composition of hydrocarbon compounds in the structure of hydrocarbon-contaminated soil (Khamehchiyan et al. 2007; Rahman et al. 2007). The amount of remained high viscose oil after evaporation procedure can be greatly influenced by size, adhesion, cohesion, and thermal conductivity of soil particles as well as thermal properties of hydrocarbon compounds (Alrtimi et al. 2016; Fine et al. 1997). Khamehchiyan et al. reported that crude oil evaporation in clayey soil (CL) is more serious than the other soil as a result of its slower heat transfer (Zhu et al. 2015). Moreover, it should be noted that thermal conductivity of soil can be related to its Specific Surface Area (SSA), and soil with higher SSA have lower thermal conductivity (Łydżba et al. 2014). In addition, from their results, it is also apparent that, at constant environmental conditions, crude oil evaporation diminished in contaminated soil with higher amounts of crude oil, and it may be associated with thermal 
conductivity, adhesion and/or cohesion properties of soil and oil hydrocarbon compounds (Khamehchiyan et al. 2007). The following equation has been proposed by Khamehchiyan et al. to determine the water content of an oil-contaminated soil after oil evaporation process:

$$
\omega(\%)=(1+m n) \frac{W_{t}}{W_{d}}-(1+n)
$$

In which $W_{t}, W_{d}, m$, and $n$ are wet weight of contaminated soil, dry weight of contaminated soil, oil residual after drying, and oil content before drying, respectively (Khamehchiyan et al. 2007).

Atterberg Limits tests were conducted on CL contaminated samples in order to evaluate alterations in PL and LL as a result of crude oil contamination in the structure of clayey soils. According to the reported results by the authors, both limits decreased with increasing crude oil content due to this fact that crude oil molecules are non-polar, and also clayey soils do not show plasticity with non-polar fluid (Kaya and Fang 2000; Quigley and Fernandez 1991; Ratnaweera and Meegoda 2006). Furthermore, it should be considered that, in this experimental program, dry clayey soil samples were firstly mixed thoroughly with crude oil, and this procedure led to uniformly contaminated soil samples in which crude oil molecules properly surrounded soil particles and weaken probable relationships between clayey particles and polar water molecules.

Based on the results of direct shear tests on clayey and sandy soil (Khamehchiyan et al. 2007), it can be said that crude oil contamination enhanced angle of internal friction of CL samples from $26^{\circ}$ for clean sample to $34.5^{\circ}$ in $16 \mathrm{wt} . \%$ contaminated specimen, and this trend was intensified by adding more crude oil rather than $12 \%$. Contrarily, in the case of sandy soil, oil contamination reduced the amount of angle of internal friction so that friction angle of almost $34^{\circ}$ in clean samples reached to around $26^{\circ}$ in $16 \mathrm{wt} . \%$ contaminated specimens for both sand. Moreover, a significant reduction of about $80 \%$ in cohesion of CL was also observed by the authors as a result of adding $16 \mathrm{wt} . \%$ of crude oil so that the majority of this 
change was taken place after mixing $\mathrm{Cl}$ with $16 \mathrm{wt} . \%$ of crude oil. Of course, there were no noticeable changes in the hydrocarbon-induced cohesion of sand as a result of raising amount of crude oil. Peak shear strength of all crude oil-contaminated soils were lower than those of uncontaminated ones; however, the amount of influences imposed by the contamination and its trend were dependent on soil type in this study. Generally speaking, permeability of all oil-contaminated soils experienced a reduction in their amounts as crude oil content increased (Anderson et al. 1985; Foreman and Daniel 1986; Uppot and Stephenson 1989). According to a series of UCS tests conducted by Khamehchiyan et al., it can be said as a conclusion that both CL and SM soil suffered from a significant decrement in their uniaxial compressive strengths. In more detail, UCS of CL fell from $3.6 \mathrm{~kg} / \mathrm{cm}^{2}$ to $0.6 \mathrm{~kg} / \mathrm{cm}^{2}$ as crude oil content rose up to $16 \mathrm{wt} . \%$ in clayey soil. Similarly, increasing crude oil content to $16 \mathrm{wt} . \%$ in SM sample could diminish uniaxial compressive strength of sand from $0.94 \mathrm{~kg} / \mathrm{cm}^{2}$ to 0.36 $\mathrm{kg} / \mathrm{cm}^{2}$.

In 2010, Jia et al. conducted extensive experimental studies about influences of hydrocarbon contamination on geotechnical properties of three different soil collected form Hai-gang region in Yellow River Delta, China (Jia et al. 2010). This area is a well-known submarine delta which is covered by river sedimentation, and has been influenced by hydrocarbon contamination during huge oil exploitation. The authors did a series of conventional geotechnical tests including PSD analysis, Atterberg limits, compaction, and direct shear test as well as ultraviolet-spectrophotometer assay to analyze oil content in the collected samples. To obtain in situ samples, the researchers planned 5 survey lines and 25 test points which had $30 \mathrm{~m}$ transverse and $20 \mathrm{~m}$ longitudinal intervals, respectively. The collected hydrocarboncontaminated soil samples were categorized into three groups in the lab based on their oil contents named as light-polluted (L), heavy-polluted (H), and medium-polluted (M) specimens. If oil content of a soil sample was less than $0.1 \mathrm{mg} / \mathrm{g}$, it was light-polluted, and if 
the content was more than $1 \mathrm{mg} / \mathrm{g}$, it was a heavy-polluted sample. Moreover, if oil content of a sample fell between $0.1 \mathrm{mg} / \mathrm{g}$ and $1 \mathrm{mg} / \mathrm{g}$, it was a medium-polluted sample. According to PSD analysis and plasticity indices, the provided samples were silty soil. Based on PSD curves presented by (Jia et al. 2010) for all of light-, medium-, and high-polluted specimens, it can be inferred that hydrocarbon contaminants coating soil grains could create bigger-sized hydrocarbon-coated particles. Additionally, according to fine grain size analysis, the number of clay-sized grains $(<0.005)$ in heavy-polluted samples is surprisingly higher than the content in light-polluted ones. The authors believed that due to dissolution of organic and inorganic composite colloids, free oxide colloid sands, and soluble salts in hydrocarbon contaminant, powerful contacts between soil particles were weakened and/or omitted. Therefore, this trend led to simply disperse soil particles and to increase the number of claysized grains, especially in heavily-polluted samples (Srivastava and Pandey 1998). Likewise, according to Atterberg limit tests conducted by Jia et al. (2010), all of Atterberg limits including LL, PL, and PI increased with increasing oil content to $14 \mathrm{mg} / \mathrm{g}$ in contaminated soil. Correctly, the value of LL enjoyed an almost $66 \%$ increment from about $24 \%$ to $40 \%$, while this growth was about $33 \%$ for PL, from approximately $17 \%$ to $23 \%$. Consequently, it can be concluded that PI could increase from $6.4 \%$ to about $18 \%$ as oil content grew to 14 $\mathrm{mg} / \mathrm{g}$. Based on the literature regarding the effects of organic pore fluid on the amount of Atterberg limits in fine-grained soil, it is logical to anticipate apparent influences of hydrocarbon contamination on Atterberg limits of clayey soil (Quigley and Fernandez 1991). In simple words, hydrocarbon compounds of crude oil as high viscose pore fluid make it difficult for soil skeleton to be altered by water, and consequently increases the value of Atterberg limits (Kaya and Fang 2000).

Jia et al. also reported the results of their compaction tests in terms of both compression coefficient and modulus under laterally constrained compression with cyclic loading (Jia et 
al. 2010). In this regard, it can be observed in their findings that although compression coefficient increased significantly as the amount of oil was raised in soil, compression modulus did not follow the same trend. This alteration can be attributed to the destructive effects of oil contamination on soil structure, thereby increasing the number of soil pores and softening soil stress-strain behavior. A precise survey on the published results of direct shear tests conducted by Jia et al. in 2010 reveals that both friction angle $(\varphi)$ and cohesion $(\mathrm{C})$ do not present any correlation with oil content under loads of 50, 100, 150, and $200 \mathrm{kPa}$. Considering this fact that strength behavior of fine-grained soil is fundamentally depended on cohesion (Boulanger et al. 1998; Das 2015; Huang et al. 1999; Sridharan and Prakash 1999), the authors believed that the hydrocarbon-induced viscosity and cohesion in the soil pores could compensate the weakened contacts among soil particles, and eventually the combination of these contrary conditions resulted in a stable trend. However, according to the in situ penetration tests, Jia et al. (2010) reported that soil strength was reduced by increasing oil content. With the aim of examining contamination effects on microstructure of soil, Jia et al. also provided and compared some micro scale pictures of light-, heavy-, and medium-oilcontaminated silty soil (Jia et al. 2010). Based on their provided images, the light oilcontaminated sample still has its inter-particle contacts structure with clear pores around grains; however, the heavy oil-contaminated one presents a granular and honeycomb texture (Izdebska-Mucha and Trzciński 2008; Izdebska-Muchaa et al. 2011).

Nazir in 2011 conducted an experimental study to examine long-term effect of motor oil contamination, in $1,3,6,12$, and 24 months after contamination took place, on geotechnical properties of over-consolidated undisturbed clay samples ( $\mathrm{CH}$ according to the USCS) which were extracted from the depth of $6.00 \mathrm{~m}$ of the drilled boreholes in Tanta area, Egypt (Nazir 2011). The soil samples included a mixture of sand (12.6 wt.\%), silt (14.2 wt.\%), and clay (73.2 wt.\%) (Based on wet mechanical analysis (ASTM 2007)) in which the clay section 
included montmorillonite (72 wt.\%), kaolinite (18.2 wt.\%), and illite (9.8 wt.\%) according to XRD analysis. Atterberg limits, UCS, and consolidation tests were then conducted by the researcher to evaluate the influences of motor oil on engineering properties of the soil. Based on the published results, both LL and PL significantly decreased with passing about 3 months after the contamination commenced, and afterwards both limits did not show considerable alterations with time. According to (Nazir 2011) and (Khamehchiyan et al. 2007), in the case of organic pore fluid like motor oil, the physicochemical changes in soil microstructure, as a result of low dielectric constant value of organic pore fluid, can make the clay behave approximately like cohesionless materials, and ultimately lessen LL. Moreover, Nazir utilized a back calculation method to determine the permeability of clean and motor oil-contaminated clay samples from the results of the consolidation tests. According to the results indicated by (Nazir 2011), at a lower stress, around the pre-consolidated stress $(100 \mathrm{kPa})$, the value of coefficient of permeability at 24-month oil-contaminated clay was approximately 3 times higher than that of clean clay, and this significant increase can be associated with the lower dielectric constant of oil making shrinkage in double layers around clay particles and creating macrospores and macrocracks in clay with time (Izdebska-Mucha and Trzciński 2008) which could be resulted in an increase in the coefficient of permeability. In addition, beyond the pre-consolidated stress, there was not obvious alteration in the coefficient of permeability caused by aging, and the coefficient of permeability of all aged samples including 24-month oil-contaminated clay similarly pursued unchanged trends as applied stress increased. The influences of continuation of the contamination on the coefficient of permeability were also presented by (Nazir 2011) for various stress ranges. With reference to the published information, it can be expressed that, at lower stresses (100 and $200 \mathrm{kPa}$ ), the effects of duration period of contamination were much more significant than at higher stresses (400 and $800 \mathrm{kPa}$ ). However, after passing a month, the coefficient of permeability in all stress values 
remained almost constant (Nazir 2011). The observed changes in permeability of motor oilcontaminated clay can be related to the lower dielectric constant value of motor oil as pore fluid, and may be explained by the double layer theory in which a reduction in the dielectric constant value of pore fluid will decrease thickness of the double layers around clay particles (Bowders and Daniel 1987; Khamehchiyan et al. 2007; Nazir 2011). Nazir also reported the effects of continuation of motor oil contamination on UCS of the clay samples. A serious decline in UCS was observed during the first 6 months after contamination occurred, and there was not any remarkable change in the strength during the next 18 months. In this research, the authors determined initial compression index $\left(\mathrm{C}_{\mathrm{c}}\right)$, swelling index $\left(\mathrm{C}_{\mathrm{r}}\right)$, and preconsolidated pressure using Cassgrande method (Cassgrande 1936) as well as over consolidation ratio (OCR) using back calculation process from stress-strain relationships. In general, OCR was not sensitive to the duration period of contamination; however, $\mathrm{C}_{\mathrm{c}}$ and $\mathrm{C}_{\mathrm{r}}$ showed different behaviors so that, during the first 6 months after contamination, motor oil contamination made $\mathrm{C}_{\mathrm{r}}$ almost double, and thereafter $\mathrm{C}_{\mathrm{r}}$ followed a constant trend (the next 18 months). On the other hand, $C_{c}$ also enjoyed a similar increase to $C_{r}$ during the first 3 months, and then reached stability.

In 2013, Khosravi et al. studied the effects of gas oil contamination on some geotechnical properties of pure kaolinite (Low plastic clay (CL) according to the USCS) via an extensive experimental program including Atterberg limits, consolidation, direct shear, and unconfined compression tests as well as scanning electron microscopy (SEM) (Khosravi et al. 2013). The used gas oil had a density of $0.8-0.84$ at $25^{\circ} \mathrm{C}$, and was provided by National Iranian Oil Refining and Distribution Company (NIORDC). The 24-hour oven-dried pure kaolinite was mixed with gas oil contamination in the amount of $2,4,6,12,16$, and $20 \mathrm{wt} . \%$ of the dried kaolinite. Then, these samples were put into containers, and kept at temperature of about $30^{\circ} \mathrm{C}$ for a week to achieve homogenous mixtures. This range of temperature was chosen in the 
experimental plan based on the usual and average conditions in the locations of Iranian refineries and oil facilities (Khosravi et al. 2013). The amount of gas oil evaporation from the contaminated clay for about 4 weeks were examined by the authors, and it was found that evaporation was significant during the first week, and the total evaporated gas oil was approximately $3 \%$ at the end of 4 weeks (considered as a negligible loss by (Khosravi et al. 2013)). Based on the in situ conditions of clayey soil in the vicinity of the refineries and oil facilities, all mixed gas oil-clay samples were prepared at the identical dry density of $60 \%$ $\left(10.14 \mathrm{kN} / \mathrm{m}^{3}\right)$. The researchers suitably employed scanning electron microscopy (SEM) to evaluate the effects of water and gas oil contamination on the soil structure. They provided SEM images of clean dry pure kaolinite, clean wet pure kaolinite (with 12 wt.\% of water), gas oil-contaminated dry pure kaolinite (with $12 \mathrm{wt} . \%$ of gas oil), and gas oil-contaminated wet pure kaolinite (with both 12 wt.\% of gas oil and 12 wt.\% of water). As it can be seen in Fig. 4, clean dry pure kaolinite had a dispersed fabric (Fig. 4(a)), and even after adding 12\% of water, the moderate dispersed fabric can be still seen in Fig. 4(b). Moreover, it can be observed in Fig. 4(c) that $12 \%$ gas oil-contaminated dry pure kaolinite had a relative flocculation since individual kaolinite particles were coated by gas oil compounds. Regarding Fig. 4(d), (Khosravi et al. 2013) reported that the presence of gas oil could improve the ability of water to create flocculation in the wet kaolinite structure (See also (Quigley and Fernandez 1991)).

According to the Atterberg Limits tests by (Khosravi et al. 2013), both LL and PI of contaminated clay increased as gas oil content grew up to $12 \%$ in which maximum LL and PI took place. After adding more than $12 \%$ of gas oil, both LL and PI experienced a steep downward trend, and reached an amount less than that of the virgin pure clay. However, in the case of PL, a very slight reduction was reported. With reference to these facts that both water and gas oil molecules are immiscible, act as two separate layers or one phase into 
another, and especially this point that gas oil molecules have no ability to generate polar covalent bonds with clay particles, it can be stated based on the diffuse double-layer (DDL) theory (Mojid 2011) that diffuse double-layers won't be expanded by gas oil molecules, and consequently small amount of water is needed to bring pure clay into plastic condition. Regarding the observed different changes in LL and due to viscous nature of the contaminant, gas oil molecules established thin viscous layers surrounding clay particles, thereby enabling clay skeleton to sustain its own weight and made LL to increase. Adding more gas oil (greater than 12\%) significantly increased the thicknesses of viscous layers around clay particles, and consequently provided the ability of slippage for particles which diminished LL.

Khosravi et al. also conducted a series of standard consolidation tests on gas oil-contaminated pure Kaolinite, and reported some changes in compression index $\left(\mathrm{C}_{\mathrm{c}}\right)$ and swelling index $\left(\mathrm{C}_{\mathrm{r}}\right)$. As gas oil content increased, $\mathrm{C}_{\mathrm{r}}$ remained almost constant and $\mathrm{C}_{\mathrm{c}}$ decreased which can be explained using the surface energy available at the gas oil-water interface (Burland 1990; Chen et al. 2000). A large surface tension provided by the surface energy at the interface can combine water droplets and make water drainage to decrease. With reference to SEM images of wet pure kaolinite with and without gas oil contamination, it can be inferred that wet pure kaolinite has more pore spaces and shows higher $\mathrm{C}_{\mathrm{c}}$. Based on the published results of direct shear tests on contaminated pure Kaolinite with 2, 6, 12, 16, and 20 wt.\% of gas oil, it was observed that hydrocarbon contaminants imposed negligible reduction in soil friction angle owing to lubrication effects of gas oil compounds; however, significant influences were observed on the cohesion of clayey soil, especially for gas oil percentages greater than 12 wt.\%, as result of a combination of the van der Waals forces and suction in gas oil-clay particle interfaces. As an overall analysis, it can be concluded that shear strength of the kaolinite, calculated using the Mohr-Coulomb failure criterion, was not considerably 
influenced by gas oil contamination. However, at the same embedded amount of water or gas oil, gas oil-contaminated dry kaolinite soil showed higher shear strength compared with wet clean kaolinite soil due to this accepted fact that flocculated soil structure has higher shear strength than dispersed one (See also (Quigley and Fernandez 1991)). According to unconfined compression tests conducted by (Khosravi et al. 2013), it is obvious that, in all contamination contents, undrained shear strength of gas oil-contaminated Kaolinite behaved linearly before reaching its maximum. Additionally, adding more oil content, up to $12 \mathrm{wt} . \%$, into soil made shear strength increase gradually, and further oil concentration (>12 wt.\%) had an opposite effect so that 16 wt.\% gas oil-contaminated Kaolinite showed a lower peak shear strength in comparison to Kaolinite with $12 \mathrm{wt} . \%$ of contamination.

In another research in 2013, Ijimdiya evaluated effects of hydrocarbon contamination on some geotechnical properties of lateritic soil which was reddish brown and collected from the depth of $0.5 \mathrm{~m}$ below the ground level of a burrow pit in Shika, Zaria, Nigeria (Ijimdiya 2013). This soil was classified as A-6 (16) and CL according to the AASHTO and the USCS, respectively. The used oil as hydrocarbon contamination was waste motor oil provided by Oando lubrication workshop located near main campus of Ahmadu Bello University, Zaria, Nigeria. The authors conducted some PSD analyses on clean and contaminated soil, and found out that contamination could significantly reduce the number of clay-sized particles in clayey soil because hydrocarbon compounds have the ability to agglomerate soil particles and to form bigger-sized aggregates, clods, and crumbs which was in a fair agreement with the relevant results of (Srivastava and Pandey 1998). The particle accumulation was intensified by increasing oil content from 2 to 6 wt.\% which was also claimed by (Jia et al. 2010). Based on the reported effects of adding waste motor oil contaminant up to $8 \mathrm{wt} . \%$ on UCS of clayey soil, it was observed that UCS values increased about $20.33 \%$ due to addition of $2 \mathrm{wt} \%$ of oil, and then followed a gradual reduction of about $45.20 \%$ (compared with its peak value) at 
$8 \mathrm{wt} . \%$ of oil. It can be explained that primary increase in UCS was due to rearrangement of the coated soil particles and also improvement in inter-particle bonding. However, the following reduction in the UCS was as a result of improving lubrication between soil particles at higher oil contents. Regarding influences of oil content on void ratio of soil under different loadings $\left(50,100,200,400,800,1600 \mathrm{kN} / \mathrm{m}^{2}\right)$ in consolidation tests, it can be totally said that the value of void ratio increased as oil content rose up to $2 \mathrm{wt} \%$ due to reduction in the number of clay-sized particles in the soil skeleton. Adding more oil up to 6 wt.\% caused a steep decrease in the void ratio, and from 6 to $8 \mathrm{wt} . \%$, void ratio of soil enjoyed a sharp increase (see also (Di Matteo et al. 2011)). Ijimdiya also reported the influences of oil contamination on coefficient of consolidation $\left(\mathrm{C}_{\mathrm{v}}\right)$ for different loading conditions. Generally speaking, for all cases, $\mathrm{C}_{\mathrm{v}}$ gradually increased as oil content reached 4 wt. $\%$, and then it enjoyed a significant increase, and peaked at $6 \mathrm{wt} . \%$; however, adding oil, more than 6 wt.\%, caused a rough decrease in $\mathrm{C}_{\mathrm{v}}$ again (Ijimdiya 2013). It can be said that the increase in $\mathrm{C}_{\mathrm{v}}$ was due to time-dependent primary soil settlement and extrusion of oil from the soil matrix under loading. Moreover, the next steep decrease in $\mathrm{C}_{\mathrm{v}}$ at higher oil contents may be owing to simultaneous consolidation and compressibility process as well as oil extrusion.

In 2014, Akinwumi et al. examined influences of oil contamination (2-10 wt.\%) on Atterberg limits, strength, and permeability of a lateritic clay (A-7-6(7) and sandy lean clay (CL) according to the AASHTO and the USCS) collected from a borrow pit located in Ogun State in southwestern Nigeria (Akinwumi et al. 2014a). The researchers carried out sieve and hydrometer analyses on uncontaminated soil, and also specific gravity, Atterberg limits, compaction, unsoaked and soaked CBR as well as permeability tests on both uncontaminated and contaminated soil. The primary specific gravity, PI, MDD, OMC, coefficient of permeability, unsoaked and soaked CBR were $2.51,18.0 \%, 18.2 \mathrm{kN} / \mathrm{m}^{3}, 15.3 \%, 8.24 \times 10^{-6}$ 
$\mathrm{cm} / \mathrm{s}, 18 \%$, and $10 \%$, respectively. Due to lower specific gravity of crude oil in comparison with the clean soil, specific gravity of contaminated soil was reasonably lower than the uncontaminated one, and, with an increase in the amount of contamination, the value of specific gravity gradually decreased. Based on the authors' report, all of PL, LL, and PI were progressively increased as crude oil was added to the soil. Considering all of plasticity charts, AASHTO, and USCS together, it was found out that after adding $10 \mathrm{wt} \%$ of crude oil into the soil which was primarily classified as A-7-6(7) and CL, it was altered into A-7-5 and an organic soil with significant plasticity $(\mathrm{OH})$. Moreover, as a result of expansion of the thickness of the diffuse double layer due to crude oil contamination, under the same compaction energy, it was not possible to reach the identical MDD in both uncontaminated and contaminated samples. Therefore, it was seen in the results that increasing the amount of crude oil increased MDD, and gradually decreased OMC. Moreover, due to depositions of big molecules of crude oil into the soil pores reducing soil pore space, adding crude oil into the soil caused a progressive decrease in its permeability. In 2014, again, Akinwumi et al. evaluated effects of waste oil engine contamination (2-10 wt.\%) on some engineering properties of the same lateritic clay (Akinwumi et al. 2014b). The uncontaminated soil had a low amount of plasticity, CBR, and also permeability. Due to the lower specific gravity of waste oil engine in comparison with the soil, as the amount of oil contaminant increased in the soil structure, the specific gravity of the contaminated soil decreased. Moreover, when oil content grew, LL and PI increased as well, but PL decreased as a result of interlayer expansion of clay mineral caused by hydrocarbon compounds of waste oil engine. Based on the results of standard proctor compaction tests, it was also observed that OMC and MDD decreased as oil content rose since hydrocarbon compounds surrounding each clay particle prevented interaction of clay particles and increased thickness of diffuse double layers which could be responsible for decreasing $\mathrm{OMC}$ and MDD, respectively. The authors also 
introduced the amount of $6 \mathrm{wt} . \%$ and $8 \mathrm{wt} . \%$ of waste oil engine as the limits for approaching maximum soaked and unsoaked CBR in this contaminated soil, respectively. It should be mentioned, however, that adding more oil beyond these limits increased the lubricant effects of oil contaminant on the friction between soil particles, and decreased strength of soil. Similar to the other relevant literature (Khamehchiyan et al. 2007; Silvestri et al. 1997), a reduction in soil permeability due to oil contamination was also observed in this study. In addition, Onyelowe in 2015 studied influences of pure crude oil contamination on the properties of Amaoba Lateritic soil (A-2-6 based on the AASHTO) collected from Amaoba borrow pit in Nigeria (Onyelowe 2015). The author evaluated the behavior of contaminated soil via several laboratory tests including PSD, water content, specific gravity, shear strength, compaction, Atterberg limit, CBR, and consolidation tests. According to the author, LL of soil decreased from $40 \%$ to $38 \%$ with embedding 2 wt. $\%$ of crude oil, and then increased by $46 \%$ as a result of adding more crude oil up to $6 \mathrm{wt} . \%$. Additionally, the author believed that a reduction in shear strength due to soil contamination might be associated with this fact that hydrocarbon compounds as non-polar liquid can increase the intermolecular force between soil particles, and accordingly improve shear strength; however, a further increase in oil content can act as a barrier between soil particles, and reduces shear strength. According to the results of standard proctor compaction tests (ASTM-D698, method A (ASTM 1999)), it can be said that with an increase in the amount of crude oil, there was a slight decrease in MDD and OMC. It is worth noting that the author figured out that the applicable amount of oil contamination which soil could hold under compaction and loading process was 2 wt.\% (Onyelowe 2015) so that for the oil percentages more than $2 \mathrm{wt} \%$, excess crude oil permeated out of the samples (see also (Khamehchiyan et al. 2007)). As a significant advantage in the pavement industry, CBR was considerably increased by about 7 times as pure crude oil was added in soil up to 6 wt.\%. (Meegoda 1992; Meegoda et al. 1998). 


\subsection{Review summary}

\subsubsection{Materials and methods}

With reference to the information presented in Table 5, it can be obviously observed that crude oil has been the most used hydrocarbon. To add to that, in some research, motor oil, gasoline, and diesel were used as hydrocarbon contaminants as well. It should be also mentioned that the amount of hydrocarbons which were used to provide contaminated specimens has been approximately in a range of 2 to $30 \mathrm{wt} . \%$. The most considered range of contamination, however, was between 2 to 10 wt.\%. Furthermore, some particular hydrocarbon-based compounds including bitumen, benzene, and kerosene were also examined in some research (Al-Sanad et al. 1995; Al-Sanad and Ismael 1997; Ola 1991; Singh et al. 2008). More importantly, up to now, various types of soil have been considered as the host medium for hydrocarbon contaminants (Table 2). On this subject, it can be articulated that both fine- and coarse-grained soils have been taken into account in the literature, and suitable information were presented by the investigators regarding possible effectiveness of hydrocarbon contaminations on geotechnical properties of soils (Table 6). More importantly, it should be stated that almost a majority of methods used to assess geotechnical properties of hydrocarbon-contaminated soils in the literature were basic experiments and tests (Table 6), and it is really needed to use advanced testing apparatus in the future endeavors to deeply evaluate the influences of this kind of contamination on engineering properties of soils.

\subsubsection{Soil microstructure and particle size distribution}

In the case of fine-grained soils, hydrocarbon-induced enlargement in soil grain size along with a reduction in the number of clay-sized grains has been repeatedly reported by various researchers based their SEM and PSD analyses so far (Ijimdiya 2013; Jia et al. 2010; Nazir 
2011; Talukdar and Saikia 2013). However, there were some contrary observations in the particles increased due to a hydrocarbon contamination so that hydrocarbon compounds have the ability to agglomerate soil particles and to form larger sized aggregates. In addition, probable dissolution of organic and inorganic composite colloids and soluble salts in hydrocarbon pollutants as pore fluid can make other changes in soil microstructure. In more details, substantial changes in surface characteristics and interactions of clayey particles as well as fabric of fine-grained soils can be caused by hydrocarbon compounds. Hydrocarboncoated clay particles have more hydrophobic nature in comparison with hydrophilic surfaces of clean clay particles, and hydrocarbon compounds are able to create adhesion among clayey particles, thereby restricting effective range of electrostatic repulsive forces. Precisely, in a far distance from the coated surface of contaminated clay, attractive forces are dominant; however, lower electrostatic repulsive forces still exist among particles in the vicinity of clay surface. Generally, hydrocarbon-contaminated fine-grained soils have a flocculated fabric with more Edge-to-Face (EF) contacts, but, in clean ones, Face-to-Face (FF) and Edge-toEdge (EE) contacts are prevalent that generate a dispersed and oriented fabric. All in all, the probable hydrocarbon-induced changes in microstructure of fine-grained soils have been summarized by the authors in Table 7. However, the degree of alterations is greatly depended on soil mineralogy and physicochemical properties of hydrocarbons, it is reasonable to observe different trends in comparison with the conclusion provided in Table 7.

In the case of coarse-grained soils, hydrocarbon compounds surrounding soil particles are able to shape new microstructures in soils with hydrocarbon-coated aggregates, and these alterations have been reported in several written works (Akinwumi et al. 2014a; Al-Sanad et al. 1995; Srivastava and Pandey 1998; Talukdar and Saikia 2013). Due to this well-known fact that geotechnical behavior of coarse-grained soils is fundamentally based on physical 
interactions among soil particles, having a clear-cut knowledge about hydrocarbon-induced influences on microstructures of soils may be beneficial to understand engineering behavior of coarse-grained soils. To this aim, SEM images (captured by KYKY - EM3200, China) of a type of natural sand, in both clean and hydrocarbon-contaminated conditions, have been provided by the authors in Fig. 5. The used sand was Firoozkooh sand (angular silica sand) which was collected by Silica Sand MFG Company from the natural silica sand mines located near Firoozkooh city in Tehran province of Iran. Moreover, the hydrocarbon contamination was a type of light crude oil provided by West Oil and Gas Production Company (WOGPC) of Iran. As it can be obviously seen in Fig. 5 ( $a$ and b), the deposition of hydrocarbon compounds into sand can bring about considerable effects on its microstructure. These alterations may be explained in two aspects. On one hand, hydrocarbon compounds can create a viscous layer coating surface of each sand particle (Fig. 5(c and d)), and on the other hand, the contaminants have the abilities to surround contact areas among sand particles and also fill empty spaces within the particles (Fig. 5(e and f)). Regarding physical effects of hydrocarbons on surface characteristics (e.g. roughness) of sand particles which are greatly dependent on hydrocarbon amount, SEM images of clean and contaminated Firoozkooh sand with 4, 8, and 12 wt.\% of light crude oil have been presented in Fig. 6. In this regard, it can be generally stated that gradually increasing the amount of hydrocarbon compounds can create hydrocarbon layers around particles and contacts. Thereafter, adding more hydrocarbons can make these layers thicker, and also fill more empty pores in sand structure. It seems that, in lower amounts of contaminants, the layers surrounding sand particles have the ability to create cohesion between particles and to sustain particles together forming a stronger structure. However, this positive effect may be accompanied by influential impacts on friction among particles, especially in smaller amounts of hydrocarbons which do not influence surface roughness (Fig. 6(b)). Seemingly, adding further hydrocarbon into sand can 


\subsubsection{Atterberg Limits}

One of the important characteristics of fine-grained soils contaminated by hydrocarbon compounds has been Atterberg limits. In a more general sense and based on an overall look at some relevant research (Akinwumi et al. 2014a; Akinwumi et al. 2014b; Alhassan and Fagge 2013; Jia et al. 2010; Kermani and Ebadi 2012; Khamehchiyan et al. 2007; Khosravi et al. 2013; Nazir 2011; Pusadkar and Bharambe 2014; Rahman et al. 2010; Solly et al. 2015; Srivastava and Pandey 1998; Ukpong and Umoh 2015; Walia et al. 2013), the authors are not able to find a comprehensive trend describing the effects of hydrocarbons on these limits. To elucidate this fact, the authors have approximately accumulated all the data provided in the literature regarding both LL and PI of hydrocarbon-contaminated soils in Fig. 7. As it can be obviously seen (Fig. 7(a)), LL of hydrocarbon-contaminated soils were placed within a specific range of percentages; however, all of the determined PI were somehow scattered (Fig. 7(b)) and there was not an expressive trend to present. However, in each particular research, it could be possible for the authors to draw a specific tendency for the limits. Based 
on DDL theory, most hydrocarbon compounds, as non-polar fluid, are immiscible in water and acting as two separated phases (or a phase into another), and won't be able to create bonds with clay particles (see also (Khosravi et al. 2013)). Moreover, it should be noted that the thickness of DDL may be affected by various characteristics of pore fluid. More importantly, the thickness decreases with increase in valency, and also it is significantly influenced by viscosity. When hydrocarbon compounds are added to fine-grained soils, their viscosity may be also affected, thereby altering the thickness of DDL. In general, these factors may result in not expanding diffuse double-layers around clay particles in the presence of hydrocarbon compounds, and soil plasticity has to take place in different amounts of water, compared with clean soil, thereby making an alteration in PL. However, regarding LL in hydrocarbon-contaminated soils, hydrocarbon molecules forming thin viscous layers surrounding clay particles make LL to change. In addition, it is beneficial to consider impacts of weathering process on the assessment of soil plasticity since physicochemical properties of hydrocarbon compounds may be influenced by weathering which are probable to occur in a wide range of environmental conditions (Al-Sanad and Ismael 1997; Nazir 2011). Moreover, various parameters including size, hydrocarbon-induced adhesion, and cohesion (Khamehchiyan et al. 2007; Nazir 2011; Sleep and McClure 2001). All in all, as it can be inferred based on the aforementioned explanation, certain impacts of hydrocarbon on Atterberg limits of soil are controversial, and there has not been a comprehensive study focusing on this subject. As it is highly dependent to soil/hydrocarbon characteristics, it is greatly suggested to carry out apt research concentering on the effects of hydrocarbon contaminants on Atterberg limits of different types of soil. 


\subsubsection{Hydraulic conductivity}

It can be generally discussed herein that hydrocarbon contaminations reduces hydraulic conductivity of soils (Akinwumi et al. 2014a; Akinwumi et al. 2014b; Al-Sanad et al. 1995; Budhu et al. 1991; Cook et al. 1992; Foreman and Daniel 1986; Khamehchiyan et al. 2007; Meegoda and Rajapakse 1993; Puri 2000; Puri et al. 1994; Rahman et al. 2010; Shin and Das 2000; Siang et al. 2014; Silvestri et al. 1997; Singh et al. 2008; Singh et al. 2009; Tuncan and Pamukcu 1992; Uppot and Stephenson 1989). Totally, deposition of hydrocarbon compounds into soil pores, as influential elements governing hydraulic conductivity of soils, considerably decreases soil permeability. Fig. 8 presents the amount of hydrocarbon-induced alterations in coefficient of permeability of soil reported by the aforementioned studies. As it was pointed by an ellipse on Fig. 8, increasing amount of hydrocarbons effectively intensifies the degree of changes in permeability, and the majority of these changes varied in a range of 20 to $80 \%$.

\subsubsection{Compaction behavior}

In general, compaction test has been conducted by geotechnical engineers to find out optimum moisture content (OMC) of a soil in which, for a particular compactive effort, maximum dry density (MDD) of soil can be accessible (Das 2015). Due to probable effects of pore fluid on soil compaction, several studies have been concentrated so far regarding compaction behaviors of hydrocarbon-contaminated soils. Table 8 provides a review on maximum dry density (MDD) and optimum moisture content (OMC) of hydrocarboncontaminated soils. In a more general sense, it can be mentioned that the effects of hydrocarbon compounds on MDD and OMC are not similar, and various trends may be addressed according to Table 8 . With reference to OMC, it should be stated that, in all relevant research (Akinwumi et al. 2014a; Akinwumi et al. 2014b; Al-Sanad et al. 1995; Kermani and Ebadi 2012; Khamehchiyan et al. 2007; Onyelowe 2015; Pusadkar and 
Bharambe 2014; Rahman et al. 2010; Silvestri et al. 1997; Srivastava and Pandey 1998; Walia et al. 2013), with the exception of (Singh et al. 2009), adding hydrocarbon compounds could significantly diminish OMC with $4.3 \%$ in CL (Akinwumi et al. 2014a) up to $86 \%$ in poorly graded sand (SP) (Khamehchiyan et al. 2007). However, (Singh et al. 2009) observed that $\mathrm{OMC}$ of both $\mathrm{CL}$ and $\mathrm{CH}$ soil increased almost by 12 and $22 \%$, respectively, as the amount of hydrocarbon content (used motor oil) rose to 9 (wt.\%).

On the other hand, MDD experienced different hydrocarbon-induced changes. In a majority of research studies (Akinwumi et al. 2014a; Akinwumi et al. 2014b; Khamehchiyan et al. 2007; Pusadkar and Bharambe 2014; Rahman et al. 2010; Silvestri et al. 1997; Singh et al. 2009; Walia et al. 2013), as hydrocarbon compounds increased in soils, MMD diminished accordingly. Moreover, some researchers observed that MDD increased as hydrocarbon content rose in soils. For Example, Kermani and Ebadi (2012) reported that MDD of silty soil could rise about $5.18 \%$ from 1640 to $1725\left(\mathrm{~kg} / \mathrm{m}^{3}\right)$ with adding $12 \mathrm{wt} . \%$ of light crude oil (Kermani and Ebadi 2012). In addition, a few studies (Al-Sanad et al. 1995; Onyelowe 2015; Srivastava and Pandey 1998) reported that as hydrocarbon content increased in soils, MDD firstly increased, and then decreased. Meanwhile, it should be noticed that the shapes of compaction curves have been also affected by hydrocarbons, and bell shapes or double-peak types were pointed in some literature (Khamehchiyan et al. 2007).

To sum up, it can be stated that in the case of sand, lubrication effects of hydrocarbon compounds on interaction between particles can be named as a key element changing compaction behavior. However, when hydrocarbon contaminations containing hydrophobic compounds are added in fine-grained soils, hydrocarbon compounds with higher molecular weight are absorbed onto the grain surfaces and surround soil particles. This process which agglomerates soil particles, decreases particle's Specific Surface Area (SSA), and reduces 
bonding strength may be responsible for altering compaction behavior of hydrocarboncontaminated fine-grained soils.

\subsubsection{Consolidation characteristics}

Based on a careful review on the effects of hydrocarbon contaminations on consolidation of soils, it can be inferred that hydrocarbon-induced changes in consolidation characteristics $\left(\mathrm{C}_{\mathrm{c}}\right.$ and $\mathrm{C}_{\mathrm{v}}$ ) of soils were highly dependent on types of both soil and hydrocarbon (Al-Sanad et al. 1995; Alhassan and Fagge 2013; Di Matteo et al. 2011; Estabragh et al. 2016; Ijimdiya 2013; Kermani and Ebadi 2012; Khosravi et al. 2013; Meegoda and Ratnaweera 1994; Nazir 2011; Onyelowe 2015; Singh et al. 2008; Srivastava and Pandey 1998; Talukdar and Saikia 2013; Tuncan and Pamukcu 1992). All in all, on one hand, some of these studies stated that compression index $\left(\mathrm{C}_{\mathrm{c}}\right)$ of soil increased with adding oil content (Al-Sanad et al. 1995; Singh et al. 2008; Srivastava and Pandey 1998), and on the other hand, a few researchers claimed the opposite behavior, especially for clayey soils (Alhassan and Fagge 2013; Khosravi et al. 2013; Talukdar and Saikia 2013; Tuncan and Pamukcu 1992). According to the surface energy method, the surface energy at the hydrocarbon-water interface creates a higher surface tension on the considered interface, and results in decreasing water drainage from soil structure. This procedure can reduce the compressibility of clayey hydrocarbon-contaminated soils. To elucidate both procedures, the hydrocarbon-induced changes in compression index $\left(\mathrm{C}_{\mathrm{c}}\right)$ of soil were presented in Fig. 9. Increasing and decreasing effects of hydrocarbon compounds on $\mathrm{C}_{\mathrm{c}}$ were indicated by positive and negative percentages on the vertical axis. Moreover, according to the provided trendline in Fig. 9, it can be generally said that as hydrocarbon content increases, the seriousness of changes in $\mathrm{C}_{\mathrm{c}}$ is also intensified. Furthermore, regarding coefficient of consolidation $\left(\mathrm{C}_{\mathrm{v}}\right)$, it can be generally stated that, 
approximately in all related literature, hydrocarbon contaminations could diminish the value of $\mathrm{C}_{\mathrm{v}}$. However, it was also depended on particular situation of each research.

\subsubsection{Angle of internal friction and cohesion}

The angle of internal friction and also cohesion originated from inter-particle relationships play important roles in defining engineering behavior of soils. Therefore, the assessment of hydrocarbon-induced effects on these parameters is a beneficial key to find more about their geotechnical behaviors. Regarding angle of internal friction, a quick review on the research studies discussing influences of hydrocarbon compounds on soil friction reveals that, approximately in all cases, hydrocarbon-based contaminations reduced angle of internal friction (Al-Sanad et al. 1995; Cook et al. 1992; Evgin and Das 1992; Khamehchiyan et al. 2007; Puri 2000; Shin et al. 2002; Siang et al. 2014; Singh et al. 2008; Srivastava and Pandey 1998). In this regard, angle of internal friction of various hydrocarbon-contaminated soils has been summarized in Fig. 10(a). Notwithstanding a slight scattering state in the results, it is possible to draw a trendline showing prevailing direction of hydrocarbon-induced changes in angle of internal friction so that a gradual reduction in angle of internal friction is obvious as a result of hydrocarbon contaminations. Moreover, as hydrocarbon concentration increases in hydrocarbon-contaminated soils, the induced difference between internal friction angle of clean and contaminated soils also increases (see (Shin et al. 2002)). As it was completely explained in section 3.2.2, these observations can be associated with lubrication effects of hydrocarbon compounds on surface roughness of particles, as vital elements creating frictional behavior of soils, which result in facilitating inter-particle sliding and slipping (Fig 5-6). In this regard, it can be stated that adding further hydrocarbon into soils can approximately cover surface roughness, and eliminate the existing friction among soil particles. Additionally, adding crude oil weakens the induced cohesion between soil grains. 
In the case of cohesion, in various research studies (Chew and Lee 2010; Francis 2013; Kermani and Ebadi 2012; Khamehchiyan et al. 2007; Khosravi et al. 2013; Srivastava and Pandey 1998), hydrocarbon-induced changes in cohesion of soil have been investigated. On this subject, their published results were accumulated in Fig. 10(b). As it was depicted, in a majority of cases, increasing hydrocarbon contamination could diminish the value of cohesion, especially in clayey soil. However, in a few studies, hydrocarbon-induced influences were not considerable. In addition, it should be added that hydrocarbon compounds have the ability to create small amount of cohesion among sand particles owing to their adhesion capacities (red lines in Fig. 10(b) - see also section 3.2.2) (Khamehchiyan et al. 2007; Srivastava and Pandey 1998). In general, probable imposed alterations on van der Waals forces and suction between soil grains as well as creation of hydrocarbon-wet conditions into soil microstructure may be responsible for reducing cohesion of hydrocarboncontaminated fine-grained soils. All in all, the rate of change in cohesion of soils as a result of hydrocarbon contaminations is highly depended on properties of soil and hydrocarbon compounds, and this matter must be considered in each assessment.

\subsubsection{Unconfined compression strength}

In Table 9, the available results of some unconfined compression tests on hydrocarboncontaminated soils have been tabulated by the authors in terms of both unconfined compression strengths $\left(\mathrm{q}_{\mathrm{u}}\right)$ and their corresponding strains $\left(\varepsilon_{\mathrm{q}}\right)$. Due to variations of soil and hydrocarbon types as well as operating conditions, it is not possible to from a general tendency about UCS of hydrocarbon-contaminated soils. However, according to the relevant literature (Ijimdiya 2013; Khamehchiyan et al. 2007; Khosravi et al. 2013; Solly et al. 2015; Walia et al. 2013), hydrocarbon compounds could bring about diminishing and enhancing influences on unconfined compression strength of soil. Moreover, in some cases (Ijimdiya 
2013; Khosravi et al. 2013), as the amount of hydrocarbon rose, UCS firstly enjoyed a gradual increase, and then moderately decreased to the lower values compared to clean soils. Moreover, Table 9 revealed that the available literature assessing UCS of hydrocarboncontaminated soils are not sufficient to suitably evaluate the effects of hydrocarbon contaminations on this important geotechnical properties of soil, so it is suggested to comprehensively study the probable effects of hydrocarbon on UCS so as to clarify the issue.

\subsubsection{Maximum shear modulus $\left(G_{\max }\right.$ or $\left.G_{0}\right)$}

In Fig. 11, the results of the experimental endeavours by (Rajabi and Sharifipour 2017a; Rajabi and Sharifipour 2017b) were depicted which was conducted with the aim of assessing probable influences of hydrocarbon contamination on maximum shear modulus of sand. Two critical amounts of crude oil content was introduced so that up to a critical amount (the first one (here 4 wt.\%)), hydrocarbon compounds could moderately increase $G_{\max }$, and beyond this amount, embedding further crude oil into sand, up to the second critical oil content, made $\mathrm{G}_{\max }$ decrease obviously to an amount lower than the virgin one. After the second critical content (here 8 wt.\%), the hydrocarbon-induced influences on $G_{\max }$ were insignificant. In this regard, it should be emphasized that the reported study merely focused on the contaminated standard sand, and the effects of hydrocarbon contamination on $G_{\max }$ of different type of soil like sandy soil, clayey soil, etc. can be considered as novel topics of future research.

\subsubsection{Weathering}

As previously explained, weathering process is an influential factor which should be accurately considered in the assessment of hydrocarbon-contaminated soils. In more details, environmental factors have the ability to change physical and chemical characteristics of 
hydrocarbon compounds in soil via sorption into soil structure, chemical reaction by existing substances in soil, volatilization into air, microbial degradation, and also dissolution in water. Therefore, aging-induced changes in hydrocarbon-contaminated soils should be accurately examined in addition to the short-term effects of hydrocarbon compounds. However, up to now, few research studies were concentrated on long-term effects of hydrocarbon contaminations on geotechnical properties of soil. In section 3.1, a brief explanation of experimental investigations by (Al-Sanad and Ismael 1997) and (Nazir 2011) about aging effects on geotechnical properties of hydrocarbon-contaminated soils were provided by the authors, and in Table 10, a summary of their results has been presented. In this regard, it can be inferred that the majority of aging-induced changes in engineering properties of soil took place during the first three months after contamination occurred. Moreover, Rajabi and Sharifipour in 2018 carried out a series of bender element test on fresh and aged hydrocarbon-contaminated sand so as to assess the influences of weathering process on $\mathrm{G}_{\max }$ of two types of standard sands (Ottawa sand and Firoozkooh sand) (Rajabi and Sharifipour 2018). According to their results, $G_{\max }$ of both sand types increased obviously due to environmental conditions up to 6 month, more seriously during the first 2 months. The authors believed that the weathering-induced changes on maximum shear modulus of hydrocarbon-contaminated soils are dependent on soil type, oil content, and time. In general, it may be reasonable to consider these observable changes only as partial studies, and it really needs to be extensively concentrated in future research. 


\section{Conclusions and recommendations}

In this paper, a comprehensive review focusing on academic literature regarding geotechnical properties of hydrocarbon-contaminated soils was presented. All in all, the following general conclusions can be inferred.

1. Based on the microstructural characterizations, the presence of hydrocarbon compounds in coarse-grained soil can considerably weaken surface roughness of particles, thereby facilitating sliding and slipping among them. On the other hand, hydrocarbon contaminations may bring about the flocculated fabrics with more Edge-to-Face (EF) contacts, less-oriented structural elements, decomposed aggregates, and bigger-sized particles in fine-grained soils.

2. Being highly affiliated with soil and hydrocarbon specifications, LL and PL of soil may be influenced by hydrocarbon contaminations. Although all the reported limits of hydrocarbon-contaminated soils were placed in specific ranges, there were not crystalclear trends to be named here describing hydrocarbon-induced changes on these limits.

3. As a frequent observation, almost all published articles declared that the coefficient of permeability of soil gradually diminished as a result of adding hydrocarbon contaminations.

4. With reference to the results of compaction and consolidation tests, it may be predictable that OMC of contaminated soils is lower than that of the clean ones; however, in the case of MDD, the hydrocarbon-induced changes may not be as straightforward as OMC. To add to that, the degree of hydrocarbon-induced changes in compression index $\left(\mathrm{C}_{\mathrm{c}}\right)$ of soil slightly intensified as the amount of hydrocarbon contamination increased in soil structure.

5. According to a general look at the assimilated data regarding angle of internal friction and cohesion of hydrocarbon-contaminated soils, it can be stated that adding hydrocarbon 
compounds can probably diminish both angle of internal friction and cohesion of soil as a result of imposing alterations in inert-particle relationships and fabric of soil.

The authors believe that, notwithstanding a great deal of research allocated to this subject heretofore, a few cases still exist that need to be concentrated more in details regarding hydrocarbon-contaminated soils including hydrocarbon-induced changes in microstructures of both coarse- and fine-grained soils, dynamic behavior of hydrocarbon-contaminated soils, and long-term influences of hydrocarbon contaminations on geotechnical properties of soils. More importantly, it should be mentioned here that the majority of research studies discussing geotechnical properties of hydrocarbon-contaminated soils has been lab-oriented works, and it really needs to perform comprehensive in-situ surveys in order to confirm and/or correct the available lab-oriented experimental findings. 


\section{References:}

Acar YB, Olivieri I (1989) Pore Fluid Effects on the Fabric and Hydraulic Conductivity of Laboratory Compacted Clay.

Ahmadi M, Manera M, Sadeghzadeh M (2016) Global oil market and the U.S. stock returns Energy 114:1277-1287 doi:http://dx.doi.org/10.1016/j.energy.2016.08.078

Al-Awadhi NM, Abdal MS, Briskey EJ, Kenneth W (1992) Assessment of technologies for the remediation of oil-contaminated soil resulting from exploded oil wells and burning oil fires in Kuwait. Paper presented at the Proceeding of 85th annual meeting and exhibition / Air \& Waste Management Association, Kansas City,

Aiban SA (1998) The Long-term Environmental Effects of the Gulf WarThe effect of temperature on the engineering properties of oil-contaminated sands Environment International 24:153-161 doi:http://dx.doi.org/10.1016/S0160-4120(97)00131-1

Aigner E, Burgess J, Carter S, Nurse J, Park H, Schoenfeld A, Tse A (2010) Tracking the oil spill in the gulf. National Oceanic and Atmospheric Administration; U.S. Coast Guard; SkyTruth; Roffer's Ocean Fishing Forecasting Service,

Akinwumi II, Diwa D, Obianigwe N (2014a) Effects of crude oil contamination on the index properties, strength and permeability of lateritic clay Internationla Journal of Applied Sciences and Engineering Research 3:816-824

Akinwumi II, Maiyaki UR, Adubi SA, Daramola SO, Ekanem BB (2014b) Effects of waste engine oil contamination on the plasticity, strength and permeability of lateritic clay International Journal of Scientific \& Technology Reseaech 3:331-335

Al-Mutairi NM (1995) Kuwait Oil-Based Pollution: Effect on Building Material Journal of Materials in Civil Engineering 7:154-160 doi:doi:10.1061/(ASCE)0899-1561(1995)7:3(154)

Al-Sanad HA, Eid WK, Ismael NF (1995) Geotechnical Properties of Oil-Contaminated Kuwaiti Sand Journal of Geotechnical Engineering 121:407-412 doi:doi:10.1061/(ASCE)07339410(1995)121:5(407)

Al-Sanad HA, Ismael NF (1997) Aging Effects on Oil-Contaminated Kuwaiti Sand Journal of Geotechnical and Geoenvironmental Engineering 123:290-293 doi:doi:10.1061/(ASCE)10900241(1997)123:3(290)

Aldstadt J, Germain SR, Grundl T, Schweitzer R (2002) An in situ laser-induced fluorescence system for polycyclic aromatic hydrocarbon-contaminated sediments. United States Environmental Agency, Great Lakes National Program Office, Chicago, Illinois, USA.

Alhassan HM, Fagge SA (2013) Effects of crude Oil, low point pour fuel oil and vacuum gas oil contamination on the geotechnical properties sand, clay and laterite soils International Journal of Engineering Research and Applications (IJERA) 3:1947-1954

Alrtimi A, Rouainia M, Haigh S (2016) Thermal conductivity of a sandy soil Applied Thermal Engineering 106:551-560 doi:http://dx.doi.org/10.1016/j.applthermaleng.2016.06.012

Anandarajah A (2003) Mechanism controlling permeability change in clays due to changes in pore fluid Journal of Geotechnical and Geoenvironmental Engineering 129:163-172

Anderson DC, Brown KW, Thomas JC (1985) Conductivity of compacted clay soils to water and organic liquids Waste Management \& Research 3:339-349 doi:http://dx.doi.org/10.1016/0734-242X(85)90127-2

Andrew ER (2009) Nuclear magnetic resonance Nuclear Magnetic Resonance, by ER Andrew, Cambridge, UK: Cambridge University Press, 2009

Archer JS, Wall CG (2012) Petroleum engineering: principles and practice. Springer Science \& Business Media,

Arman A (1969) A definition of organic soils. Louisiana state Univ., Div of Engineering Research,, Louisiana, USA 
Aske N, Kallevik H, Sjöblom J (2001) Determination of saturate, aromatic, resin, and asphaltenic (SARA) components in crude oils by means of infrared and near-infrared spectroscopy Energy \& Fuels 15:1304-1312

ASTM (1999) Annual book of ASTM standards. . ASTM, ASTM, Philadelphia, PA

ASTM (2007) ASTM D422-63(2007)e2, Standard Test Method for Particle-Size Analysis of Soils. ASTM, West Conshohocken, PA

Berger W, Kalbe U, Goebbels J (2002) Fabric studies on contaminated mineral layers in composite liners Applied Clay Science 21:89-98 doi:http://dx.doi.org/10.1016/S0169-1317(01)00095-3

Bjørseth A (1983) Handbook of polycyclic aromatic hydrocarbons

Bon R, Minami K (1986) The role of construction in the National economy Habitat International 10:93-99 doi:http://dx.doi.org/10.1016/0197-3975(86)90073-1

Bossert I, Bartha R (1984) The fate of petroleum in soil eco-system. In: R.M. Atalas (ed) Petroleum Microbiology. Macmimillan Co, New York,

Boulanger RW, Meyers MW, Mejia LH, Idriss IM (1998) Behavior of a fine-grained soil during the Loma Prieta earthquake Canadian Geotechnical Journal 35:146-158 doi:10.1139/t97-078

Bowders JJJ, Daniel DE (1987) Hydraulic Conductivity of Compacted Clay to Dilute Organic Chemicals Journal of Geotechnical Engineering 113:1432-1448 doi:doi:10.1061/(ASCE)07339410(1987)113:12(1432)

Brown CW, Lynch PF, Ahmadjian M (1975) Applications of Infrared Spectroscopy in Petroleum Analysis and Oil Spill Identification Applied Spectroscopy Reviews 9:223-248 doi:10.1080/05704927508081491

Budhu M, Giese Jr RF, Campbell G, Baumgrass L (1991) The permeability of soils with organic fluids Canadian Geotechnical Journal 28:140-147 doi:10.1139/t91-015

Bunger JW, Thomas KP, Dorrence SM (1979) Compound types and properties of Utah and Athabasca tar sand bitumens Fuel 58:183-195 doi:http://dx.doi.org/10.1016/0016-2361(79)90116-9

Burland JB (1990) On the compressibility and shear strength of natural clays Géotechnique 40:329378 doi:doi:10.1680/geot.1990.40.3.329

Calabrese EJ, Kostecki PT, Dragun J (2005) CONTAMINATED SOILS, SEDIMENTS AND WATER Volume 10: Successes and Challenges vol 10. Springer US, USA

Carrigy MA (1967) The Physical and Chemical Nature of a Typical Tar Sand: Bulk Properties and Behaviour. Paper presented at the 7th World Petroleum Congress, Mexico City, Mexico, 2-9 April, 1967

Cassgrande A (1936) The determination of the preconsolidation load and its practical significance. Paper presented at the 1st ICSMFE,

Chang SE, Stone J, Demes K, Piscitelli M (2014) Consequences of oil spills: a review and framework for informing planning Ecology and Society 19 doi:10.5751/ES-06406-190226

Chang W, Dyen M, Spagnuolo L, Simon P, Whyte L, Ghoshal S (2010) Biodegradation of semi-and non-volatile petroleum hydrocarbons in aged, contaminated soils from a sub-Arctic site: laboratory pilot-scale experiments at site temperatures Chemosphere 80:319-326

Chen J, Anandarajah A, Inyang H (2000) Pore Fluid Properties and Compressibility of Kaolinite Journal of Geotechnical and Geoenvironmental Engineering 126:798-807 doi:doi:10.1061/(ASCE)1090-0241(2000)126:9(798)

Chew SJ, Lee CY (2010) Simple shear behaviour of palm biodiedsel contaminated soil ARPN Journal of Engineering and Applied Sciences 5:6-9

Cook EE, Puri VK, Shin EC (1992) Geotechnical Characteristics Of Crude Oil-Contaminated Sands. Paper presented at the The Second International Offshore and Polar Engineering Conference, San Francisco, California, USA,

Das BM (2015) Principles of Foundation Engineering, 8th Edition. Cengage Learning,

Davis JB, Farmer VE, Kreider RE, Straub AE, Reese KM (1972) Migration of petroleum products in soil and ground water: principles and countermeasures. American Petroleum Inst., Washington, DC, 
Di Matteo L, Bigotti F, Ricco R (2011) Compressibility of Kaolinitic Clay Contaminated by EthanolGasoline Blends Journal of Geotechnical and Geoenvironmental Engineering 137:846-849 doi:doi:10.1061/(ASCE)GT.1943-5606.0000494

Duffy JJ, Peake E, Mohtadi MF (1980) Oil spills on land as potential sources of groundwater contamination Environment International 3:107-120 doi:http://dx.doi.org/10.1016/01604120(80)90045-8

Durand B, Liss LA (2002) Characterizing Risks Posed by Petroleum Contaminated Sites: Implementation of the MADEP VPH/EPH Approach. COMMONWEALTH OF MASSACHUSETTS, EXECUTIVE OFFICE OF ENVIRONMENTAL AFFAIRS, DEPARTMENT OF ENVIRONMENTAL PROTECTION, ONE WINTER STREET, BOSTON, MA 02108 617-292-5500

Elazhari-Ali A, Singh AK, Davenport RJ, Head IM, Werner D (2013) Biofuel components change the ecology of bacterial volatile petroleum hydrocarbon degradation in aerobic sandy soil Environmental pollution 173:125-132

Engelhardt $\mathrm{H}$ (2012) High performance liquid chromatography. Springer Science \& Business Media,

Estabragh AR, Beytolahpour I, Moradi M, Javadi AA (2016) Mechanical behavior of a clay soil contaminated with glycerol and ethanol European Journal of Environmental and Civil Engineering 20:503-519 doi:10.1080/19648189.2015.1047900

Etkin DS (1999) Historical overview of soil spills from all courses (1960-1998). Oil Spill Intelligence Report Arlington, Massachusetts

Evgin E, Das BM Mechanical behavior of an oil contaminated sand. In: Acar. Ua (ed) Envir. Geotechnol., Proc., Mediterranean Conf., Rotterdam. The Netherlands, 1992. Balkema Publishers, pp 101-108

Fabbri D, Rombolà AG, Torri C, Spokas KA (2013) Determination of polycyclic aromatic hydrocarbons in biochar and biochar amended soil Journal of Analytical and Applied Pyrolysis 103:60-67

Fanchi JR, Christiansen RL (2016) Introduction to Petroleum Engineering. John Wiley \& Sons, Inc.,, The United State of America

Fang H, Daniels J (1997) Introduction to Environmental Geotechnology. CRC Press,

Fernandez F, Quigley RM (1991) Controlling the destructive effects of clay - organic liquid interactions, by application of effective stresses Canadian Geotechnical Journal 28:388-398 doi:10.1139/t91-049

Fine P, Graber ER, Yaron B (1997) Soil interactions with petroleum hydrocarbons: Abiotic processes Soil Technology 10:133-153 doi:http://dx.doi.org/10.1016/S0933-3630(96)00088-8

Foreman DE, Daniel DE (1986) Permeation of Compacted Clay with Organic Chemicals Journal of Geotechnical Engineering 112:669-681 doi:doi:10.1061/(ASCE)0733-9410(1986)112:7(669)

Francis IA (2013) Correlation between the bearing capacity of crude oil contaminated soil of mgbede and the percentage contamination Journal of Civil Engineering and Architecture 7:1595-1600

Franklin AG, Orozco LF, Semrau R (1973) Compaction and Strength of Slightly Organic Soils Journal of the Soil Mechanics and Foundations Division (ASCE) 99:541-557

Galceran M, Moyano E (1994) High-performance liquid chromatography-mass spectrometry (pneumatically assisted electrospray) of hydroxy polycyclic aromatic hydrocarbons Journal of Chromatography A 683:9-19

Gale RW (2013) Comparison of Aliphatic Hydrocarbons, Polycyclic Aromatic Hydrocarbons, Polychlorinated Biphenyls, Polybrominated Diphenylethers, and Organochlorine Pesticides in Pacific Sanddab (Citharichthys Sordidus) from Offshore Oil Platforms and Natural Reefs Along the California Coast.

Haas JS, Bushman JF, Howard DE, Wong JL, Eckels JD (2002) Portable gas chromatograph mass spectrometer for on-site chemical analyses. Google Patents,

Harrington JA Infrared fibers and their applications. In, 2003. SPIE-International Society for Optical Engineering,

Harrison RM (2001) Pollution: Causes, Effects and Control. Royal Society of Chemistry (RS.C), UK

Harrison RM (2006) An Introduction to Pollution Science. Royal Society of Chemistry, 
Hasan A. Al-Sanad WKE, and Nabil F. Ismael (1995) Geotechnical properties of oil-contaminated Kuwaiti Sand Journal of Geotechnical Engineering 121:407-413

Heumann KG (1992) Isotope dilution mass spectrometry International Journal of Mass Spectrometry and Ion Processes 118:575-592

Hoddinott K, O'Shay T (1994) Analysis of Soils Contaminated with Petroleum Constituents (STP1221). ASTM International ASTM International

Hosseini MH, Rezaee M, Mashayekhi HA, Akbarian S, Mizani F, Pourjavid MR (2012) Determination of polycyclic aromatic hydrocarbons in soil samples using flotation-assisted homogeneous liquid-liquid microextraction Journal of Chromatography A 1265:52-56

Howard PH, Boethling RS, Jarvis WF, Meylan WM, Michalenko EM (1991) Handbook of Environmental Degradation Rates. CRC Press

Huang A, Hsu H, Chang J (1999) The behavior of a compressible silty fine sand Canadian Geotechnical Journal 36:88-101 doi:10.1139/t98-090

Huat BBK, Prasad A, Asadi A, Kazemian S (2014) Geotechnics of Organic Soils and Peat. CRC Press/Balkema, Taylor \& Francis Group, London, UK

ljimdiya TS (2013) The Effects of Oil Contamination on the Consolidation Properties of Lateritic Soil Development and Applications of Oceanic Engineering (DAOE) 2:53-59

Izdebska-Mucha D, Trzciński J (2008) Effects of petroleum pollution on clay soil microstructure geologija 50:S68-S74 doi:10.2478/v10056-008-0027-0

Izdebska-Muchaa D, Trzciński J, Zbik M, Frost RL (2011) Influence of hydrocarbon contamination on clay soil microstructure Clay Minerals 46:47-58 doi:10.1180/claymin.2011.046.1.47

Jia YG, Wu Q, Meng X, Yang X, Yang Z, Zhang G (2010) Case Study on Influences of Oil Contamination on Geotechnical Properties of Coastal Sediments in The Yellow River Delta. In: Chen Y, Zhan L, Tang X (eds) Advances in Environmental Geotechnics: Proceedings of the International Symposium on Geoenvironmental Engineering in Hangzhou, China, September 8-10, 2009. Springer Berlin Heidelberg, Berlin, Heidelberg, pp 767-771. doi:10.1007/978-3-642-044601_94

Kabata-Pendias A (2010) Trace Elements in Soils and Plants, Fourth Edition. CRC Press

Kaya A, Fang H (2000) The effects of organic fluids on physicochemical parameters of fine-grained soils Canadian Geotechnical Journal 37:943-950 doi:10.1139/t00-023

Kermani M, Ebadi T (2012) The Effect of Oil Contamination on the Geotechnical Properties of FineGrained Soils Soil and Sediment Contamination: An International Journal 21:655-671 doi:10.1080/15320383.2012.672486

Khamehchiyan M, Hossein Charkhabi A, Tajik M (2007) Effects of crude oil contamination on geotechnical properties of clayey and sandy soils Engineering Geology 89:220-229 doi:http://dx.doi.org/10.1016/i.enggeo.2006.10.009

Khosravi E, Ghasemzadeh H, Sabour MR, Yazdani H (2013) Geotechnical properties of gas oilcontaminated kaolinite Engineering $\quad$ Geology $166: 11-16$ doi:http://dx.doi.org/10.1016/i.enggeo.2013.08.004

Kopka J (2006) Gas chromatography mass spectrometry Plant Metabolomics:3-20

Kuwait-Oil-Company (1991a) Report on the clean-up of oil contaminated sand, Kuwait.

Kuwait-Oil-Company (1991b) Report on the Oil Lakes, Kuwait.

Lakowicz JR (1999) Fluorescence anisotropy. In: Principles of fluorescence spectroscopy. Springer, pp 291-319

Lee PY, Suedkamp RJ (1972) Characteristics of irregularly shaped compaction curves of soils Highway Research Record, National Academy of Science, Washington, DC, 381:1-9

Ling SY, Yong LC (2013) Behavior of piles in palm biodiesel contaminated mining sand International journal of environmental science 3:1822-1830

Loehr RC, Higgins GC (1965) Comparison of lipid extraction methods International Journal of Air and Water Pollution 9:55-67 
Loehr RC, Webster MT, Smith JR (2000) Fate of Treated and Weathered Hydrocarbons in Soil-LongTerm Changes Practice Periodical of Hazardous, Toxic, and Radioactive Waste Management 4:53-59 doi:doi:10.1061/(ASCE)1090-025X(2000)4:2(53)

Łydżba D, Rajczakowska M, Różański A, Stefaniuk D (2014) Influence of the Moisture Content and Temperature on the Thermal Properties of Soils: Laboratory Investigation and Theoretical Analysis Procedia Engineering

91:298-303 doi:http://dx.doi.org/10.1016/j.proeng.2014.12.064

McGill WB, Rowell MJ (1980) Determination of oil content of oil contaminated soil Science of The Total Environment 14:245-253 doi:http://dx.doi.org/10.1016/0048-9697(80)90026-1

Meegoda J (1992) Reuse of petroleum contaminated soils in asphalt concrete vol 5.

Meegoda J, Chen B, Gunasekera SD, Pederson P Compaction characteristics of contaminated soilsreuse as a road base material. In: C. Vipulanandan DJE (ed) Recycled Materials in Geotechnical Applications. Geotechnical Special Publication, ASCE, 1998. ASCE, pp 165-209

Meegoda J, Rajapakse RA (1993) Short-Term and Long-Term Permeabilities of Contaminated Clays Journal of Environmental Engineering 119:725-743 doi:doi:10.1061/(ASCE)07339372(1993)119:4(725)

Meegoda J, Ratnaweera P (1994) Compressibility of contaminated fine-grained soils Geotechnical Testing Journal 17:101-112 doi:10.1520/GTJ10078J

Mirsal IA (2004) Soil Pollution Origin, Monitoring \& Remediation. Springer, Germany

Mojid MA (2011) Diffuse Double Layer (DDL). In: Gliński J, Horabik J, Lipiec J (eds) Encyclopedia of Agrophysics. Springer Netherlands, Dordrecht, pp 213-214. doi:10.1007/978-90-481-35851_41

Molnárné Guricza L, Schrader W (2015) Electrospray ionization for determination of non-polar polyaromatic hydrocarbons and polyaromatic heterocycles in heavy crude oil asphaltenes Journal of Mass Spectrometry 50:549-557

Mori S, Barth HG (2013) Size exclusion chromatography. Springer Science \& Business Media,

Muccio Z, Jackson GP (2009) Isotope ratio mass spectrometry Analyst 134:213-222

Nachtergaele $F$ (2015) Status of the World's Soil Resources - Main report. Intergovernmental Technical Panel on Soils (ITPS), Rome

Naeini SA, Shojaedin MM (2014) Effect of oil contamination on the liquefaction behavior of sandy soils International Journal of Environmental, Chemical, Ecological, Geological and Geophysical Engineering 8:289-292

Nasr AMA (2013) Uplift Behavior of Vertical Piles Embedded in Oil-Contaminated Sand Journal of Geotechnical and Geoenvironmental Engineering 139:162-174 doi:doi:10.1061/(ASCE)GT.1943-5606.0000739

Nazir AK (2011) Effect of motor oil contamination on geotechnical properties of over consolidated clay Alexandria Engineering Journal 50:331-335 doi:http://dx.doi.org/10.1016/i.aej.2011.05.002

Nölscher A, Sinha V, Bockisch S, Klüpfel T, Williams J (2012) Total OH reactivity measurements using a new fast Gas Chromatographic Photo-Ionization Detector (GC-PID) Atmospheric Measurement Techniques 5:2981-2992

Ochepo J, Joseph V (2014) Effect of oil contamination on lime stabilized soil Jordan Journal of Civil Engineering 8:88-96

Ogboghodo IA, Iruaga EK, Osemwota IO, Chokor JU (2004) An Assessment of the Effects of Crude Oil Pollution on Soil Properties, Germination and Growth of Maize (Zea Mays) using Two Crude Types - Forcados Light and Escravos Light Environmental Monitoring and Assessment 96:143-152 doi:10.1023/b:emas.0000031723.62736.24

Okparanma RN, Mouazen AM (2013a) Determination of total petroleum hydrocarbon (TPH) and polycyclic aromatic hydrocarbon (PAH) in soils: a review of spectroscopic and nonspectroscopic techniques Applied Spectroscopy Reviews 48:458-486 
Okparanma RN, Mouazen AM (2013b) Visible and near-infrared spectroscopy analysis of a polycyclic aromatic hydrocarbon in soils The Scientific World Journal 2013

Ola SA (1991) Geotechnical properties and behaviour of Nigerian tar sand Engineering Geology 30:325-336 doi:http://dx.doi.org/10.1016/0013-7952(91)90066-T

Olah GA, Molnar A (2003) Hydrocarbon chemistry. John Wiley \& Sons, The united State of America

Onyelowe KC (2015) Pure crude oil contamination on Amaoba lateritic soil The Electronic Journal of Geotechnical Engineering (EJGE) 20:1129-1142

Oomens J, Tielens A, Sartakov BG, von Helden G, Meijer G (2003) Laboratory infrared spectroscopy of cationic polycyclic aromatic hydrocarbon molecules The Astrophysical Journal 591:968

Oyegbile OB, Ayininuola GM (2013) Laboratory Studies on the Influence of Crude Oil Spillage on Lateritic SoilShear Strength: A Case Study of Niger Delta Area of Nigeria Journal of Earth Sciences and Geotechnical Engineering 3:73-83

Pacific States/British Columbia Oil Spill Task Force (2016) Annual Summary of West Coast Oil Spill Data. Pacific States/British Columbia Oil Spill Task Force, USA

Pascucci S (2011) Soil Contamination. InTech, Janeza Trdine 9, 51000 Rijeka, Croatia

Puri VK (2000) Geotechnical Aspects of Oil-Contaminated Sands Journal of Soil Contamination 9:359374 doi:10.1080/10588330091134301

Puri VK, Das BM, Cook EE, Shin EC (1994) Geotechnical Properties of Crude Oil Contaminated Sand. doi:10.1520/STP12658S

Pusadkar SS, Bharambe PS (2014) Performance of petrol and diesel contaminated black cotton soil International Journal of Engineering Research \& Technology (IJERT) 3:536-539

Quigley RM, Fernandez F (1991) Hydrocarbon Liquids and Clay Microstructure. In: Bennett RH et al. (eds) Microstructure of Fine-Grained Sediments: From Mud to Shale. Springer New York, New York, NY, pp 469-474. doi:10.1007/978-1-4612-4428-8_50

Rahman H, Abduljauwad SN, Akram SN (2007) Geotechnical Behavior of Oil-Contaminated FineGrained Soils Electronic Journal of Geotechnical Engineering 12

Rahman ZA, Hamzah U, Taha MR, Ithnain NS, Ahmad N (2010) Influence of Oil Contamination on Geotechnical Properties of Basaltic Residual Soil American Journal of Applied Sciences 7:8 doi:10.3844/ajassp.2010.954.961

Rajabi H, Sharifipour M (2017a) Effects of light crude oil contamination on small-strain shear modulus of Firoozkooh sand European Journal of Environmental and Civil Engineering:1-17 doi:10.1080/19648189.2017.1347525

Rajabi H, Sharifipour M (2017b) An Experimental Characterization of Shear Wave Velocity (Vs) in Clean and Hydrocarbon-Contaminated Sand Geotechnical and Geological Engineering doi:10.1007/s10706-017-0274-0

Rajabi H, Sharifipour M (2018) Influence of weathering process on small-strain shear modulus (Gmax) of hydrocarbon-contaminated sand Soil Dynamics and Earthquake Engineering 107:129-140 doi:https://doi.org/10.1016/i.soildyn.2018.01.006

Ratnaweera P, Meegoda J (2006) Shear Strength and Stress-Strain behavior of Contaminated Soils Geotechnical Testing Journal 29:1-8 doi:http://dx.doi.org/10.1520/GTJ12686

Rosenberger L (2015) The Strategic Importance of the Global Oil Market. LULU Press, Strategic Studies Institute College, U.S.A.W.

Sadler R, Connell D Analytical methods for the determination of total petroleum hydrocarbons in soil. In: Proceedings of the fifth national workshop on the assessment of site contamination. National Environmental Protection Council-Environmental Protection \& Heritage Council. Adelaide, Australia, 2003. pp 133-150

Schumacher BA (2002) Methods for the determination of total organic carbon (TOC) in soils and sediments Ecological Risk Assessment Support Center 2002:1-23

Secretariat O (2010) OPEC long-term strategy. Organization of the Petroleum Exporting Countries, Helferstorferstrasse 17 A-1010 Vienna, Austria 
Secretariat O (2012) OPEC Statute. Organization of the Petroleum Exporting Countries, Helferstorferstrasse 17, A-1010 Vienna, Austria

Seeley SK, Bandurski SV, Brown RG, McCurry JD, Seeley JV (2007) A comprehensive two-dimensional gas chromatography method for analyzing extractable petroleum hydrocarbons in water and soil Journal of chromatographic science 45:657-663

Shang D, Kim M, Haberl M (2014) Rapid and sensitive method for the determination of polycyclic aromatic hydrocarbons in soils using pseudo multiple reaction monitoring gas chromatography/tandem mass spectrometry Journal of Chromatography A 1334:118-125

Sherma J (2006) Thin-Layer Chromatography. Wiley Online Library,

Shin EC, Das BM (2000) Some Physical Properties of Unsaturated Oil-Contaminated Sand. In: Advances in Unsaturated Geotechnics. pp 142-152. doi:doi:10.1061/40510(287)9

Shin EC, Das BM (2001) Bearing Capacity of Unsaturated Oil-Contaminated Sand International Journal of Offshore and Polar Engineering 11:220-226

Shin EC, Lee JB, Das BM (1999) Bearing Capacity of a Model Scale Footing on Crude OilContaminated Sand Geotechnical \& Geological Engineering 17:123-132 doi:10.1023/a:1016078420298

Shin EC, Omar MT, Tahmaz AA, Das BM Shear strength and hydraulic conductivity of oilcontaminated sand. In: L.G. de Mello MA (ed) Proceedings of the Fourth International Congress on Environmental Geotechnics,, Rio de Janeiro, Brazil, 2002. A.A. Balkema Publishers, Lisse,, pp 9-13

Siang AJLM, Wijeyesekera DC, Yahya SMAS, Ramlan M (2014) Innovative testing investigations on the influence of particle morphology and oil contamination on the geotechnical properties of sand International Journal of Integrated Engineering 6:60-66

Silvestri V, Mikhail N, Souli M (1997) Permeability Response of Oil-Contaminated Compacted Clays ASTM International STP1275:62-74

Singh SK, Srivastava RK, John S (2008) Settlement Characteristics of Clayey Soils Contaminated with Petroleum Hydrocarbons Soil and Sediment Contamination: An International Journal 17:290300 doi:10.1080/15320380802007028

Singh SK, Srivastava RK, John S (2009) Studies on soil contamination due to used motor oil and its remediation Canadian Geotechnical Journal 46:1077-1083 doi:10.1139/T09-047

Sleep BE, McClure PD (2001) The effect of temperature on adsorption of organic compounds to soils Canadian Geotechnical Journal 38:46-52 doi:10.1139/t00-067

Snape I, Harvey PM, Ferguson SH, Rayner JL, Revill AT (2005) Investigation of evaporation and biodegradation of fuel spills in Antarctica I. A chemical approach using GC-FID Chemosphere 61:1485-1494

Solly G, Aswathy EA, Berlin S, Krishnaprabha NP, Maria G (2015) Study of geotechnical properties of diesel oil contaminated soil International Journal of Civil and Structural Engineering Research 2:113-117

Sridharan A, Prakash K (1999) Mechanisms controlling the undrained shear strength behaviour of clays Canadian Geotechnical Journal 36:1030-1038 doi:10.1139/t99-071

Srivastava RK, Pandey VD Geotechnical evaluation of oil contaminated soil. In: Sarsby RW (ed) the proceeding of CREEN 2 in the second international symposium on Geotechnics Related to the Environment Krakow, Poland, 1998. Thomas Telford, London,

Stegmann R, Brunner G, Calmano W, Matz G (2001) Treatment of Contaminated Soil: Fundamentals, Analysis, Applications vol 1. Springer-Verlag Berlin Heidelberg. doi:10.1007/978-3-66204643-2

Suatoni J, Garber H, Davis B (1975) Hydrocarbon group types in gasoline-range materials by high performance liquid chromatography Journal of Chromatographic Science 13:367-371

Summons RE, Powell TG, Boreham CJ (1988) Petroleum geology and geochemistry of the Middle Proterozoic McArthur Basin, Northern Australia: III. Composition of extractable hydrocarbons Geochimica et Cosmochimica Acta 52:1747-1763 
Talukdar DK, Saikia BD (2013) Effect of crude oil on some consolidation properties of clayey soil International Journal of Emerging Technology and Advanced Engineering 3:117-120

Taylor LT (2008) Supercritical fluid chromatography Analytical chemistry 80:4285-4294

Tuncan A, Pamukcu S Geotechnical Properties of petroleum and sludge contaminatd marine sediments. In: the Second (1992) International Offshore and Polar Engineering Conference, San Francisco, USA,, 1992 1992. The International Society of Offshore and Polar Engineers, pp 14-19

Ukpong EC, Umoh IC (2015) Effects of ccrude oil spillage on geotecchnical propertiess of lateritic soil in Okoroete, eastern Obololo International Journal of Engineering and Applied Sciences 7:1224

UNEP (2014) Global Environment Outlook-5 (GEO-5): Environment for the future we want. UNEP, Nairobi, Kenya

Uppot JO, Stephenson RW (1989) Permeability of Clays Under Organic Permeants Journal of Geotechnical Engineering 115:115-131 doi:doi:10.1061/(ASCE)0733-9410(1989)115:1(115)

van der Perk M (2006) Soil and Water Contamination: from molecular to catchment scale. Taylor \& Francis/Balkema, P.O. Box 447, 2300 AK Leiden, The Netherlands

Villalobos M, Avila-Forcada AP, Gutierrez-Ruiz ME (2008) An improved gravimetric method to determine total petroleum hydrocarbons in contaminated soils Water, air, and soil pollution 194:151-161

Walia BS, Singh G, Kaur M (2013) Study of diesel contaminated clayey soil. Paper presented at the Proceedings of Indian Geotechnical Conference, Roorkee, India, December 22-24

Wei M-Y, Wen S-D, Yang X-Q, Guo L-H (2009) Development of redox-labeled electrochemical immunoassay for polycyclic aromatic hydrocarbons with controlled surface modification and catalytic voltammetric detection Biosensors and Bioelectronics 24:2909-2914

Whitson W (1999) B: SUMMARY OF SIGNIFICANT SPILL EVENTS International Oil Spill Conference Proceedings 1999:51-53 doi:doi:10.7901/2169-3358-007-51

Whittaker M, Pollard SJT, Fallick TE (1995) Characterisation of Refractory Wastes at Heavy OilContaminated Sites: A Review of Conventional and Novel Analytical Methods Environmental Technology 16:1009-1033 doi:10.1080/09593331608616339

Yang Y, Hawthorne SB, Miller DJ (1995) Comparison of sorbent and solvent trapping after supercritical fluid extraction of volatile petroleum hydrocarbons from soil Journal of Chromatography A 699:265-276

Yong LC (2000) Geoenvironmental Engineering: Contaminated Soils, Pollutant Fate, and Mitigation. In. CRC Press p307

Zhu H, Chen Z, Wang Y, Yan Z (2015) Experimental investigation on heat transfer characteristics of soft clay at high temperatures Japanese Geotechnical Society Special Publication 1:40-44 doi:10.3208/jgssp.CPN-16 


\section{List of Tables:}

Table 1. The largest hydrocarbon contaminations in history since 1900

Table 2. A summary of studies on geotechnical properties of hydrocarbon-contaminated soils

Table 3. Analytical methods for determination of Total Petroleum Hydrocarbons in soils

Table 4. Performance of analytical methods in determination of targeted hydrocarbon compounds in soils

Table 5. A summary of types and amounts of hydrocarbon compounds considered in the studies on geotechnical properties of hydrocarbon-contaminated soils

Table 6. Geotechnical tests on hydrocarbon-contaminated soils

Table 7. Hydrocarbon-induced changes in the microstructure of fine-grained soils

Table 8. A summary of maximum dry density and optimum moisture content of hydrocarbon-contaminated soils

Table 9. Unconfined compressive strength $\left(\mathrm{q}_{\mathrm{u}}\right)$ of hydrocarbon-contaminated soils

Table 10. Effects of weathering and aging process on geotechnical properties of hydrocarbon-contaminated soils 


\section{List of Figures:}

Fig. 1. The volumes of different types of hydrocarbon contaminations occurred in the west coast of United States of America (2002-2015)

Fig. 2. Different kinds of hydrocarbons

Fig. 3. SEM images of a particular clayey soil in (a and c) clean, and (b and d) hydrocarboncontaminated conditions. Reprinted from (Izdebska-Mucha and Trzciński 2008) with permission from The Publishing Department of Lithuanian Academy of Sciences

Fig. 4. SEM images of (a) clean dry pure kaolinite, (b) clean wet pure kaolinite (12 wt.\% of water) (c) gas oil-contaminated dry pure kaolinite (12 wt.\% of gas oil) (d) gas oilcontaminated wet pure kaolinite (12 wt.\% of gas oil and $12 \mathrm{wt} . \%$ of water). Reprinted from (Khosravi et al. 2013) with permission from Elsevier

Fig. 5. SEM images of (a) clean and (b) hydrocarbon-contaminated Firoozkooh sand

Fig. 6. SEM images of Firoozkooh sand: (a) clean, and contaminated by (b) 4 wt.\%, (C) 8 wt.\%, (d) 12 wt.\% of light crude oil

Fig. 7. Effects of hydrocarbon contaminations on (a) liquid limit (LL) and (b) Plasticity Index (PI) of fine-grained soils

Fig. 8. Effects of hydrocarbon contaminations on coefficient of permeability

Fig. 9. Hydrocarbon-induced changes in compression index $\left(\mathrm{C}_{\mathrm{c}}\right)$ of soils

Fig. 10. Influences of hydrocarbon contaminations on (a) angle of internal friction, and (b) cohesion of soils

Fig. 11. Influences of hydrocarbon contaminations on $\mathrm{G}_{\max }$ of sand 
Table 1. The largest hydrocarbon contaminations in history since 1900

\begin{tabular}{|l|l|l|l|l|}
\hline \multicolumn{1}{|c|}{ Location } & Amount (Tones) & Date & \multicolumn{1}{c|}{ Spill Type } & Cause(s) \\
\hline Kern County, California, United States & $1,227,600$ & 1909 & Oil Spill & Wellhead blowout \\
\hline Persian Gulf (Kuwait) & $1,091,405$ & 1991 & Oil Spill & War \\
\hline Gulf of Mexico & 470,779 & 2010 & Crude oil & Wellhead blowout \\
\hline Gulf of Mexico & 470,000 & 1979 & Oil Spill & Wellhead blowout \\
\hline Tobago & 287,000 & 1979 & Oil Spill & Collision \\
\hline Persian Gulf (Iran) & 260,000 & 1983 & Crude oil Spill & Collision and bombing \\
\hline 700 nautical miles off Angola coast & 260,000 & 1991 & Iranian heavy crude oil & Fire / Explosion \\
\hline Saldanha Bay South Africa & 252,000 & 1983 & Light crude oil & Fire \\
\hline Brittany, France & 223,000 & 1978 & Oil Spill & Collision \\
\hline Gulf of Mexico & 162,337 & 2010 & Crude oil & Wellhead blowout \\
\hline Mediterranean Sea near Genoa, Italy & 144,000 & 1991 & Crude oil & Explosion \\
\hline 800 km southeast of Tripoli, Libya & 142,860 & 1980 & Crude oil & Wellhead blowout \\
\hline 700 nautical miles off Nova Scotia Canada & 132,000 & 1988 & Crude oil & Heavy weather / Fire \\
\hline Isles of Scilly, England & 119,000 & 1967 & Kuwait crude oil & Navigational error \\
\hline Gulf of Oman & 115,000 & 1972 & Crude oil & Collision \\
\hline North Sea, Belgium & 107,140 & 1971 & Oil Spill & Unknown \\
\hline Shuaiba, Kuwait & 106,120 & 1981 & Storage tank & Unknown \\
\hline $\begin{array}{l}\text { Usinsk in Northern Russia (Komi } \\
\text { Republic) }\end{array}$ & 104,420 & 1994 & Oil Spill & $\begin{array}{l}\text { Ruptured pipeline, } \\
\text { old equipment }\end{array}$ \\
\hline La Coruña, Spain & & & & Collision \\
\hline Navarino Bay Greece & 100,000 & 1976 & Oil Spill & Fire / Explosion \\
\hline
\end{tabular}


Table 2. A summary of studies on geotechnical properties of hydrocarbon-contaminated soils

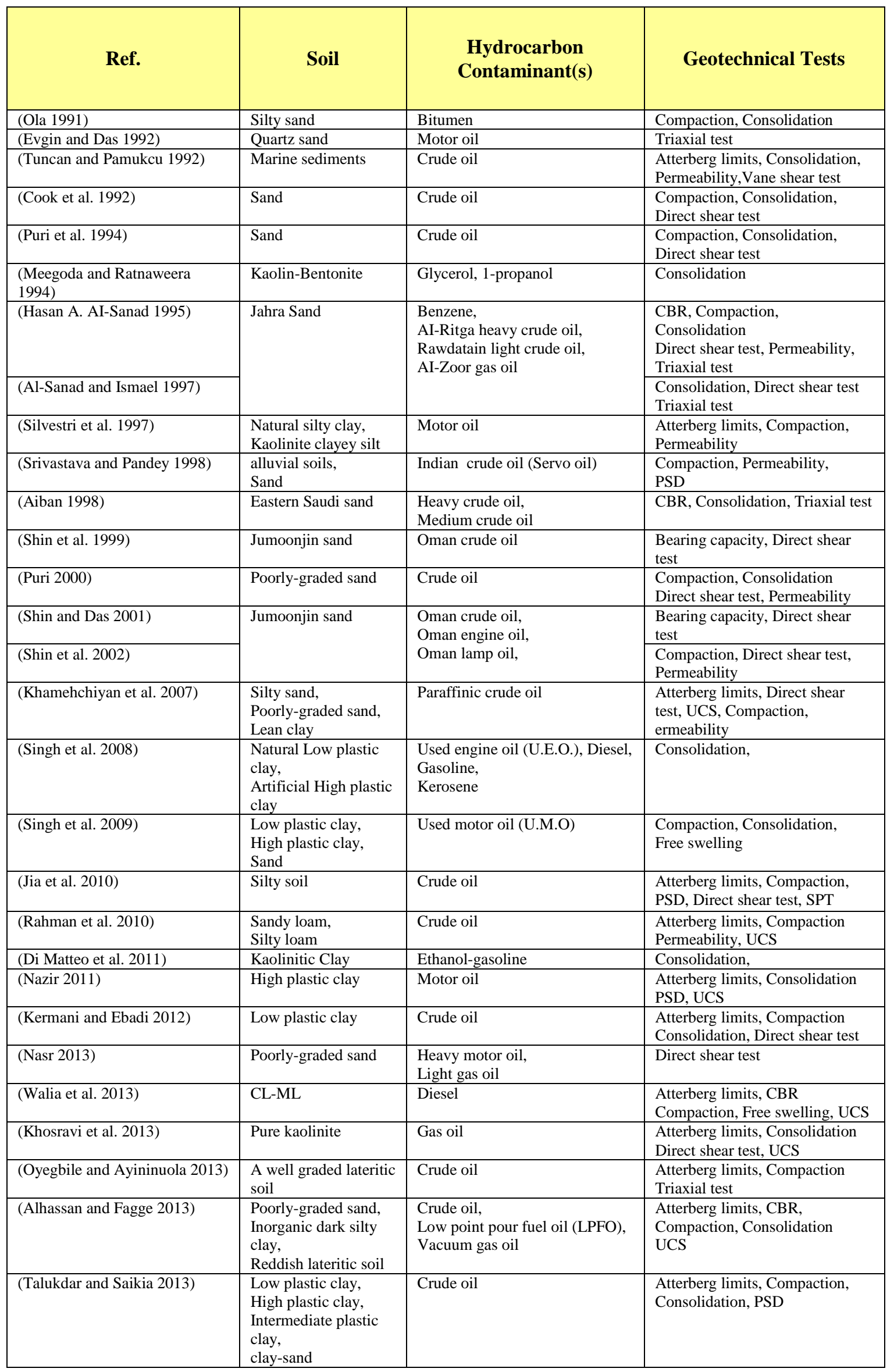




\begin{tabular}{|l|l|l|l|}
\hline (Ling and Yong 2013) & Well-graded sand & Palm biodiesel & Direct shear test \\
\hline (Ijimdiya 2013) & Low plastic clay & Waste motor oil & $\begin{array}{l}\text { Compaction, Consolidation, } \\
\text { PSD, UCS }\end{array}$ \\
\hline (Francis 2013) & $\begin{array}{l}\text { A mixture of clay and } \\
\text { silt }\end{array}$ & Crude oil & Bearing capacity test \\
\hline (Akinwumi et al. 2014a) & Sandy lean clay & Nigerian crude oil & $\begin{array}{l}\text { Atterberg limits, CBR, } \\
\text { Compaction, Permeability }\end{array}$ \\
\hline (Pusadkar and Bharambe 2014) & Black Cotton soil & Petrol and diesel & $\begin{array}{l}\text { Atterberg limits, CBR, } \\
\text { Compaction }\end{array}$ \\
\hline (Siang et al. 2014) & $\begin{array}{l}\text { Well-graded sand } \\
\text { Gap-graded sand }\end{array}$ & Palm and engine oil & Direct shear test, Permeability \\
\hline (Ochepo and Joseph 2014) & Low plastic clay & Spent oil & Compaction, UCS \\
\hline (Naeini and Shojaedin 2014) & $\begin{array}{l}\text { Firoozkooh sand (No. } \\
161)\end{array}$ & Crude oil & Triaxial test \\
\hline (Akinwumi et al. 2014b) & Low plastic clay & Waste Engine Oil & $\begin{array}{l}\text { Atterberg limits, CBR, } \\
\text { Compaction, Permeability }\end{array}$ \\
\hline (Ukpong and Umoh 2015) & Silty sand & Crude oil & $\begin{array}{l}\text { Atterberg limits, CBR } \\
\text { Compaction, PSD }\end{array}$ \\
\hline (Solly et al. 2015) & Clayey sand & Diesel & $\begin{array}{l}\text { Atterberg limits, CBR } \\
\text { Compaction, UCS }\end{array}$ \\
\hline (Onyelowe 2015) & Clayey sand & Pure crude oil & $\begin{array}{l}\text { Atterberg limits, CBR } \\
\text { Compaction, Consolidation } \\
\text { Direct shear test, PSD }\end{array}$ \\
\hline
\end{tabular}


Table 3. Analytical methods for determination of Total Petroleum Hydrocarbons in soils

\section{Analytical methods for determination of Total Petroleum Hydrocarbons in Soil}

\begin{tabular}{|c|c|c|}
\hline \multicolumn{2}{|c|}{ Field methods (in-situ methods) } & \multirow{2}{*}{ Laboratory Methods } \\
\hline Common (non-specific) methods & Specific methods & \\
\hline $\begin{array}{l}\text { - Gas Chromatography with Flame } \\
\text { Ionization (GC-FID), } \\
\text { - Gas Chromatography with Photo- } \\
\text { ionization Detection (GC-PID), } \\
\text { - Gravimetric Determination, Infrared } \\
\text { Spectrophotometry (IR), } \\
\text { - Turbidimetry Ultraviolet, } \\
\text { - Fluorescence Spectroscopic methods, } \\
\text { - Thin-layer Chromatography (TLC), } \\
\text { - High Performance Liquid } \\
\text { Chromatography (HPLC), } \\
\text { - Size-exclusion Chromatography, } \\
\text { Supercritical Fluid Chromatography } \\
\text { (SFC), } \\
\text { - Total Organic Carbon, } \\
\text { - Isotope Ratio Mass Spectrometry, } \\
\text { - Fiber Optic IR Sensor, }\end{array}$ & $\begin{array}{l}\text { - Nuclear Magnetic } \\
\text { Resonance (NMR), } \\
\text { - Isotope Dilution Mass } \\
\text { Spectrometry (IDMS), } \\
\text { - Field Portable Gas } \\
\text { Chromatography Mass } \\
\text { Spectrometry (GC-MS), } \\
\text { - Electrospray Ionization } \\
\text { Mass Spectrometry (ESI- } \\
\text { MS), } \\
\text { - High Performance Liquid } \\
\text { Chromatography Mass } \\
\text { Spectrometry (HPLC-MS), }\end{array}$ & $\begin{array}{l}\text { - General Gravimetry, } \\
\text { - Infrared (IR) Spectroscopy, } \\
\text { - Gas Chromatography Flame } \\
\text { Ionization Detection (GC-FID)*, } \\
\text { - Lab-Based Gas } \\
\text { Chromatography Mass } \\
\text { Spectrometry (GC-MS)* }\end{array}$ \\
\hline
\end{tabular}


Table 4. Performance of analytical methods in determination of targeted hydrocarbon

compounds in soils

\begin{tabular}{|l|c|c|}
\hline \multirow{2}{*}{\multicolumn{1}{c|}{ Analytical methods }} & \multicolumn{2}{|c|}{ Targeted hydrocarbon compounds in soils } \\
\cline { 2 - 3 } & $\begin{array}{c}\text { Total Petroleum Hydrocarbons } \\
\text { (TPH) }\end{array}$ & $\begin{array}{c}\text { Polycyclic Aromatic } \\
\text { Hydrocarbons (PAHs) }\end{array}$ \\
\hline General Gravimetry & $\checkmark$ & NA \\
\hline Immunoassay & $\checkmark$ & $\checkmark$ \\
\hline $\begin{array}{l}\text { Gas Chromatography Flame } \\
\text { Ionization Detection (GC-FID) }\end{array}$ & $\checkmark$ & NA \\
\hline $\begin{array}{l}\text { Gas Chromatography Mass } \\
\text { Spectrometry (GC-MS) }\end{array}$ & $\checkmark$ & $\checkmark$ \\
\hline Fluorescence Spectroscopy & $\checkmark$ & $\checkmark$ \\
\hline Raman Spectroscopy & $\checkmark$ & $\checkmark$ \\
\hline Infrared Spectroscopy & $\checkmark$ & $\checkmark$ \\
\hline $\begin{array}{l}\text { Visible and near-infrared } \\
\text { Spectroscopy }\end{array}$ & $\checkmark$ & $\checkmark$ \\
\hline
\end{tabular}


Table 5. A summary of types and amounts of hydrocarbon compounds considered in the studies on geotechnical properties of hydrocarbon-contaminated soils

\begin{tabular}{|c|c|c|c|}
\hline Hydrocarbon & Ref. & Hydrocarbon name (if applicable) & $\begin{array}{c}\text { Amount } \\
\text { (wt. \%) }\end{array}$ \\
\hline Crude oil & $\begin{array}{l}\text { (Tuncan and Pamukcu 1992) } \\
\text { (Puri et al. 1994) } \\
\text { (Al-Sanad et al. 1995) } \\
\text { (Al-Sanad and Ismael 1997) } \\
\text { (Srivastava and Pandey 1998) } \\
\text { (Aiban 1998) } \\
\text { (Shin et al. 1999) } \\
\text { (Puri 2000) } \\
\text { (Shin and Das 2000) } \\
\text { (Shin and Das 2001) } \\
\text { (Ogboghodo et al. 2004) } \\
\text { (Khamehchiyan et al. 2007) } \\
\text { (Kermani and Ebadi 2012) } \\
\text { (Oyegbile and Ayininuola 2013) } \\
\text { (Alhassan and Fagge 2013) } \\
\text { (Talukdar and Saikia 2013) } \\
\text { (Francis 2013) } \\
\text { (Akinwumi et al. 2014a) } \\
\text { (Naeini and Shojaedin 2014) } \\
\text { (Onyelowe 2015) }\end{array}$ & $\begin{array}{l}\text { Philadelphia Crude oil } \\
\text { Not specified } \\
\text { AI-Ritga (H) \& Rawdatain (L) crude oil (Kuwait) } \\
\text { AI-Ritga (H) \& Rawdatain (L) crude oil (Kuwait) } \\
\text { Servo oil } \\
\text { Heavy and medium crude oil } \\
\text { Oman crude oil } \\
\text { Not specified } \\
\text { Oman crude oil } \\
\text { Oman crude oil } \\
\text { Forcados \& Escravos light crude oil (Nigeria) } \\
\text { Iranian light crude oil (Paraffinic) } \\
\text { Iranian light crude oil (Tehran oil refinery) } \\
\text { Not specified } \\
\text { Not specified } \\
\text { Not specified } \\
\text { Nigerian crude oil (Bonny Light) } \\
\text { Nigerian crude oil } \\
\text { Iranian light crude oil (Tehran oil refinery) } \\
\text { Not specified }\end{array}$ & $\begin{array}{l}5,10,15 \\
9.5,19,28.5 \\
2,4,6 \\
2,4,6 \\
3,6,9,12 \\
2,4,6 \\
1.3,3.8,4.2 \\
9.5,19,28.5 \\
2,4,6 \\
2,4,6 \\
0.5-40 \mathrm{~mL} \cdot \mathrm{kg}^{-1} \\
4,8,12,16 \\
4,8,12 \\
10 \\
2,4,6 \\
3,6,9 \\
5,10,15,20 \\
2,4,6,8,10 \\
4,8,12 \\
2,4,6\end{array}$ \\
\hline Motor oil/Engine oil & $\begin{array}{l}\text { (Puri et al. 1994) } \\
\text { (Silvestri et al. 1997) } \\
\text { (Puri 2000) } \\
\text { (Shin and Das 2000) } \\
\text { (Shin and Das 2001) } \\
\text { (Singh et al. 2008) } \\
\text { (Singh et al. 2009) } \\
\text { (Ijimdiya 2013) } \\
\text { (Akinwumi et al. 2014b) } \\
\end{array}$ & $\begin{array}{l}\text { Commercial grade motor oil (50W30, 10W30, 20W50) } \\
\text { Not specified } \\
\text { Commercial grade motor oil (50W30, 10W30, 20W50) } \\
\text { Oman engine oil } \\
\text { Oman engine oil } \\
\text { Not specified } \\
\text { Used engine oil (U.E.O.) } \\
\text { Waste motor oil (Oando lubrication workshop) } \\
\text { Not specified }\end{array}$ & $\begin{array}{l}10.54,21.07,31.61 \\
4,6,8 \\
10.54,21.07,31.61 \\
2,4,6 \\
2,4,6 \\
3,6,9 \\
3,6,9 \\
1,2,3 \\
2,4,6,8,10\end{array}$ \\
\hline Gasoline & $\begin{array}{l}\text { (Al-Sanad et al. 1995) } \\
\text { (Al-Sanad and Ismael 1997) } \\
\text { (Singh et al. 2008) } \\
\text { (Khosravi et al. 2013) } \\
\text { (Nasr 2013) } \\
\text { (Alhassan and Fagge 2013) } \\
\end{array}$ & $\begin{array}{l}\text { AI-Zoor } \\
\text { AI-Zoor } \\
\text { Not specified } \\
\text { Iranian Gasoline (provided by NIORDC of Iran) } \\
\text { Not specified } \\
\text { Not specified }\end{array}$ & $\begin{array}{l}2,4,6 \\
2,4,6 \\
3,6,9 \\
2,6,12,16,20 \\
1,2,3 \\
2,4,6\end{array}$ \\
\hline Diesel & $\begin{array}{l}\text { (Singh et al. 2008) } \\
\text { (Walia et al. 2013) } \\
\text { (Ling and Yong 2013) } \\
\text { (Pusadkar and Bharambe 2014) } \\
\text { (Solly et al. 2015) }\end{array}$ & $\begin{array}{l}\text { Not specified } \\
\text { Not specified } \\
\text { Palm biodiesel } \\
\text { Not specified } \\
\text { Not specified }\end{array}$ & $\begin{array}{l}3,6,9 \\
4,8,12 \\
3,6,10 \\
3,6,9 \\
4,8,12 \\
\end{array}$ \\
\hline Others & $\begin{array}{l}\text { (Ola 1991) } \\
\text { (Al-Sanad et al. 1995) } \\
\text { (Al-Sanad and Ismael 1997) } \\
\text { (Singh et al. 2008) }\end{array}$ & $\begin{array}{l}\text { Bitumen } \\
\text { Benzene } \\
\text { Benzene } \\
\text { Not specified } \\
\end{array}$ & $\begin{array}{l}3-5 \\
2,4,6 \\
2,4,6 \\
3,6,9\end{array}$ \\
\hline
\end{tabular}


Table 6. Geotechnical tests on hydrocarbon-contaminated soils

\begin{tabular}{|c|c|c|c|c|c|c|c|c|c|}
\hline \multirow[b]{2}{*}{ Ref. } & \multicolumn{9}{|c|}{$\begin{array}{c}\text { Geotechnical tests on hydrocarbon-contaminated } \\
\text { soil }\end{array}$} \\
\hline & \% & 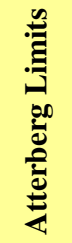 & 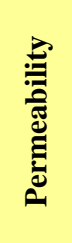 & 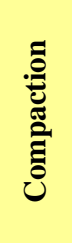 & 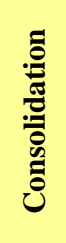 & $\sum_{D}^{\infty}$ & 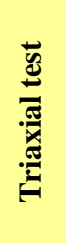 & 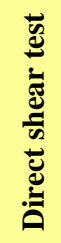 & $\frac{\infty}{0}$ \\
\hline (Tuncan and Pamukcu 1992) & & & $\checkmark$ & & $\checkmark$ & & & & \\
\hline (Cook et al. 1992) & & & $\checkmark$ & & & & & $\checkmark$ & \\
\hline (Evgin and Das 1992) & & & & & & & $\checkmark$ & & \\
\hline (Puri et al. 1994) & & & $\checkmark$ & $\checkmark$ & & & & $\checkmark$ & \\
\hline (Meegoda and Ratnaweera 1994) & & & & & $\checkmark$ & & & & \\
\hline (Al-Sanad et al. 1995) & $\checkmark$ & & $\checkmark$ & $\checkmark$ & $\checkmark$ & & $\checkmark$ & $\checkmark$ & $\checkmark$ \\
\hline (Al-Sanad and Ismael 1997) & & & & & $\checkmark$ & & $\checkmark$ & $\checkmark$ & \\
\hline (Silvestri et al. 1997) & $\checkmark$ & & $\checkmark$ & $\checkmark$ & & & & & \\
\hline (Srivastava and Pandey 1998) & $\checkmark$ & $\checkmark$ & & $\checkmark$ & $\checkmark$ & & $\checkmark$ & & \\
\hline (Aiban 1998) & & & & & $\checkmark$ & & $\checkmark$ & & $\checkmark$ \\
\hline (Shin et al. 1999) & & & & & & & & $\checkmark$ & \\
\hline (Puri 2000) & & & $\checkmark$ & $\checkmark$ & & $\checkmark$ & & $\checkmark$ & \\
\hline (Shin and Das 2000) & & & $\checkmark$ & $\checkmark$ & & & & $\checkmark$ & \\
\hline (Khamehchiyan et al. 2007) & & $\checkmark$ & $\checkmark$ & $\checkmark$ & & $\checkmark$ & & $\checkmark$ & \\
\hline (Singh et al. 2008) & & & & & $\checkmark$ & & & & \\
\hline (Singh et al. 2009) & & & $\checkmark$ & $\checkmark$ & & & & & \\
\hline (Jia et al. 2010) & $\checkmark$ & $\checkmark$ & & $\checkmark$ & & & & $\checkmark$ & \\
\hline (Rahman et al. 2010) & & $\checkmark$ & $\checkmark$ & $\checkmark$ & & & & $\checkmark$ & \\
\hline (Di Matteo et al. 2011) & & $\checkmark$ & & & $\checkmark$ & & & & \\
\hline (Nazir 2011) & & $\checkmark$ & & & $\checkmark$ & $\checkmark$ & & & \\
\hline (Kermani and Ebadi 2012) & & $\checkmark$ & & $\checkmark$ & $\checkmark$ & & & $\checkmark$ & \\
\hline (Nasr 2013) & & & & & & & & $\checkmark$ & \\
\hline (Walia et al. 2013) & & $\checkmark$ & & $\checkmark$ & & $\checkmark$ & & & \\
\hline (Khosravi et al. 2013) & $\checkmark$ & $\checkmark$ & & & $\checkmark$ & $\checkmark$ & & $\checkmark$ & \\
\hline (Oyegbile and Ayininuola 2013) & & $\checkmark$ & & $\checkmark$ & & & $\checkmark$ & & \\
\hline (Alhassan and Fagge 2013) & & $\checkmark$ & & $\checkmark$ & $\checkmark$ & & $\checkmark$ & & $\checkmark$ \\
\hline (Talukdar and Saikia 2013) & & & $\checkmark$ & & $\checkmark$ & & & & \\
\hline (Ling and Yong 2013) & & & & & & & & $\checkmark$ & \\
\hline (Ijimdiya 2013) & $\checkmark$ & & & & $\checkmark$ & $\checkmark$ & & & \\
\hline (Akinwumi et al. 2014a) & & $\checkmark$ & $\checkmark$ & $\checkmark$ & & & & & $\checkmark$ \\
\hline (Akinwumi et al. 2014b) & & $\checkmark$ & $\checkmark$ & $\checkmark$ & & & & & $\checkmark$ \\
\hline (Pusadkar and Bharambe 2014) & & $\checkmark$ & & $\checkmark$ & & & & & $\checkmark$ \\
\hline (Siang et al. 2014) & & & $\checkmark$ & & & & & $\checkmark$ & \\
\hline (Ochepo and Joseph 2014) & & & & $\checkmark$ & & $\checkmark$ & & & $\checkmark$ \\
\hline (Naeini and Shojaedin 2014) & & & & & & & $\checkmark$ & & \\
\hline (Ukpong and Umoh 2015) & $\checkmark$ & $\checkmark$ & & $\checkmark$ & & & & & $\checkmark$ \\
\hline (Solly et al. 2015) & & $\checkmark$ & & $\checkmark$ & & $\checkmark$ & & & $\checkmark$ \\
\hline (Onyelowe 2015) & $\checkmark$ & $\checkmark$ & & $\checkmark$ & $\checkmark$ & & & $\checkmark$ & $\checkmark$ \\
\hline
\end{tabular}


Table. 7. Hydrocarbon-induced changes in the microstructure of fine-grained soils

\begin{tabular}{|c|c|c|}
\hline \multirow{2}{*}{$\begin{array}{c}\text { Qualitative } \\
\text { parameters of } \\
\text { microstructure of } \\
\text { fine-grained soils }\end{array}$} & \multicolumn{2}{|c|}{ Hydrocarbon-induced changes in microstructure } \\
\hline & Clean fine-grained soils & $\begin{array}{l}\text { Hydrocarbon-contaminated fine- } \\
\text { grained soils }\end{array}$ \\
\hline Particle surface & - Unchanged & - Hydrocarbon-coated particles \\
\hline Inter-particle properties & $\begin{array}{l}\text { - Hydrophilic surface of } \\
\text { particles, } \\
\text { - No induced adhesion, } \\
\text { - Clay-normal electric charged } \\
\text { double layer, } \\
\text { - Long-range electrostatic } \\
\text { repulsive forces among particles, }\end{array}$ & $\begin{array}{l}\text { - Hydrophobic surface of hydrocarbon- } \\
\text { coated particles, } \\
\text { - Hydrocarbon-induced adhesion among } \\
\text { particles, } \\
\text { - Lower electric charge among double } \\
\text { layers of coated particles, } \\
\text { - Short- range ( } \leq 8 \mathrm{~nm} \text { of separation } \\
\text { distance between particles) electrostatic } \\
\text { repulsive forces among particles with } \\
\text { lower values compared with clean fine- } \\
\text { grained soils, } \\
\text { - Attractive forces among hydrocarbon- } \\
\text { coated layers of particles (in } \geq 8 \mathrm{~nm} \text { of } \\
\text { separation distance between particles), }\end{array}$ \\
\hline Fabric & $\begin{array}{l}\text { - Dispersed fabric, } \\
\text { - Face-to-Face (FF) contacts } \\
\text { among particles, } \\
\text { - Edge-to-Edge (EE) contacts } \\
\text { among particles, } \\
\text { - An oriented fabric, } \\
\text { - Smaller pores, }\end{array}$ & $\begin{array}{l}\text { - Flocculated fabric, } \\
\text { - Edge-to-Face (EF) contacts among } \\
\text { particles more usual, } \\
\text { - lesser smaller pores compared with } \\
\text { clean fine-grained soils, } \\
\text { - Less oriented fabric, } \\
\text { - decomposed aggregates }\end{array}$ \\
\hline
\end{tabular}


Table. 8. A summary of maximum dry density and optimum moisture content of hydrocarbon-contaminated soils

\begin{tabular}{|c|c|c|c|c|c|c|c|c|c|c|c|c|c|c|c|c|c|c|c|c|c|c|}
\hline \multirow{3}{*}{ Ref. } & \multirow{3}{*}{$\begin{array}{l}\text { Soil } \\
\text { type }\end{array}$} & \multirow{3}{*}{$\begin{array}{l}\text { Hydrocarbon } \\
\text { type }\end{array}$} & \multirow{2}{*}{\multicolumn{2}{|c|}{$\begin{array}{l}\text { Clean } \\
\text { sample }\end{array}$}} & \multicolumn{18}{|c|}{ Hydrocarbon content (wt.\%) in contaminated samples } \\
\hline & & & & & \multicolumn{2}{|c|}{2} & \multicolumn{2}{|c|}{3} & \multicolumn{2}{|c|}{4} & \multicolumn{2}{|c|}{6} & \multicolumn{2}{|c|}{8} & \multicolumn{2}{|c|}{9} & \multicolumn{2}{|c|}{10} & \multicolumn{2}{|c|}{12} & \multicolumn{2}{|c|}{16} \\
\hline & & & 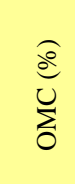 & 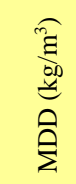 & 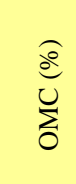 & 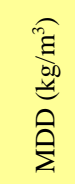 & $\frac{\widehat{e}}{\sum_{0}^{0}}$ & 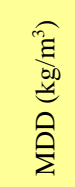 & $\begin{array}{l}\widehat{\varrho} \\
\sum_{0}^{0}\end{array}$ & 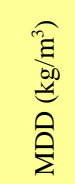 & $\begin{array}{l}\widehat{d} \\
\underset{0}{0}\end{array}$ & 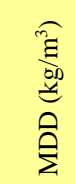 & 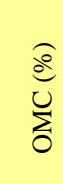 & 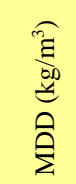 & $\frac{0}{0}$ & 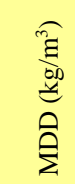 & $\begin{array}{l}\frac{0}{0} \\
\sum_{0}^{0}\end{array}$ & 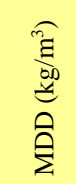 & $\frac{\widehat{\varrho}}{\tilde{O}}$ & 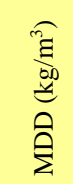 & $\begin{array}{l}\widehat{\varrho} \\
\sum_{0}^{0}\end{array}$ & 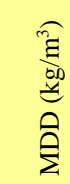 \\
\hline (Al-Sanad et al. 1995) & Sand & Heavy crude oil & 12 & 1890 & 7.5 & 1940 & & & 7 & 1930 & 2 & 1825 & & & & & & & & & & \\
\hline (Silvestri et al. 1997) & $\begin{array}{l}\text { Kaolinite } \\
\text { Natural Clay }\end{array}$ & $\begin{array}{l}\text { Motor oil } \\
\text { Motor oil }\end{array}$ & $\begin{array}{l}27 \\
27\end{array}$ & $\begin{array}{l}1425 \\
1420\end{array}$ & 25 & 1420 & & & $\begin{array}{l}23 \\
26\end{array}$ & $\begin{array}{l}1415 \\
1395\end{array}$ & $\begin{array}{l}21.5 \\
22.5\end{array}$ & $\begin{array}{l}1375 \\
1380\end{array}$ & 22 & 1375 & & & & & & & & \\
\hline (Srivastava and Pandey 1998) & $\begin{array}{l}\text { Alluvial soil } \\
\text { Sand }\end{array}$ & $\begin{array}{l}\text { Servo oil } \\
\text { Servo oil }\end{array}$ & $\begin{array}{l}16 \\
12.7\end{array}$ & $\begin{array}{l}1840 \\
1745\end{array}$ & & & $\begin{array}{l}15.5 \\
15.5\end{array}$ & $\begin{array}{l}1860 \\
1710\end{array}$ & & & $\begin{array}{l}12.6 \\
8.7\end{array}$ & $\begin{array}{l}1880 \\
1720\end{array}$ & & & $\begin{array}{l}11.1 \\
4.7\end{array}$ & $\begin{array}{l}1865 \\
1665\end{array}$ & & & $\begin{array}{l}10.1 \\
2.6\end{array}$ & $\begin{array}{l}1835 \\
1635\end{array}$ & & \\
\hline (Khamehchiyan et al. 2007) & $\begin{array}{l}\text { CL } \\
\text { SP } \\
\text { SM }\end{array}$ & $\begin{array}{l}\text { Light crude oil } \\
\text { Light crude oil } \\
\text { Light crude oil }\end{array}$ & $\begin{array}{l}16.4 \\
14.4 \\
13.2\end{array}$ & $\begin{array}{l}1864 \\
1900 \\
1828\end{array}$ & & & & & $\begin{array}{l}13.8 \\
10 \\
9.6\end{array}$ & $\begin{array}{l}1852 \\
1872 \\
1830\end{array}$ & & & $\begin{array}{l}9.5 \\
8.4 \\
7.2\end{array}$ & $\begin{array}{l}1832 \\
1844 \\
1820\end{array}$ & & & & & $\begin{array}{l}7.2 \\
5.6 \\
5.5\end{array}$ & $\begin{array}{l}1800 \\
1840 \\
1818\end{array}$ & $\begin{array}{l}3.2 \\
2.0 \\
2.8\end{array}$ & $\begin{array}{l}1812 \\
1824 \\
1812\end{array}$ \\
\hline (Singh et al. 2009) & $\begin{array}{l}\mathrm{CL} \\
\mathrm{CH}\end{array}$ & $\begin{array}{l}\text { Used motor oil } \\
\text { Used motor oil }\end{array}$ & $\begin{array}{l}14.9 \\
19.5\end{array}$ & $\begin{array}{l}1815 \\
1560\end{array}$ & & & $\begin{array}{l}15.5 \\
21.6\end{array}$ & $\begin{array}{l}1785 \\
1532\end{array}$ & & & $\begin{array}{l}16.2 \\
21.7\end{array}$ & $\begin{array}{l}1726 \\
1510\end{array}$ & & & $\begin{array}{l}16.8 \\
23.3\end{array}$ & $\begin{array}{l}1677 \\
1501\end{array}$ & & & & & & \\
\hline (Rahman et al. 2010) & $\begin{array}{l}\text { Sandy loam } \\
\text { Silty loam }\end{array}$ & $\begin{array}{l}\text { Crude oil } \\
\text { Crude oil }\end{array}$ & $\begin{array}{l}23 \\
23.5\end{array}$ & $\begin{array}{l}1670 \\
1600\end{array}$ & & & & & $\begin{array}{l}21.4 \\
22.5\end{array}$ & $\begin{array}{l}1570 \\
1580\end{array}$ & & & $\begin{array}{l}20 \\
22\end{array}$ & $\begin{array}{l}1550 \\
1560\end{array}$ & & & & & $\begin{array}{l}18.5 \\
20\end{array}$ & $\begin{array}{l}1530 \\
1550\end{array}$ & $\begin{array}{l}17.5 \\
16.5\end{array}$ & $\begin{array}{l}1500 \\
1550\end{array}$ \\
\hline (Kermani and Ebadi 2012) & Silty soil & Light crude oil & 21 & 1640 & & & & & 16 & 1690 & & & 13.5 & 1695 & & & & & 11 & 1725 & & \\
\hline (Walia et al. 2013) & CL-ML & Diesel & 10.3 & 1765 & & & & & 9.06 & 1697 & & & 8.75 & 1667 & & & 8.00 & 1648 & & & & \\
\hline (Akinwumi et al. 2014a) & $\overline{C L}$ & Nigerian crude oil & 15.3 & 1822 & 15.1 & 1810 & & & 14.8 & 1805 & 14.7 & 1803 & 14.6 & 1792 & & & 14.6 & 1785 & & & & \\
\hline (Akinwumi et al. 2014b) & $\mathrm{CL}$ & Engine oil & 15.4 & 1822 & 13.60 & 1820 & & & 12.4 & 1817 & 10.7 & 1810 & 9.3 & 1806 & & & 7.8 & 1795 & & & & \\
\hline (Pusadkar and Bharambe 2014) & Black Cotton & $\begin{array}{l}\text { Petrol } \\
\text { Diesel }\end{array}$ & $\begin{array}{l}15.89 \\
15.89\end{array}$ & $\begin{array}{l}1291 \\
1291\end{array}$ & & & $\begin{array}{l}14.52 \\
14.32\end{array}$ & $\begin{array}{l}1131 \\
1211\end{array}$ & & & $\begin{array}{l}14.32 \\
14.12\end{array}$ & $\begin{array}{l}10.07 \\
10.51\end{array}$ & & & $\begin{array}{l}14.22 \\
13.93\end{array}$ & $\begin{array}{l}8.75 \\
9.70\end{array}$ & & & & & & \\
\hline (Onyelowe 2015) & Clayey sand & Crude oil & 16.2 & 1900 & 12.2 & 1935 & & & 13 & 1900 & 13.8 & 1900 & & & & & & & & & & \\
\hline
\end{tabular}


Table. 9. Unconfined compressive strength $\left(\mathrm{q}_{\mathrm{u}}\right)$ of hydrocarbon-contaminated soils

\begin{tabular}{|c|c|c|c|c|c|c|c|c|c|c|c|c|c|c|c|c|c|c|}
\hline \multirow{3}{*}{ Ref. } & \multirow{3}{*}{$\begin{array}{l}\text { Soil } \\
\text { type }\end{array}$} & \multirow{3}{*}{$\begin{array}{c}\text { Hydrocarbon } \\
\text { type }\end{array}$} & \multirow{2}{*}{\multicolumn{2}{|c|}{$\begin{array}{c}\text { Clean } \\
\text { sample }\end{array}$}} & \multicolumn{14}{|c|}{ Hydrocarbon content (wt.\%) in contaminated samples } \\
\hline & & & & & \multicolumn{2}{|c|}{2} & \multicolumn{2}{|c|}{4} & \multicolumn{2}{|c|}{6} & \multicolumn{2}{|c|}{8} & \multicolumn{2}{|c|}{12} & \multicolumn{2}{|c|}{14} & \multicolumn{2}{|c|}{16} \\
\hline & & & $\underbrace{\widehat{Q}}_{\omega^{\sigma}}$ & $\underset{\sigma}{\stackrel{\Xi}{\sigma}}$ & $\underbrace{\widehat{Q}}_{\omega^{\sigma}}$ & $\frac{\pi}{\tilde{\sigma}}$ & $\underbrace{\frac{\rho}{\rho}}_{\omega^{\sigma}}$ & 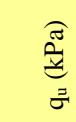 & $\underbrace{0}$ & $\frac{\pi}{\tilde{\sigma}}$ & $\underbrace{0}_{\omega}$ & $\frac{\pi}{\sqrt{3}}$ & $\underbrace{0}$ & $\frac{2}{2}$ & $\underbrace{2}$ & $\underbrace{\frac{\pi}{2}}_{\bar{\sigma}}$ & $\underbrace{\varrho}_{\omega^{0}}$ & $\frac{\pi}{2}$ \\
\hline (Khamehchiyan et al. 2007) & $\begin{array}{l}\mathrm{CL} \\
\mathrm{SM}\end{array}$ & $\begin{array}{l}\text { Light crude oil } \\
\text { Light crude oil }\end{array}$ & $\begin{array}{l}4.40 \\
2.90\end{array}$ & $\begin{array}{l}36 \\
9.4\end{array}$ & & & \begin{tabular}{|l|}
5.20 \\
1.90
\end{tabular} & $\begin{array}{l}40 \\
8.8\end{array}$ & & & $\begin{array}{l}4.00 \\
1.80\end{array}$ & $\begin{array}{l}22 \\
6.6\end{array}$ & $\begin{array}{l}3.60 \\
2.60\end{array}$ & $\begin{array}{l}16 \\
5.8\end{array}$ & & & $\begin{array}{l}7.60 \\
2.80\end{array}$ & $\begin{array}{l}8.0 \\
3.6\end{array}$ \\
\hline (Walia et al. 2013) & CL-ML & Diesel & 100 & 140 & & & 155 & 90 & & & 160 & 65 & 150 & 35 & & & & \\
\hline (Khosravi et al. 2013) & Pure kaolinite & Gas oil & & & 1.2 & 12 & 0.95 & 12.5 & 0.82 & 14 & & & 0.9 & 20 & 1.1 & 17.5 & & \\
\hline (Ijimdiya 2013) & Low plastic clay & Waste motor oil & & 155 & & 185 & & 180 & & 152 & & 105 & & & & & & \\
\hline (Solly et al. 2015) & Clayey sand & Diesel & & 17 & & & & 18 & & & & 25 & & 29 & & & & \\
\hline
\end{tabular}


Table. 10. Effects of weathering process on geotechnical properties of hydrocarbon-contaminated soils

\begin{tabular}{l|l|l|ll}
\hline 21 & & & Short-and long-term geotechnical properties of hydrocarbon-contaminated soil
\end{tabular}

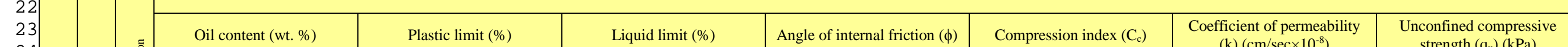

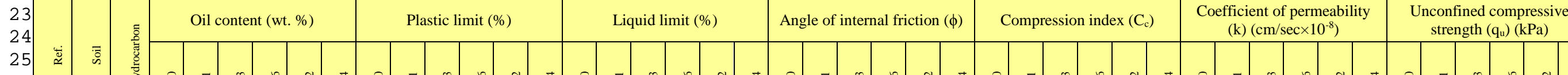

25

25

26

28

29

30

31 .

32 .

33

34

푼

35 च च

36 苟 :

36
37

38 这

$\begin{array}{lll}38 & \varangle\end{array}$

40

41

42
43

45 चे च च

46 .

47 है

48

49

50

51 * Not reported

52 ** Not applicable

53

54
55

56

57

58

59

60

61

62 


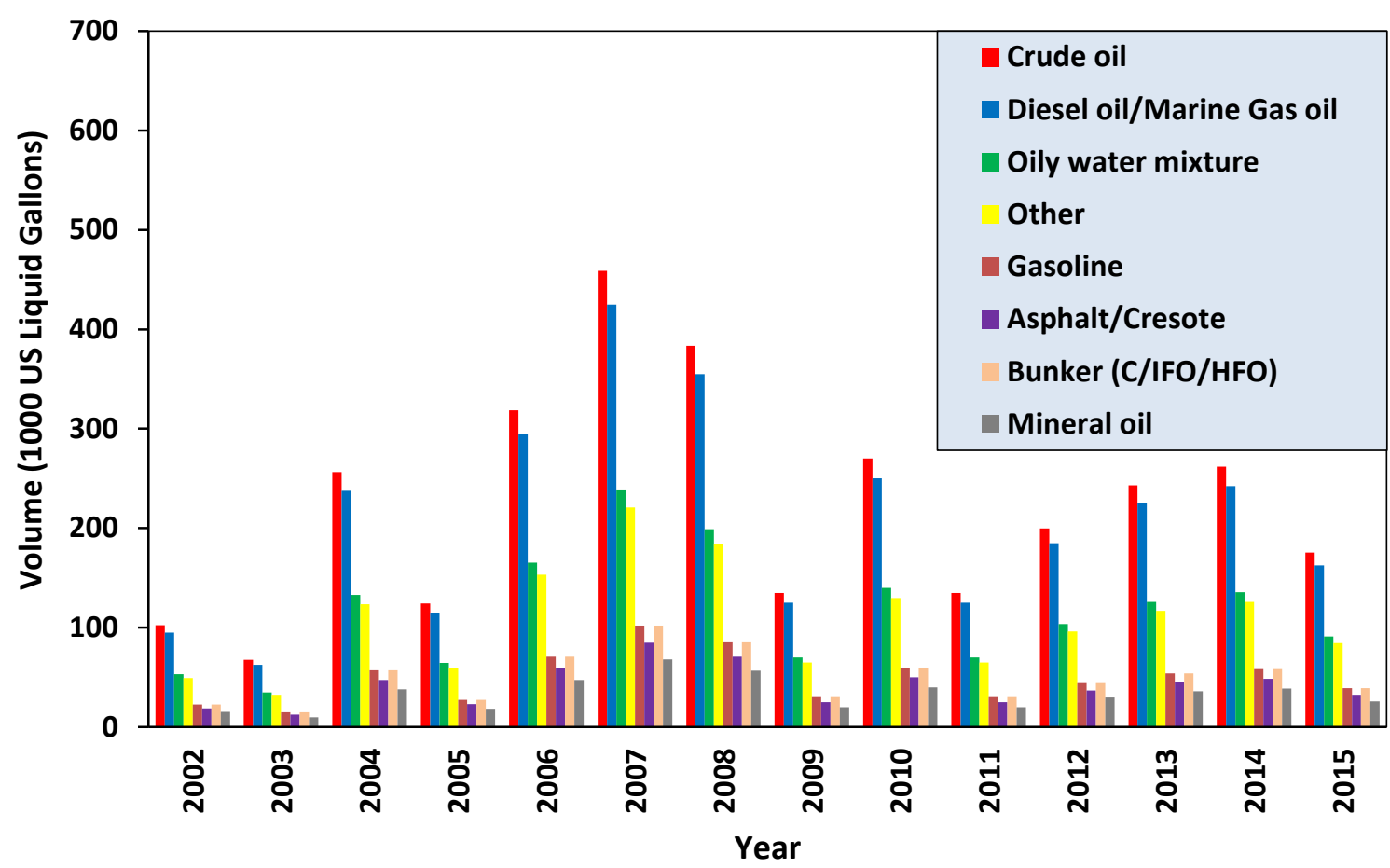

Fig. 1. The volumes of different types of hydrocarbon contaminations occurred in the west coast of United States of America (2002-2015) 


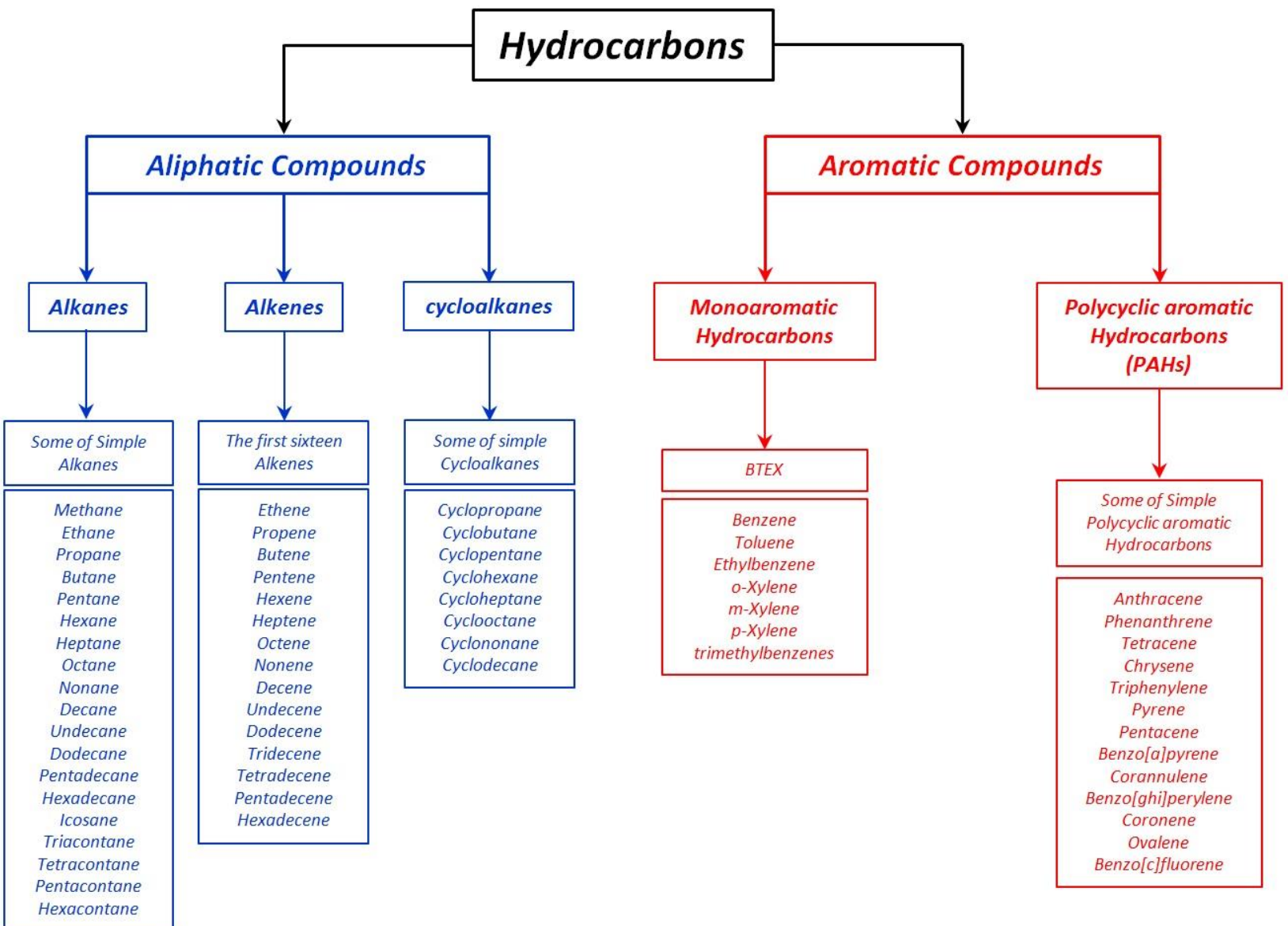

Fig. 2. Different kinds of hydrocarbons 

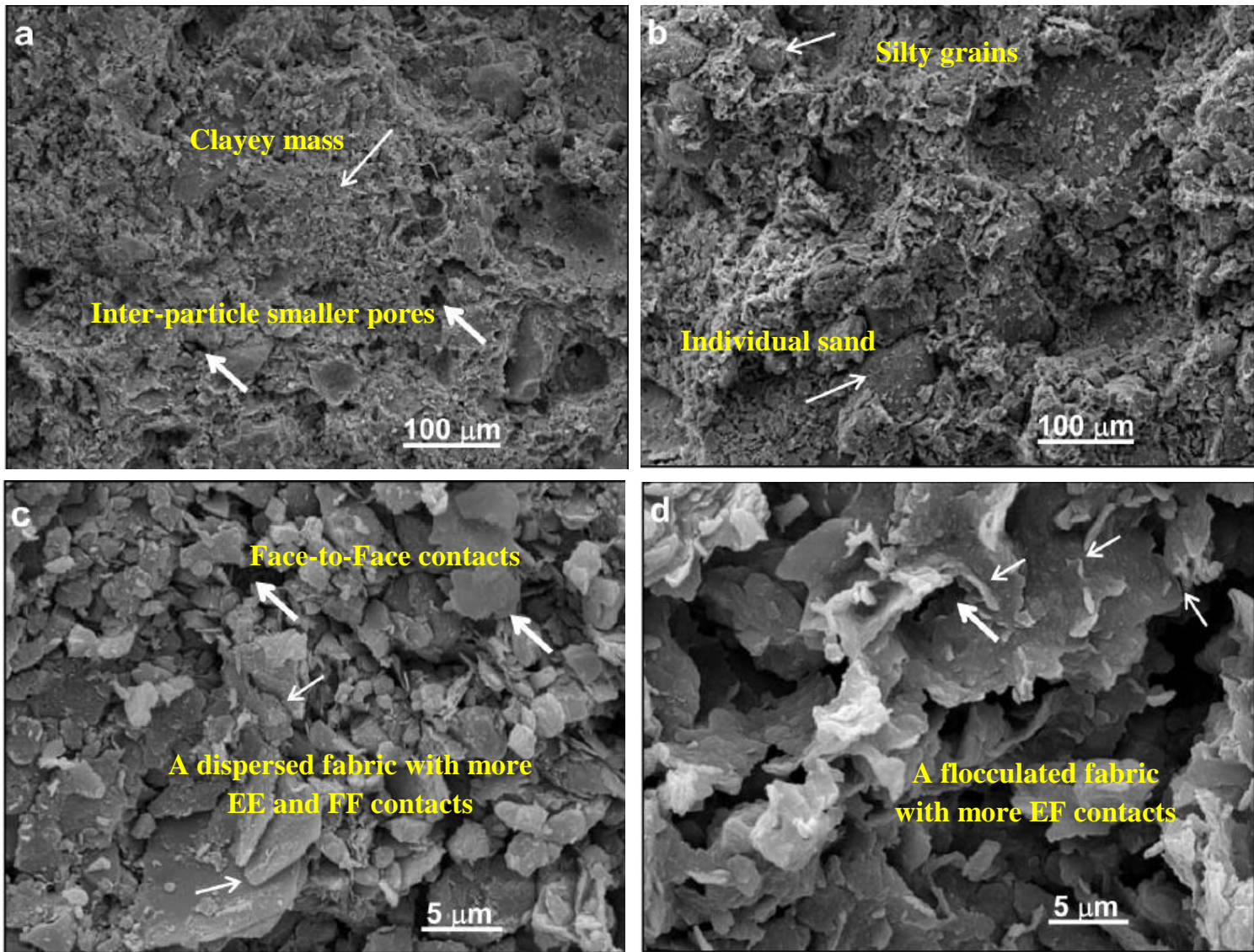

Fig. 3. SEM images of a particular clayey soil in (a and c) clean, and (b and d) hydrocarboncontaminated conditions. Reprinted from (Izdebska-Mucha and Trzciński 2008) with permission from The Publishing Department of Lithuanian Academy of Sciences 

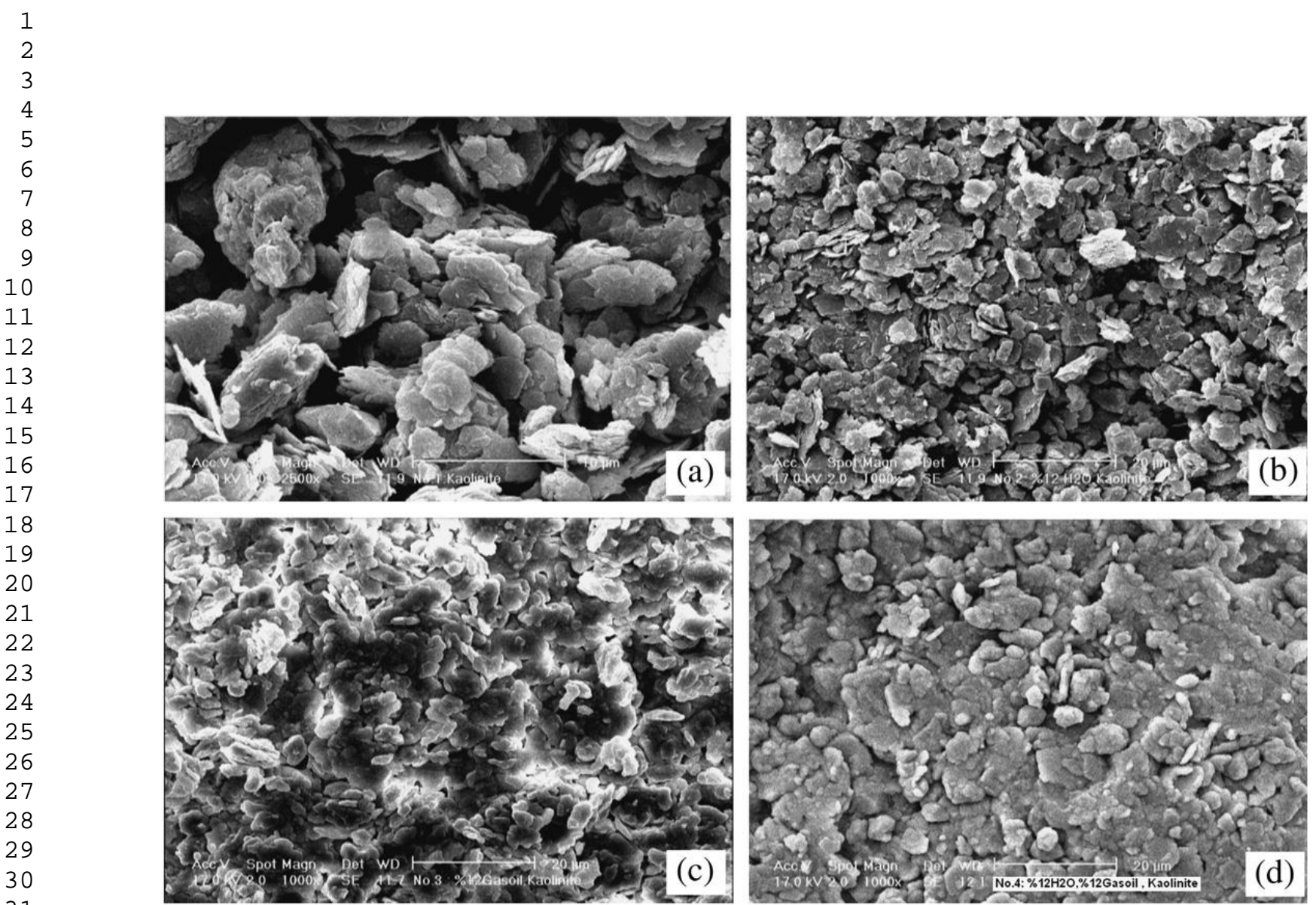

Fig. 4. SEM images of (a) clean dry pure kaolinite, (b) clean wet pure

kaolinite (12 wt.\% of water) (c) gas oil-contaminated dry pure kaolinite (12 wt.\% of gas oil)

(d) gas oil-contaminated wet pure kaolinite (12 wt.\% of gas oil and $12 \mathrm{wt} . \%$ of water).

Reprinted from (Khosravi et al. 2013) with permission from Elsevier 


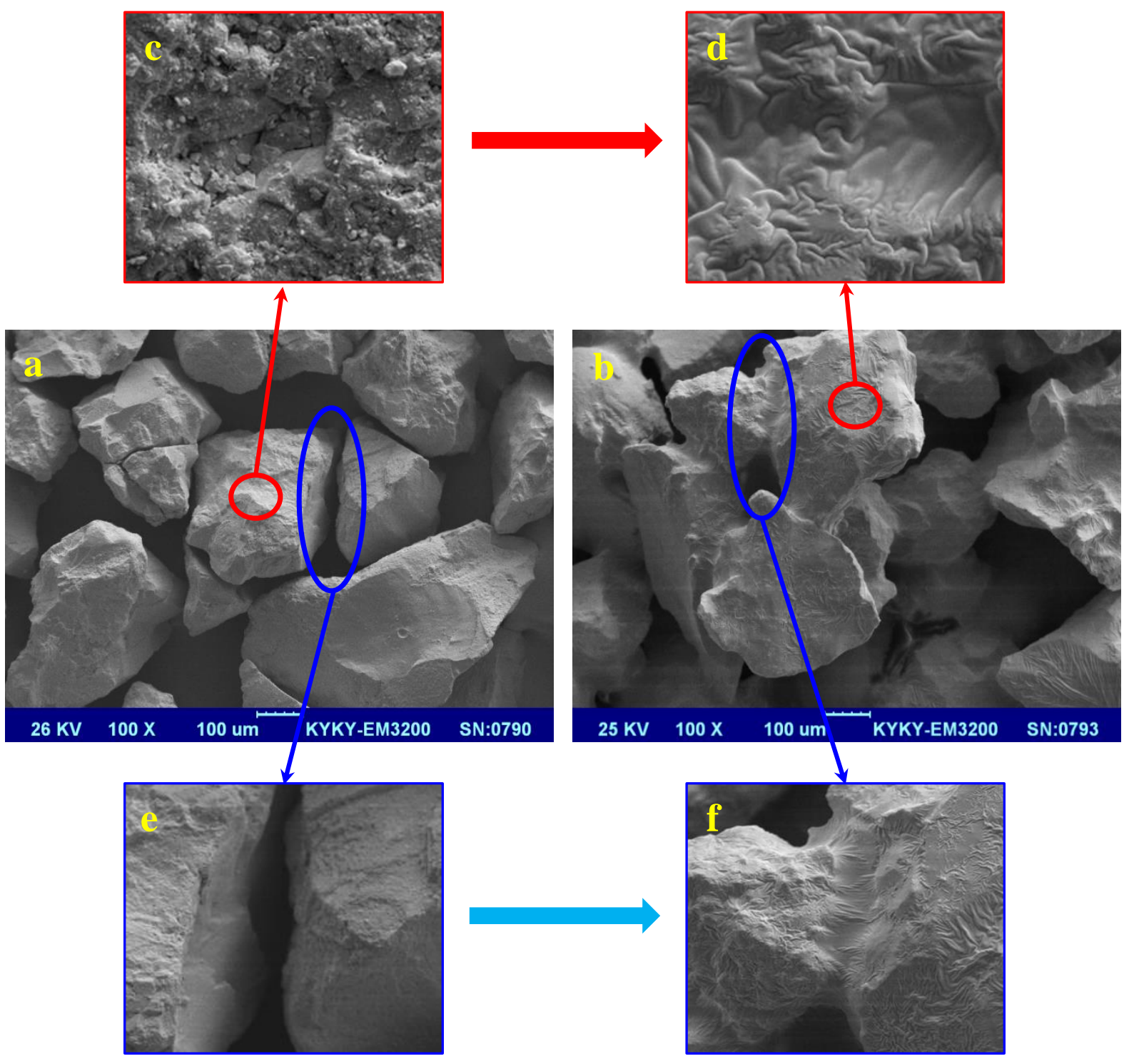

Fig. 5. SEM images of (a) clean and (b) hydrocarbon-contaminated Firoozkooh sand (provided by the authors) 

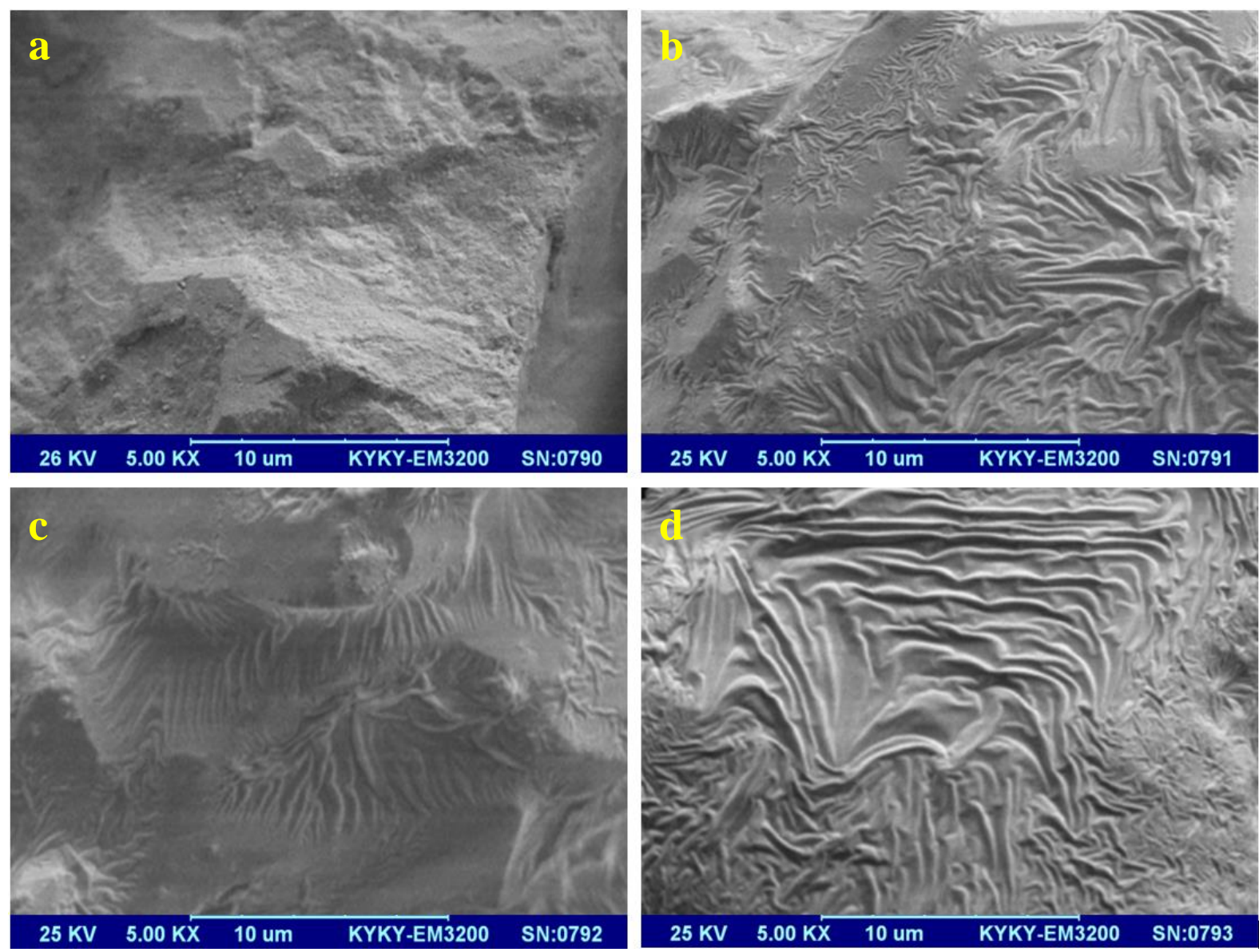

Fig. 6. SEM images of Firoozkooh sand: (a) clean, and contaminated by (b) 4 wt.\%, (C) 8

wt.\%, (d) 12 wt.\% of light crude oil (provided by the authors) 

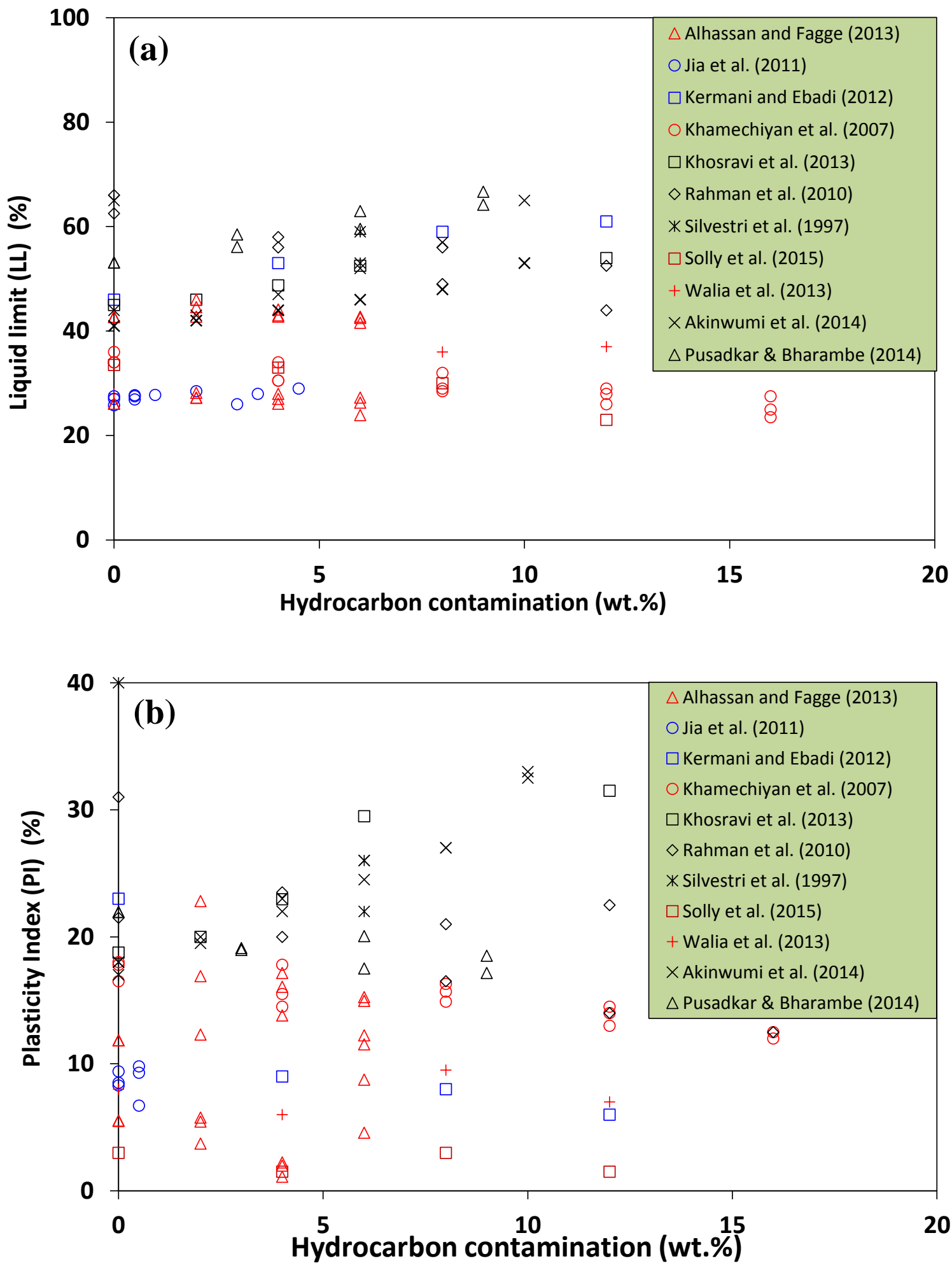

Fig. 7. Effects of hydrocarbon contaminations on (a) liquid limit (LL) and (b) Plasticity Index (PI) of fine-grained soils 
Hydrocarbon contamination (wt.\%)

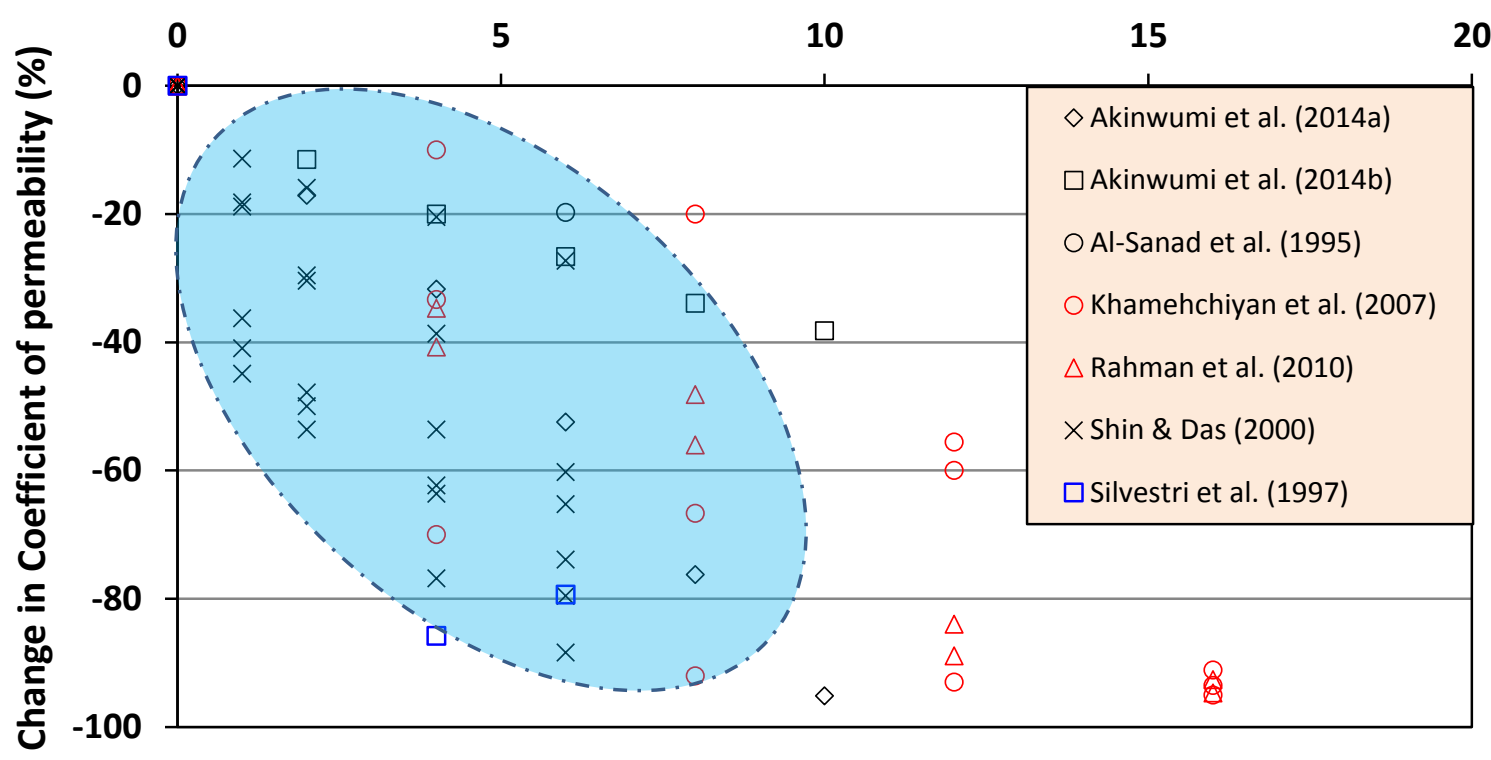

Fig. 8. Effects of hydrocarbon contaminations on coefficient of permeability 


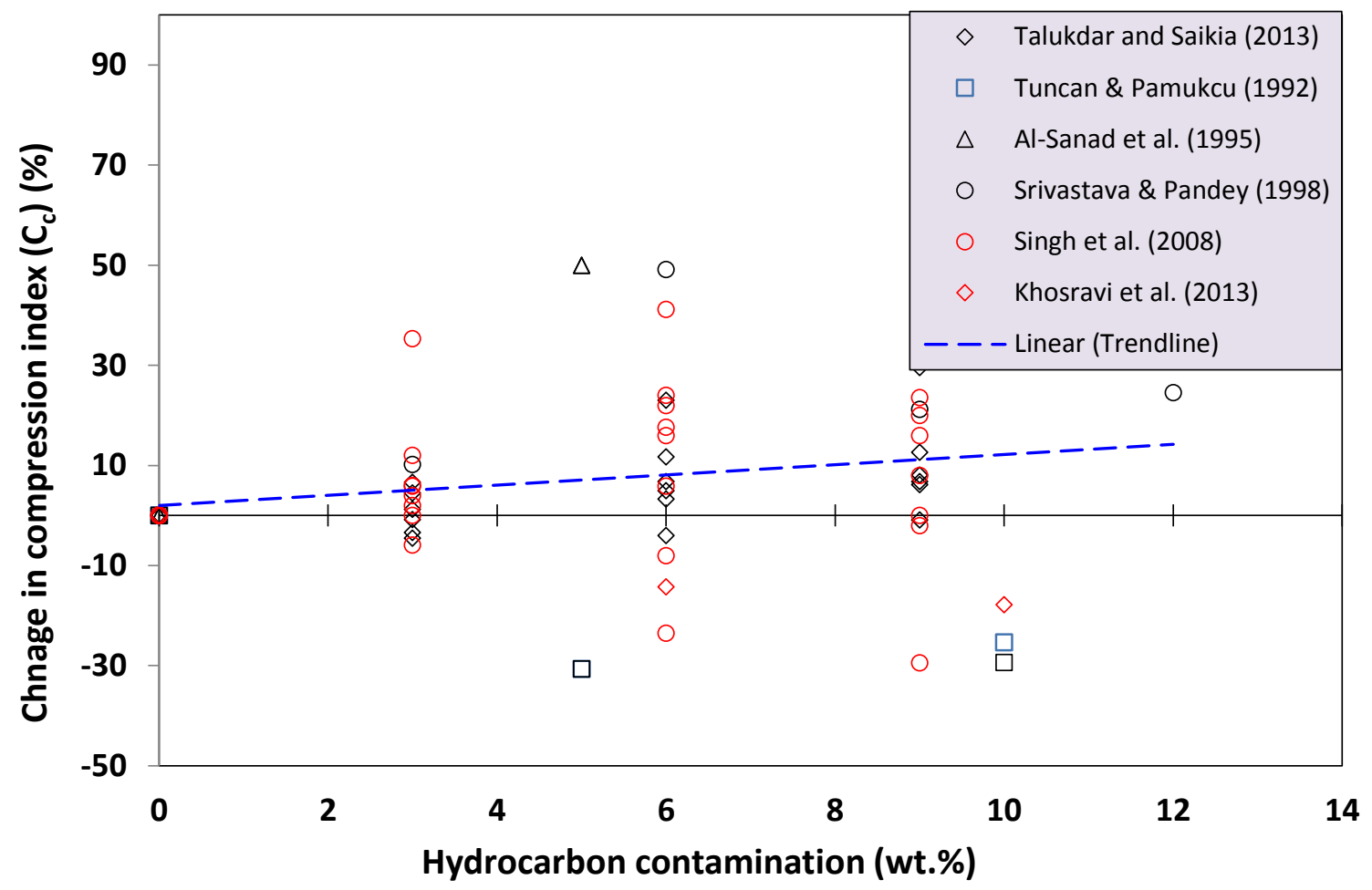

Fig. 9. Hydrocarbon-induced changes in compression index $\left(\mathrm{C}_{\mathrm{c}}\right)$ of soils 

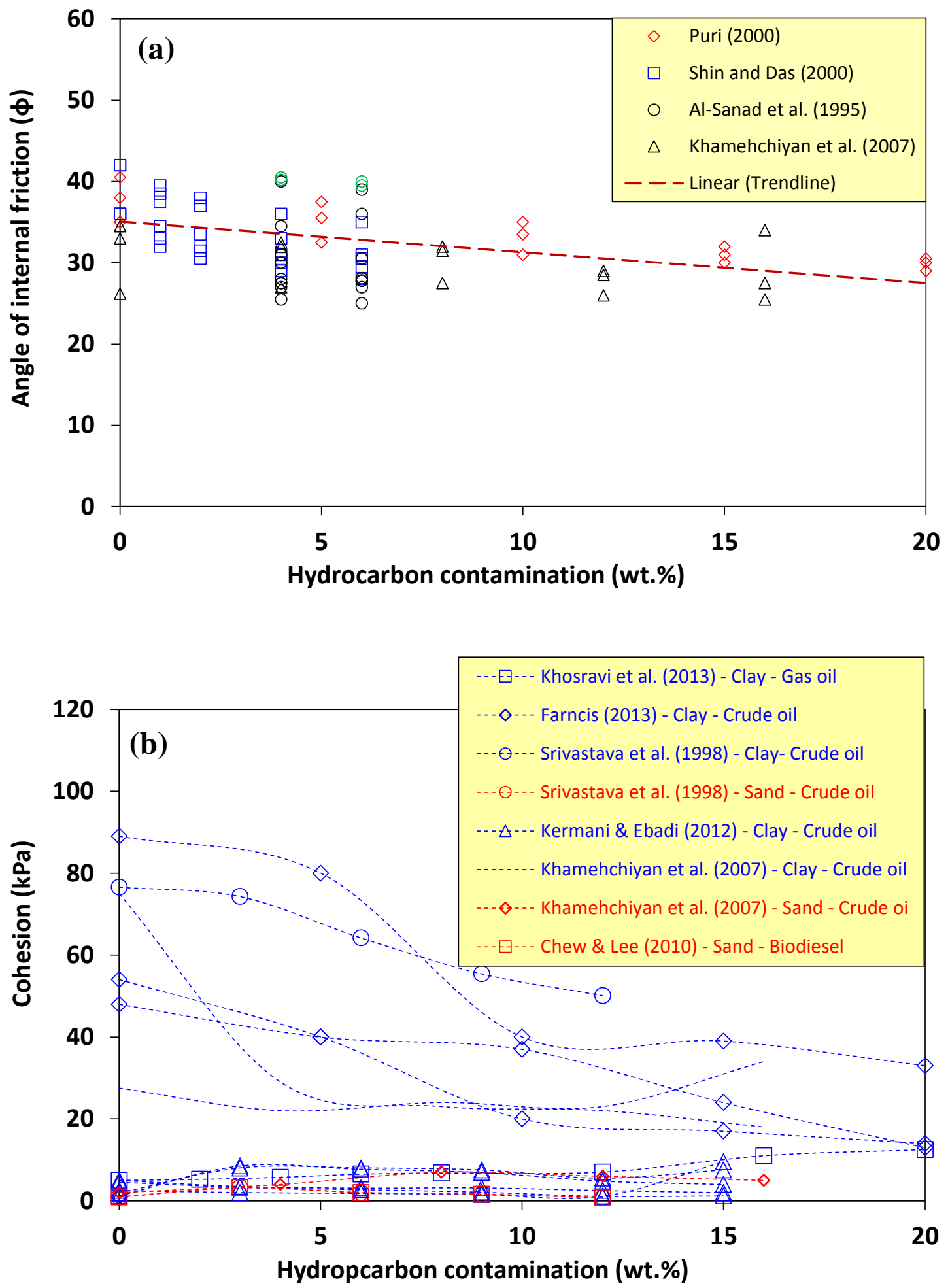

Fig. 10. Influences of hydrocarbon contaminations on (a) angle of internal friction, and (b) cohesion of soils 


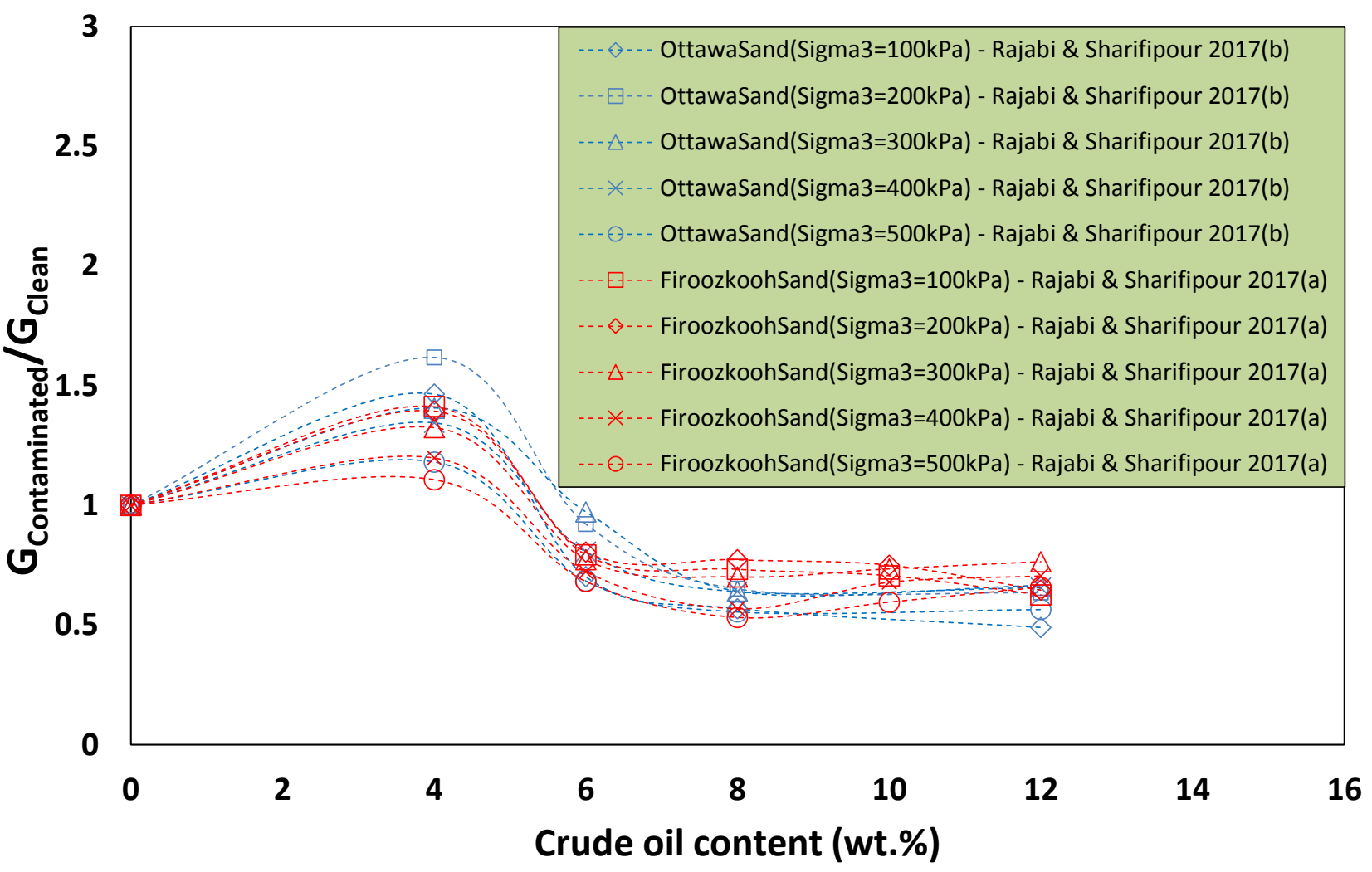

Fig. 11. Influences of hydrocarbon contaminations on $G_{\max }$ of sand 